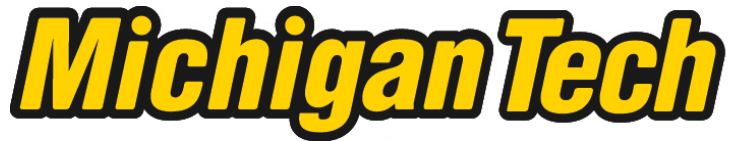 \\ Michigan Technological University Create the Future Digital Commons @ Michigan Tech
}

Dissertations, Master's Theses and Master's Reports - Open

Dissertations, Master's Theses and Master's

Reports

2012

\section{Molecular modeling of EPON 862-DETDA polymer}

Ananyo Bandyopadhyay

Michigan Technological University

Follow this and additional works at: https://digitalcommons.mtu.edu/etds

Part of the Engineering Science and Materials Commons

Copyright 2012 Ananyo Bandyopadhyay

\section{Recommended Citation}

Bandyopadhyay, Ananyo, "Molecular modeling of EPON 862-DETDA polymer ", Dissertation, Michigan Technological University, 2012.

https://doi.org/10.37099/mtu.dc.etds/21

Follow this and additional works at: https://digitalcommons.mtu.edu/etds

Part of the Engineering Science and Materials Commons 


\title{
MOLECULAR MODELING OF EPON 862-DETDA POLYMER
}

By

Ananyo Bandyopadhyay

\begin{abstract}
A DISSERTATION
Submitted in partial fulfillment of the requirements for the degree of
\end{abstract}

DOCTOR OF PHILOSOPHY

(Materials Science and Engineering)

MICHIGAN TECHNOLOGICAL UNIVERSITY

2012

Copyright @ Ananyo Bandyopadhyay 2012 
This dissertation, "Molecular Modeling of EPON 862-DETDA Polymer," is hereby approved in partial fulfillment of the requirements for the Degree of DOCTOR OF PHILOSOPHY IN MATERIALS SCIENCE AND ENGINEERING.

Department of Materials Science and Engineering

Signatures:

Dissertation Advisor:

Dr. Gregory M. Odegard

Department Chair:

Dr. Mark R. Plichta

Date: 
This dissertation

is dedicated

to my dear grandmother

Subhra Guha 


\section{TABLE OF CONTENTS}

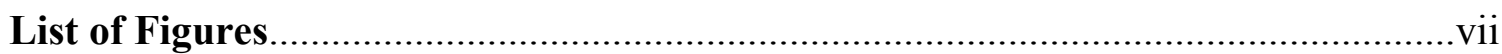

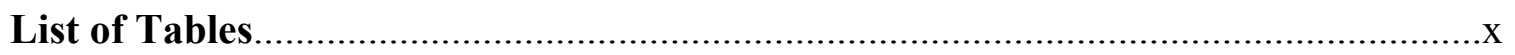

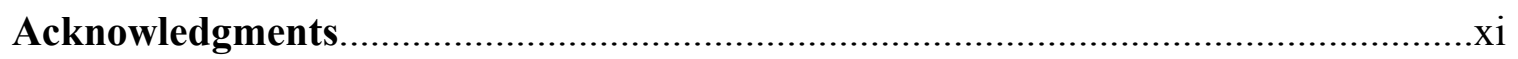

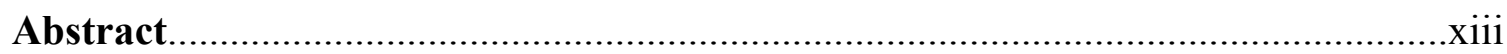

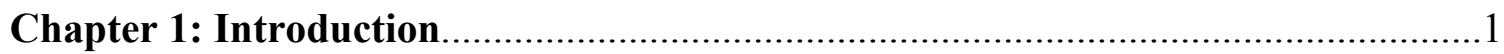

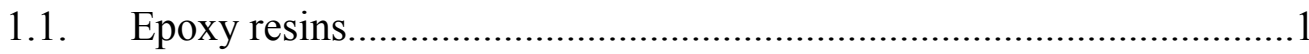

1.2. Molecular Dynamics................................................................

Chapter 2: Force Field and Model Parameters.............................................. 8

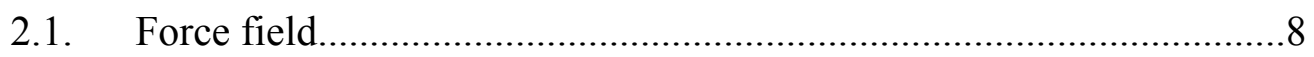

2.2. Modeling 2:1 stoichiometric mixture..........................................10

Chapter 3: Modeling Procedures.......................................................................... 15

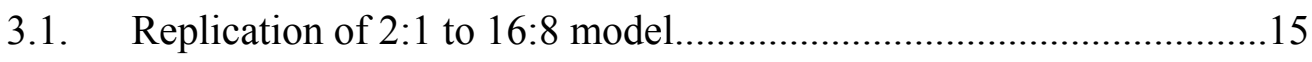

3.2. Replication of crosslinked 16:8 to $432: 216$ model...........................16

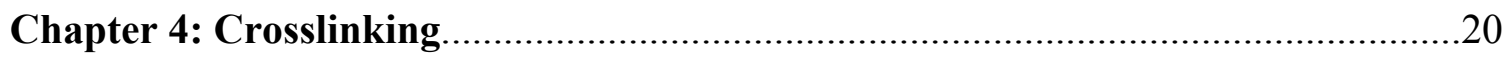

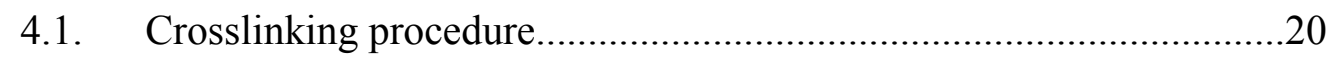


Chapter 5: Validation of Equilibrated Crosslinked models....................................30

5.1. Glass transition temperature range determination............................30

5.2. Volume shrinkage and thermal expansion coefficients.....................33

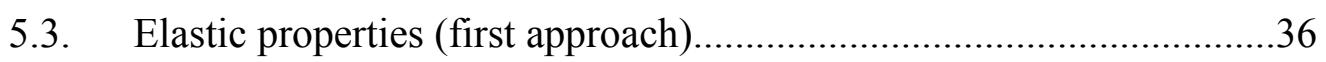

5.4. Elastic properties (second approach)...........................................41

Chapter 6: Modeling of physically aged samples...................................................44

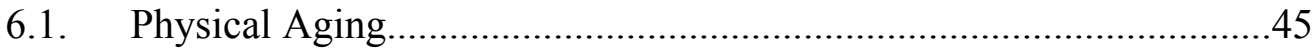

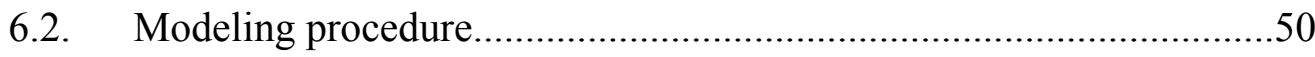

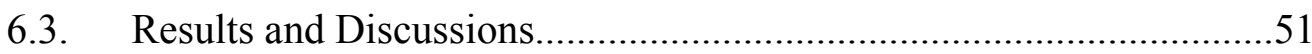

6.4. Conclusions of physical aging study..........................................57

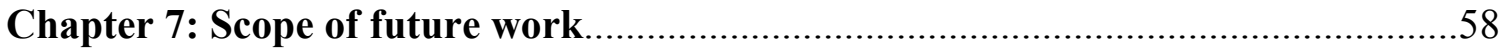

7.1. Failure studies in unaged conditions...........................................58

7.2. Other phenomena occurring during physical aging.........................59

7.3. Chemical and Hydro-thermal aging.............................................61

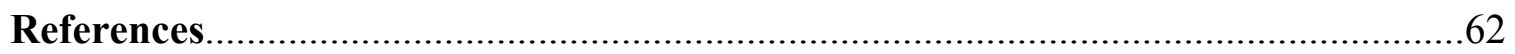

\section{Appendix A}

LAMMPS sample codes for energy minimization, NVT dynamics, measurement of elastic moduli and glass-transition temperature ..............................................6 
A.1. Molecular Energy Minimization simulation.........................................68

A.2. NVT Molecular Dynamics simulation for equilibration.......................69

A.3. Simulated heating for measuring Glass-Transition Temperature and volume shrinkage using NPT (constant pressure and temperature) ensemble. 70

A.4. Simulations for measuring positive and negative volumetric strains for calculation of bulk modulus .71

A.5. Simulations for measuring positive and negative shear strains for calculation of shear modulus .73

A.6. NPH (constant enthalpy and pressure) simulations for measuring tensile strains along $\mathrm{X}, \mathrm{Y}$ and $\mathrm{Z}$ axes for calculation of Young's modulus .75

\section{Appendix B}

AWK script for finding distances between crosslinking atoms .78

\section{Appendix C}

Copyright Agreements and Permissions

C.1. Copyright agreement for using selected text and figures 2.2, 4.1, 4.2, 4.3, 4.4, 5.1, 5.3 in Chapters 2, 3, 4 and 5 .79

C.2. Copyright agreement for using selected text and figure 6.2 in Chapter 6.

C.3. Permission to use figure 1.3a in Chapter 1 86 


\section{LIST OF FIGURES}

1.1. Epoxide ring with two reacting Carbon atoms and one Oxygen atom...................1

1.2. Crosslink formation in micro scale and atomic scale

4

1.3. (a) Energy landscape of a complex molecular model and (b) Energy vs. distance plot of a single covalent bond [(a) Image courtesy of http://dillgroup.stonybrook.edu/energy-landscapes, (C) Dr.

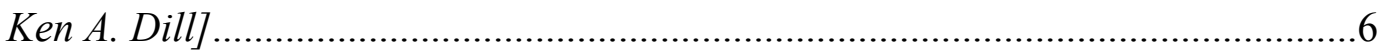

2.1. Molecular structures of EPON 862 resin and DETDA molecules. Atoms marked in red and inside boxes have been considered as united atoms. The numbers indicate the atom IDs. .10

2.2. Two EPON 862 molecules modeled in a perpendicular arrangement with one DETDA molecule in between. The Oxygen atom of the epoxide ring is marked red and is present along with $\mathrm{CH}_{2}$ and $\mathrm{CH}_{3}$ alkyl groups in a triangular manner at the opposite ends of the figure on the four sides.

3.1. Eight times replication of 2:1 model. The 2:1 EPON 862-DETDA structures have been rotated and translated in different ways so that none of them had similar conformations 
3.2. Evolution of EPON:DETDA model having 432:216 stoichiometric ratio. (A) 16:8 structure replicated 27 times in a $3 \times 3 \times 3$ array to form a $432: 216$ structure and (B) 27 clusters arranged in a $3 \times 3 \times 3$ array and each cluster is a $16: 8$ crosslinked structure (Atom spheres are at the same resolution for comparison of sizes of simulation boxes in the 3 figures). 19

4.1. First step of Crosslinking reaction: The lone pair of electrons of the nitrogen atom attacks the carbon atom next to the epoxide oxygen, forming a $\mathrm{C}-\mathrm{N}$ bond and leaving a negative charge on the oxygen and a positive charge on the nitrogen. (The wavy lines represent the remaining parts of the EPON 862 and DETDA molecules in the respective structures). 22

4.2. Second and Final steps of crosslinking reaction: (A) The negatively charged oxygen abstracts a proton from the neighboring protonated amine, resulting in an alcohol group and an amine group and the crosslinking is complete. (B) The same crosslinked nitrogen reacts with another epoxide end of EPON 862 in the same way and forms two crosslinks. .24

4.3. The dependence of the crosslink density on crosslinking cutoff distance for two different crosslinked structures .25

4.4. Spatial Density distributions of $54 \%, 63 \%, 76 \%$ and $88 \%$ crosslinked structures along the length of simulation box. $26,27,28$ 
5.1. Density vs. temperature curves for $54 \%, 63 \%$ and $76 \%$ crosslinked system

5.2. Volume shrinkages with respect to the volume at $300^{\circ} \mathrm{C}$ for $54 \%, 63 \%$ and $76 \%$ crosslinked structures. 34

5.3. Stress vs. Strain graph for tensile deformation along $Y$ - axis at $0.7 \%$ strain of $70 \%$ crosslinked model.

6.1. Schematic showing the definition of free volume, volumetric reduction, and configurational change in a crosslinked epoxy polymer.

6.2. Specific volume vs. temperature for a typical epoxy polymer. The shaded region indicates the amount of free volume in the polymer.

6.3. Change in enthalpy $(\Delta h)$ vs. change in volume $\left(\Delta v / v_{o}\right)$ for eight different samples of crosslinked EPON 862-DETDA molecular models. Units- $\Delta h$ in $\mathrm{J} / \mathrm{g}, \Delta v / v_{0}$ is unitless. $.53,54$

6.4. Experimental data for specific enthalpy relaxation for epoxy. The solid line is a linear regression fit for the four data sets 


\section{LIST OF TABLES}

2.1. Atom IDs defined in EPON 862 and DETDA and their corresponding types.

3.1. Translations and Rotations applied to coordinates of $16: 8$ models to get 26 different replicates for forming the 432:216 models.

5.1. Thermal Expansion Coefficients of crosslinked structures .36

5.2. Mechanical properties of crosslinked models based on $1^{\text {st }}$ approach (units in $\mathrm{GPa})$.

5.3. Mechanical properties of crosslinked models based on $2^{\text {nd }}$ approach (units in $\mathrm{GPa})$ .43

6.1. Values of the constant $\alpha(\mathrm{J} / \mathrm{g})$ for each sample of each crosslink density........ .52 


\section{ACKNOWLEDGMENTS}

My PhD had been a nice journey of over four years in which I have learnt a lot about Materials Science and have met nice people with whom I always enjoyed working. I am extremely thankful to Dr. Gregory Odegard for advising me in my $\mathrm{PhD}$ research. He has been not only my adviser but also a great mentor and he has guided me so that I can have a great career ahead. I am thankful to him for giving me the great opportunity to work on this project for the last four and half years.

I am thankful to Dr. Ranjit Pati, Dr. Reza Shahbazian-Yassar and Dr. Yu Wang for being in my $\mathrm{PhD}$ committee. Without their support and vital suggestions, it would have been difficult to complete my PhD. I am grateful to Dr. Kris E. Wise from NASA and Dr. Thomas C. Clancy from National Institute of Aerospace (NIA) for giving me the chance to visit NIA and work with them for one month in 2009. I am thankful to Dr. Ajit Roy of Air Force Research Laboratory (AFRL), Dr. Sarah Jane Frankland of NIA, Dr. Steve Plimpton of Sandia National Laboratories, Dr. Jeffrey Hinckley, Dr. John Connell and Dr. Mia Siochi from NASA for funding this research.

This research was funded by NASA under the Aircraft Aging and Durability Project (Grant NNX07AU58A) and by the Air Force Office of Scientific Research under the Low Density Materials Program (Grant FA9550-09-1-0375).

I need to mention here that my $\mathrm{PhD}$ career will be memorable as I came across some great people in my research group. Ben Jensen, Shreehari Elangovan, Cameron Hadden, Puneet Soman, Aniket Waghchaure, Joe Wlodyka, Nikhil Anand and Pavan Valavala are the ones with whom I not only enjoyed working but also became good friends of mine.

I made many friends in the last four and half years since I came to Houghton and some of them will be my friends forever. I got the opportunity to go around the Upper Peninsula and experience the beauty of pure Michigan. Houghton had been my home away from my home in India and I feel blessed to have stayed in this beautiful place. 
My special thanks go to Nathan Schulke and other staff of the IT department of Michigan Tech for providing the tech support. I am thankful to Beth Ruohonen, Margaret Rothenberger, Edward Laitila from Materials Science and Engineering (MSE) department and Mike Lacourt, Joanne Stimac from Mechanical Engineering department for their support. I am extremely grateful to Dr. Mark R. Plichta and Dr. Calvin White of MSE for their continued support during my PhD.

Finally I would like to thank my parents, sister and all other family members for their continued support. Last but not the least, I am grateful to my wife, Swagata, who had been beside me through the ups and downs of my life and without her, this $\mathrm{PhD}$ would never have been possible.

Ananyo Bandyopadhyay

April 2012

Houghton, Michigan

USA 


\section{ABSTRACT}

EPON 862 is an epoxy resin which is cured with the hardening agent DETDA to form a crosslinked epoxy polymer and is used as a component in modern aircraft structures. These crosslinked polymers are often exposed to prolonged periods of temperatures below glass transition range which cause physical aging to occur. Because physical aging can compromise the performance of epoxies and their composites and because experimental techniques cannot provide all of the necessary physical insight that is needed to fully understand physical aging, efficient computational approaches to predict the effects of physical aging on thermo-mechanical properties are needed. In this study, Molecular Dynamics and Molecular Minimization simulations are being used to establish well-equilibrated, validated molecular models of the EPON 862-DETDA epoxy system with a range of crosslink densities using a united-atom force field. These simulations are subsequently used to predict the glass transition temperature, thermal expansion coefficients, and elastic properties of each of the crosslinked systems for validation of the modeling techniques. The results indicate that glass transition temperature and elastic properties increase with increasing levels of crosslink density and the thermal expansion coefficient decreases with crosslink density, both above and below the glass transition temperature. The results also indicate that there may be an upper limit to crosslink density that can be realistically achieved in epoxy systems. After evaluation of the thermo-mechanical properties, a method is developed to efficiently establish molecular models of epoxy resins that represent the corresponding real molecular structure at specific aging times. Although this approach does not model the physical aging process, it is useful in establishing a molecular model that resembles the physically-aged state for

further use in predicting thermo-mechanical properties as a function of aging time. An equation has been predicted based on the results which directly correlate aging time to aged volume of the molecular model. This equation can be helpful for modelers who want to study properties of epoxy resins at different levels of aging but have little information about volume shrinkage occurring during physical aging. 


\section{CHAPTER 1: INTRODUCTION}

\subsection{Epoxy resins}

Epoxy-matrix composites are one of the primary structural materials used in modern civilian and military aircrafts. Their popularity is due to their excellent specific stiffness, specific strength, and processing properties. Because the mechanical properties of epoxy composites depend significantly on the molecular scale structure of these materials, structure-property relationships are needed to permit design optimization. This also applies to processing conditions, which can significantly alter the structure, and therefore properties, of epoxy composites.

Epoxide resins contain an epoxide group, which is also known as an oxirane, epoxy or ethoxyline group. ${ }^{1}$ This group is a three-membered oxide ring as shown in Figure 1.1. The resins are compounds containing more than one epoxide group per molecule and they polymerize by using these epoxy groups. The polymerization takes place by using a cross-linking agent which is also known as a curing agent or hardener. After polymerization, a tough three-dimensional network is formed which makes the resin dense in nature. The resin is then said to be cured and such cured resins are used in various purposes. The uncured uncrosslinked resins are of liquid nature and have limited uses.

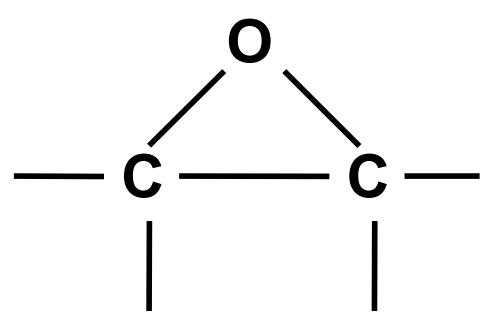

Figure 1.1. Epoxide ring with two reacting Carbon atoms and one Oxygen atom 
Cured epoxy resins have the following advantageous properties: ${ }^{1}$

a) Excellent adhesion to reinforcements

b) Low shrinkage during cure

c) Good mechanical and electrical properties

d) High heat and good fatigue resistance

e) Good chemical and moisture resistance

Thus cured epoxy resins find their uses as adhesives, laminates with fiber reinforcements, road and bridge coatings, jigs, fixtures, insulating cables, foundry patterns, molds and tools used in metal forming.

These resins have been in great usage in the last ten years in the aerospace industries. Composites based on epoxy resins are often used in structural applications in the aerospace industry; where environmental conditions include cyclic exposure to high heat and humidity. ${ }^{2}$ Heat and humidity result in changes of the physical and mechanical properties of the epoxy composite. Repeated changes in temperature and exposure to humidity cause aging of the epoxy resins and this aging can be reversible or a nonreversible process. Reversible aging processes include physical aging, plasticization while non-reversible processes include hydrolysis, oxidative aging and micro-cracking. EPON 862 epoxy resin is one of this kind of epoxy resins which is being used to a great extent as a material for composite engine fan casings and as a structural material for the new generation composite aircrafts. EPON 862 is usually cured with a curing agent known as Diethylene Toluene Diamine (DETDA) to form a cross-linked resin having the above mentioned good properties.

Experiments have been done for studying physical aging and hydrothermal aging of epoxies. ${ }^{3-21}$ These studies have dealt with the changes of glass-transition temperature due to densification of epoxies and other changes in physical and mechanical properties because of changes in the polymer micro-structure. But the performance of cured epoxy resins largely depends on the amount of curing. Whenever an epoxy resin is mixed with a 
curing agent, cross-linking occurs at a very fast rate and monomer chains get covalently bonded to each other with molecules of curing agent providing the connecting link. Figure 1.2 shows how crosslinked epoxies look at the micro scale and at the atomic scale. As more and more crosslinks are being formed, entanglements are formed which hinder the movements of the uncrosslinked, freely moving monomer chains and slow down the rate of crosslinking reactions. Thus, a fully crosslinked network is never formed and unfortunately it is difficult to quantify the crosslink density of real epoxies. The extent of cure can be monitored during the polymerization reaction using Infrared (IR) or dielectric spectroscopy. These techniques utilize changes in spectral features, such as the intensity of the epoxide group vibration (IR) ${ }^{20,22}$ or the frequency of maximum permittivity or loss (dielectric) ${ }^{23,24}$, to determine the progress of reaction. So while these methods permit the study of the cure reaction and yield a relative measure of the extent of reaction, they cannot determine the actual crosslink density for a cured epoxy sample. This work is aimed at understanding aging phenomenon as a function of crosslinking and as a result computational methods have been used.

Computational methods have been recently used in the last ten years for studying behavior of polymeric materials at the atomic scale. Experiments usually can explain phenomena from macro scale to up to nano scale but not beyond that. While this is an advantage of using computational methods, there is a disadvantage as well. The time scale involved in experiments cannot be duplicated in computational methods as most of these computational methods can simulate phenomena occurring up to nanoseconds. Nevertheless, trial-and-error approaches for experimentally optimizing the processing conditions of epoxy materials can become time-consuming and expensive. Over the last two decades, molecular dynamics (MD) simulations based on bead-spring models ${ }^{25,26}$ and Monte-Carlo simulations based on bond-fluctuation models ${ }^{27-29}$ have been used to study the molecular behavior of epoxy materials. The bead-spring models do not fully consider the details of the molecular structures and thus cannot predict the influence of specific groups of atoms on the physical properties. In the last few years, MD at the 
atomic scale has been quite successful in exploring different phenomena occurring at pico- to nano-second time scales in epoxy resins. ${ }^{30}$

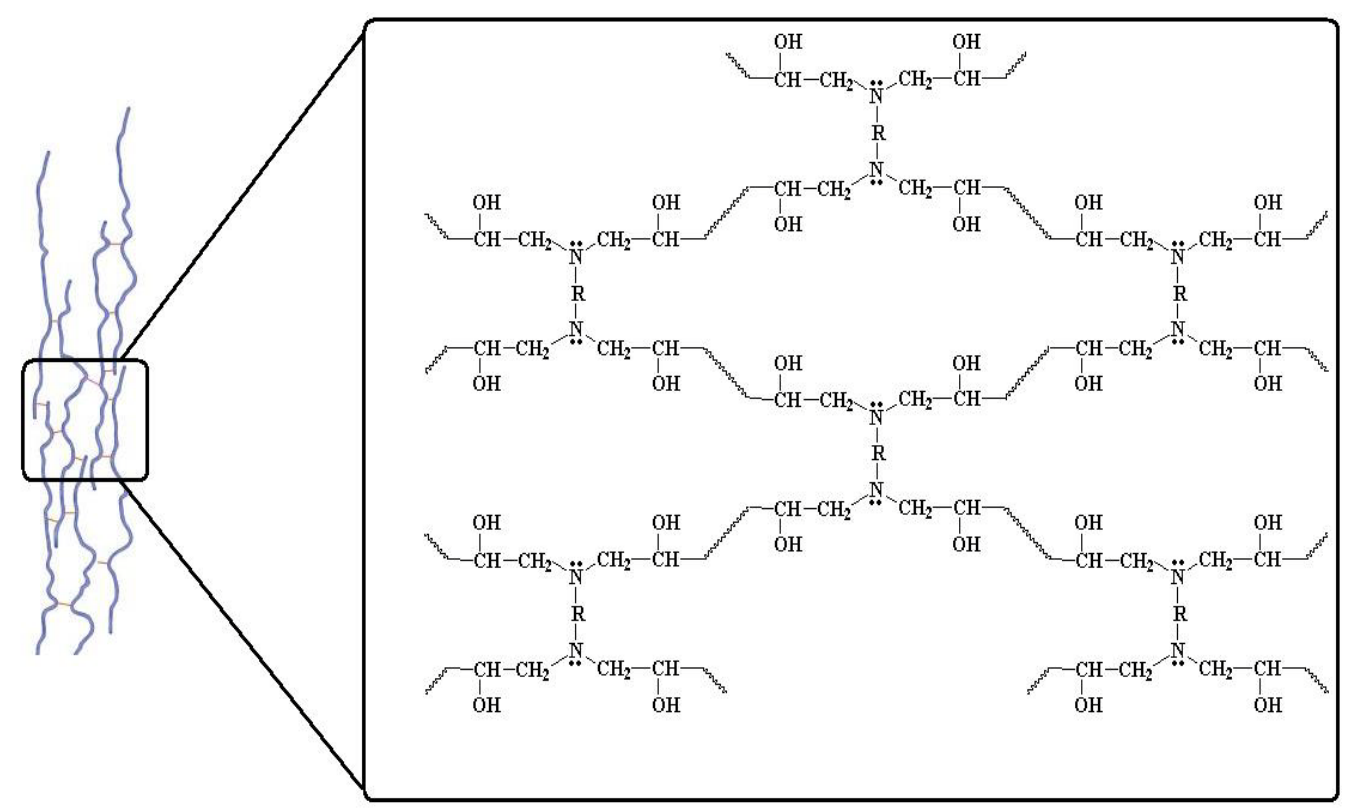

Figure 1.2. Crosslink formation in micro scale and atomic scale

\subsection{Molecular Dynamics}

According to www.wikipedia.org, "Molecular dynamics is a form of computer simulation in which atoms and molecules are allowed to interact for a period of time by approximations of known physics, giving a view of the motion of the atoms". It is a special type of molecular modeling based on statistical mechanics; the main justification of the MD method being "statistical ensemble averages are equal to time averages of the system, known as the ergodic hypothesis". MD usually consists of four kinds of simulations:

1. Microcanonical ensemble (NVE ensemble) -In the NVE ensemble, the system does not undergo any changes in number of moles $(\mathrm{N})$, volume (V) and energy (E). It is an 
adiabatic process where there is no heat exchange. A microcanonical molecular dynamics trajectory has its total energy conserved in this ensemble with continuous exchange going on between potential and kinetic energies.

2. Canonical ensemble (NVT ensemble) - In the NVT ensemble, number of moles (N), temperature $(\mathrm{T})$ and volume $(\mathrm{V})$ are conserved and is known as constant temperature molecular dynamics. In this ensemble, the energies of exothermic and endothermic processes are exchanged with a thermostat. Different types of thermostat methods are available to add and remove energy from the MD system in an almost realistic way.

3. Isothermal-Isobaric (NPT ensemble) - In the isothermal-isobaric ensemble, number of moles $(\mathrm{N})$, pressure $(\mathrm{P})$ and temperature $(\mathrm{T})$ are conserved. Both thermostat and a barostat are needed. The volume is allowed to change freely as a result of the fluctuations occurring due to minute changes in temperature and pressure.

4. Isoenthalpic-Isobaric (NPH ensemble) - In this ensemble, number of moles $(\mathrm{N})$, pressure $(\mathrm{P})$ and enthalpy $(\mathrm{H})$ are conserved. One more degree of freedom is added into the system in the form of a variable volume $(\mathrm{V})$ to which the coordinates of all particles are relative. Volume (V) becomes a dynamic variable with kinetic energy given by $\mathrm{PV}$. The enthalpy $\mathrm{H}=\mathrm{E}+\mathrm{PV}$ is kept constant while the internal energy $\mathrm{E}$ and the kinetic energy PV are allowed to change.

Another kind of simulation which does not come into the domain of MD but is used in conjunction with MD is Energy Minimization. Energy Minimization is the process of making small adjustments to geometries of molecules and minimizing the energy of the total molecular model. ${ }^{31}$ As shown in Figure 1.3b, the position of minimum energy of a bond is at the bottom of the well of the energy vs. distance graph. The position 4 in Figure $1.3 \mathrm{~b}$ indicates a high energy conformation of a particular bond in the molecular level. Minimization can help in changing the conformations of the molecules in the model without providing any kinetic energies to the atoms/molecules and thereby help the model reach positions 3 or 2 . Though the energy vs. distance plot in 2 dimensions looks like a simple one but when the model consists of thousands of polymer monomers 
(each monomer is a molecule) and millions of bonds, the energy landscape of the entire model becomes a complex one and takes a shape in conformation space as shown in Figure 1.3a. Energy minimization simulations continue till there is no change in energies of the models in the last and penultimate iterations. In most of the cases for big molecular models of polymers, the structures reach an energy state that is close to the lowest point in the energy landscape but not exactly the lowest point. In this work few hundreds of energy minimization and more than hundred NVT and NPT simulations have been used for equilibrating the crosslinked epoxy resin molecular models.

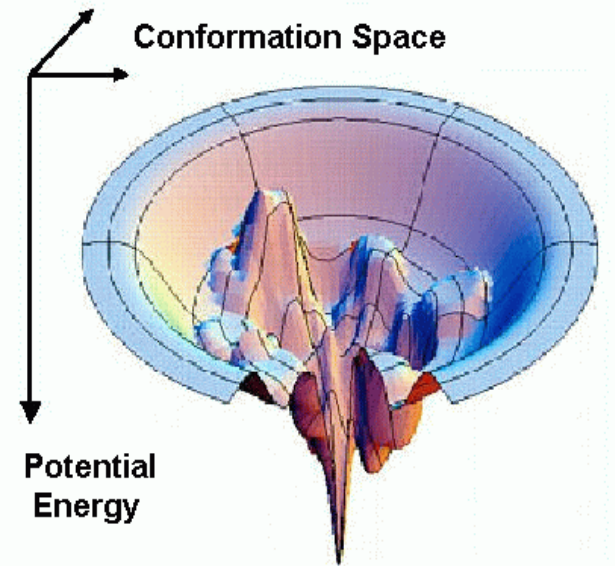

Equilibrium State

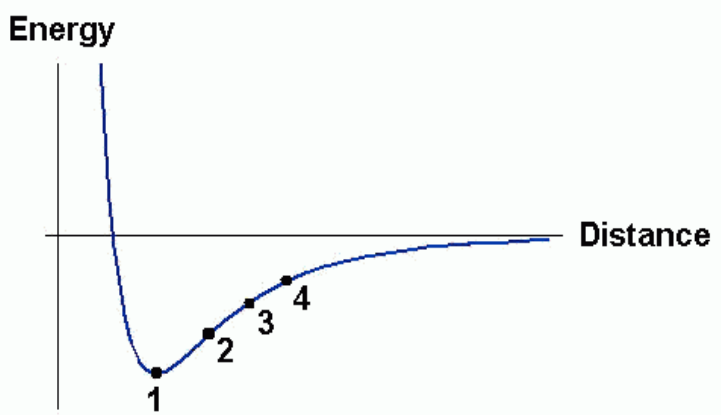

(b)

Figure 1.3. (a) Energy landscape of a complex molecular model and (b) Energy vs. distance plot of a single covalent bond [(a) Image courtesy of http://dillgroup.stonybrook.edu/energy-landscapes, O Dr. Ken A. Dill]

Regarding modeling of cured epoxy resins, the biggest challenge is to model the crosslinking reaction. Many researchers have studied the formation of crosslinked epoxy resins using different approaches of simulated crosslinking. Doherty et al. ${ }^{32}$ modeled poly(methacrylate) networks using lattice-based simulations in a polymerization MD scheme. Yarovsky and Evans ${ }^{33}$ discussed a crosslinking technique which they used to crosslink low molecular-weight, water-soluble, phosphate-modified epoxy resins 
(CYMEL 1158). The crosslinking reactions were carried out simultaneously (static crosslinking process). Crosslinking of epoxy resins using molecular dynamics was performed by $\mathrm{Xu}$ et al. ${ }^{34}$ and their model was used to study the diffusion of water in crosslinked networks. An iterative Molecular Dynamics (MD)/Molecular Minimization (MM) procedure was used to crosslink an epoxy resin (DGEBA), with one crosslink established per iteration. Other computational studies ${ }^{35,36}$ involving crosslinking of epoxies have been performed. All of the studies discussed thus far were performed on relatively small model systems (less than 2200 atoms).

Heine et al. ${ }^{37}$ simulated large PDMS networks using a dynamic crosslinking approach and Varshney et al. ${ }^{30}$ used Heine's dynamic crosslinking approach and Xu's MD/MM concept ${ }^{34}$ to crosslink EPON 862 with DETDA. Varshney et al. ${ }^{30}$ modeled two different systems having molecules of EPON 862 and DETDA in the ratios of 128:64 and 256:128 (EPON :DETDA). Although these studies have made significant progress in the molecular modeling of crosslinked epoxies, relatively large molecular models $(>15,000$ atoms) have not yet been developed to predict the influence of crosslink density on a wide range of thermo-mechanical properties of EPON 862-DETDA polymers.

The objective of this research was to establish relatively large molecular models of the EPON 862-DETDA crosslinked epoxy system and to predict the influence of crosslink density on the thermomechanical properties and influence of physical aging. An efficient and accurate methodology of creating molecular models of a crosslinked epoxy system containing more than 25,000 atoms was developed and the models created by this methodology were being used for subsequent studies. Chapters 2, 3 and 4 discuss about the different steps of the model building methodology. Chapter 5 discusses about the validation of the model building methodology by evaluation of different thermomechanical properties and the influence of crosslink density on the properties. Chapter 6 discusses about the theory of physical aging and modeling approach. 


\section{CHAPTER 2: FORCE FIELD AND MODEL PARAMETERS ${ }^{1}$}

This chapter describes the procedures for building the initial 2:1 stoichiometric model of EPON 862-DETDA mixture. The techniques for creating a monomer/hardener solution are described first, followed by the discussion about atom types and force field parameters. The initial model building approach is unique and few assumptions have been made to establish the model.

\subsection{Force field}

The OPLS United Atom force field was developed by Jorgensen and co-workers ${ }^{38-41}$. In this force field, the total energy of a molecular system is a sum of all the individual energies associated with bond, angle, dihedral, and 12-6 Lennard-Jones interactions. The bond energy is given as

$$
E_{b o n d s}=\sum_{b o n d s} K_{r}\left(r-r_{o}\right)^{2}
$$

where $K_{r}$ is a force constant, $r$ is the distance between the two atoms considered, and $r_{o}$ is the equilibrium bond distance. The energy associated with bond-angle bending is

$$
E_{\text {angles }}=\sum_{\text {angles }} K_{\theta}\left(\theta-\theta_{o}\right)^{2}
$$

\footnotetext{
${ }^{1}$ Portions of text in this chapter have been reprinted and Figure 2.2 has been redrawn with permission from Bandyopadhyay, A.; Valavala, P. K.; Clancy, T. C.; Wise, K. E.; Odegard, G. M. Polymer 2011, 52, (11), 2445-2452. (C) Elsevier Ltd. Please refer Appendix C.1 for copyright information.
} 
where $K_{\theta}$ is a force constant, $\theta$ is the bond angle, and $\theta_{o}$ is the equilibrium bond angle. The bond stretching and bending functions are quadratic which give an adequate description of the structures and energies of relatively unstrained organic molecules. The dihedral potential is given by

$$
\begin{aligned}
E_{\text {dihedrals }}= & \frac{V_{1}}{2}[1+\cos \phi]+\frac{V_{2}}{2}[1-\cos 2 \phi]+ \\
& \frac{V_{3}}{2}[1+\cos 3 \phi]+\frac{V_{4}}{2}[1-\cos 4 \phi]
\end{aligned}
$$

where $V_{1}, V_{2}, V_{3}$ and $V_{4}$ are coefficients in the Fourier series ${ }^{39,41}$ and $\phi$ is the dihedral angle. A Fourier series approach of the torsional energy gives good indication of the conformation changes occurring due to torsions present in short and long chains of polymer molecules. The 12-6 Lennard Jones interactions or van der Waal's interactions are given by

$$
E_{i j}=4 \varepsilon_{i j}\left[\left(\frac{\sigma_{i j}}{r_{i j}}\right)^{12}-\left(\frac{\sigma_{i j}}{r_{i j}}\right)^{6}\right]
$$

where the equilibrium spacing parameter $\sigma$ of the Lennard-Jones potential was considered to be the arithmetic mean of the individual parameters of the respective atom types for this work while the well depth parameter $\varepsilon$ was taken to be the geometric mean of the values of the respective atom types. The $r$ is the distance between the two nonbonding atoms denoted by $i$ and $j$. No charges were allotted to atoms and the overall structure was kept neutral. 


\subsection{Modeling 2:1 stoichiometric mixture}

The initial uncrosslinked molecular model structure was established using a procedure similar to that used by Varshney et al ${ }^{30}$. A small-scale MD model was established for a mixture of EPON 862 monomer (Di-glycidyl ether of Bisphenol-F) and crosslinking agent DETDA (Diethylene Toluene Diamine). The molecules of EPON 862 and DETDA are shown in Figure 2.1. By using the OPLS united atom force field, all $\mathrm{CH}_{3}, \mathrm{CH}_{2}, \mathrm{CH}$, and alkyl groups were modeled as single united atoms with their corresponding masses, except for the $\mathrm{C}$ and $\mathrm{H}$ atoms in the phenyl rings of both the monomer and hardener molecules and one $\mathrm{CH}_{3}$ group directly connected to the phenyl ring of the DETDA molecule. In Figure 2.1, the united atoms have been marked red in boxes and the atom ids have been shown beside each atom. The atom ids were used to identify each atom and assign coordinates to them.

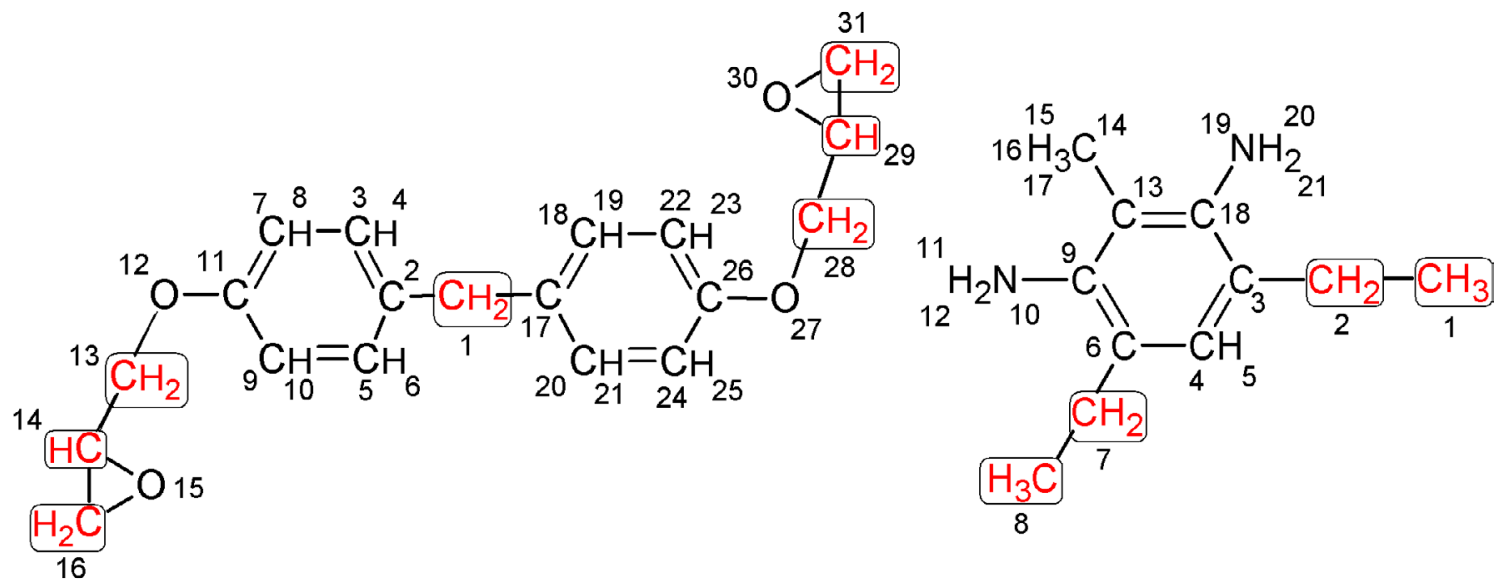

Figure 2.1. Molecular structures of EPON 862 resin and DETDA molecules. Atoms marked in red and inside boxes have been considered as united atoms. The numbers indicate the atom IDs. 
The OPLS force field was used to identify each type of atom. The masses of the united atoms were defined as the combined mass of the individual atoms present in the united atom. The atoms were classified into 13 types and Table 2.1 shows the atom types and the atom IDs that belong to each individual type.

Table 2.1. Atom IDs defined in EPON 862 and DETDA and their corresponding types

\begin{tabular}{|c|c|c|}
\hline EPON 862 Atom Ids & DETDA Atom Ids & Atom types \\
\hline 1 & 2,8 & $\begin{array}{l}\mathrm{sp}^{3} \text { Carbon with two } \\
\text { Hydrogens }\end{array}$ \\
\hline $\begin{array}{c}2,3,5,7,9,17,18,20 \\
22,24\end{array}$ & $3,4,6,9,13,18$ & $\begin{array}{c}\text { Aromatic Carbon as in } \\
\text { Tyrosine }\end{array}$ \\
\hline $4,6,8,10,19,21,23,25$ & 5 & $\begin{array}{l}\text { Aromatic Hydrogen } \\
\text { connected to Carbon }\end{array}$ \\
\hline 11,26 & & $\begin{array}{c}\text { Carbon connected to } \mathrm{OH}^{-} \text {in } \\
\text { Tyrosine }\end{array}$ \\
\hline 12,27 & & Oxygen in $\mathrm{OH}^{-}$in Tyrosine \\
\hline $13,16,28,31$ & & $\begin{array}{l}\mathrm{sp}^{3} \text { Carbon with two } \\
\text { Hydrogens as in Glycine } \\
\text { Methyl Ester }\end{array}$ \\
\hline 14,29 & & $\begin{array}{l}\mathrm{sp}^{3} \text { Carbon with one } \\
\text { Hydrogen as in alpha } \\
\text { Methyl Ester }\end{array}$ \\
\hline \multirow[t]{6}{*}{15,30} & & Oxygen as in ether/ester \\
\hline & 1,7 & $\begin{array}{l}\mathrm{sp}^{3} \text { Carbon with three } \\
\text { Hydrogens in Isoleucine }\end{array}$ \\
\hline & 10,19 & $\begin{array}{c}\text { Nitrogen as in } \mathrm{NH}_{2}^{-} \text {of } \\
\text { Aniline }\end{array}$ \\
\hline & $11,12,20,21$ & $\begin{array}{c}\text { Hydrogen as in } \mathrm{NH}_{2}^{-} \text {of } \\
\text { Aniline }\end{array}$ \\
\hline & 14 & $\begin{array}{c}\text { Carbon as in } \mathrm{CH}_{3}^{+} \text {of } \\
\text { Toluene }\end{array}$ \\
\hline & $15,16,17$ & $\begin{array}{c}\text { Hydrogen as in } \mathrm{CH}_{3}^{+} \text {of } \\
\text { Toluene }\end{array}$ \\
\hline
\end{tabular}


After the atom types were defined, the bonds were defined using the bond parameters of the force field. The equilibrium bond lengths $\left(r_{0}\right)$ along with the force constants $\left(K_{r}\right)$ for all bonds were defined in the coordinates file. 6 types of different bonds were present in EPON 862 and 3 more bond types in DETDA. 7 angle types in EPON 862 and 5 more angle types in DETDA were defined based on the types of atoms that were connected. The following assumptions were made while selecting the angle parameters of equilibrium bond angles $\left(\theta_{o}\right)$ and force constants $\left(K_{\theta}\right)$ because of the non-availability of the exact angle types.

\section{Assumptions about Angle types:-}

1. $\mathrm{CH}-\mathrm{CH}_{2}-\mathrm{O}$ was considered same as $\mathrm{CH}_{2}-\mathrm{CH}-\mathrm{O}$

2. $\mathrm{CH}_{2}-\mathrm{O}-\mathrm{CH}, \mathrm{C}-\mathrm{O}-\mathrm{CH}_{2}, \mathrm{CH}_{2}-\mathrm{O}-\mathrm{CH}_{3}, \mathrm{CH}_{2}-\mathrm{O}-\mathrm{CH}_{2}$ and $\mathrm{CH}-\mathrm{O}-\mathrm{CH}$ were considered to be having same parameters

3. $\mathrm{CH}_{2}-\mathrm{CH}-\mathrm{CH}_{2}, \mathrm{CH}_{3}-\mathrm{CH}-\mathrm{CH}_{2}, \mathrm{CH}_{3}-\mathrm{CH}-\mathrm{CH}_{3}, \mathrm{CH}-\mathrm{CH}-\mathrm{CH}_{3}, \mathrm{CH}-\mathrm{CH}-\mathrm{CH}_{3}$ and CH$\mathrm{CH}-\mathrm{CH}$ were considered to be having same parameters

4. C-C-N was assumed as $\mathrm{C}-\mathrm{C}-\mathrm{C}$

5. $\mathrm{CH}_{3}-\mathrm{CH}_{2}-\mathrm{C}$ was considered as $\mathrm{CH}-\mathrm{CH}_{2}-\mathrm{CH}$

The dihedrals were more in number than angles and bonds and were classified into 6 types. The dihedral parameters are the Fourier constants $\left(V_{1}, V_{2}, V_{3}\right.$ and $\left.V_{4}\right)$ and in all cases, OPLS force field gives values of zero for $V_{l}$ and $V_{2}$. The assumptions for dihedral parameters because of the non-availability of exact dihedral types are given below.

\section{Assumptions about Dihedral types:-}

1. $\mathrm{C}-\mathrm{C}-\mathrm{CH}_{2}-\mathrm{C}$ was assumed as $\mathrm{C}-\mathrm{C}-\mathrm{C}-\mathrm{C}$ where all $\mathrm{C}$ are aromatic Carbon atoms

2. C-O-CH$-\mathrm{CH}, \mathrm{CH}-\mathrm{O}-\mathrm{CH}-\mathrm{CH}$ and $\mathrm{CH}_{2}-\mathrm{CH}-\mathrm{O}-\mathrm{CH}_{2}$ were considered same

3. $\mathrm{CH}_{2}-\mathrm{CH}-\mathrm{CH}_{2}-\mathrm{O}, \mathrm{C}-\mathrm{CH}-\mathrm{CH}_{2}-\mathrm{O}$ and $\mathrm{CH}_{2}-\mathrm{CH}-\mathrm{CH}_{2}-\mathrm{O}$ were considered same

4. $\mathrm{CH}_{3}-\mathrm{CH}_{2}-\mathrm{C}-\mathrm{C}$ was assumed as $\mathrm{C}-\mathrm{C}-\mathrm{C}-\mathrm{C}$ where all $\mathrm{C}$ are aromatic Carbon atoms

5. All Nitrogen atoms in DETDA were considered as Carbon atoms 
Usually the main contribution to potential energy is caused by bond energy because less energy is required to distort an angle or a dihedral away from equilibrium than to stretch or compress a bond. Thus the force constants associated with angles and dihedrals are proportionately smaller than bond force constants. ${ }^{42}$ Thus it can be expected that these assumptions do not affect the potential energy of the molecular model significantly.

The first model had two molecules of EPON 862 and one molecule of DETDA. This is the stoichiometric ratio in which EPON 862 and DETDA are usually mixed in order to achieve the best properties through maximum crosslinking. Once all the parameters were defined, the coordinates of all the atoms along with the number of bonds, angles and dihedrals and their respective parameters were written to a data file in the native LAMMPS format ${ }^{43}$. The two EPON 862 molecules were arranged at $90^{\circ}$ to each other and were separated by a distance of $1.8 \AA$ as shown in Figure 2.2. The DETDA molecule was placed in the gap of $1.8 \AA$ between the two EPON molecules. The three molecules were placed in a cubic simulation box of size $80 \times 80 \times 80 \AA^{3}$. The simulation box was made big so as to have a gaseous system of two chains of EPON 862 and one chain of DETDA.

The 3 molecules were subjected to four energy molecular minimizations (MM) and three NVT (constant volume and temperature) molecular dynamics (MD) in between the minimizations to minimize internal forces (thus reduce internal residual stresses) resulting from the construction of bonds, bond angles, and bond dihedrals. The NVT dynamics were conducted at $600 \mathrm{~K}$ for 100 picoseconds for providing sufficient velocities to the atoms of the chains and allow them to move to different positions that might lead them to a lower energy state. It is important to mention here that the NVT ensemble made use of the Nose/Hoover thermostat and barostat for temperature and pressure control ${ }^{44}$. In the minimizations, two different approaches were considered: a) steepest descent and b) conjugate gradient ${ }^{45}$. The two minimizations are mentioned as follows:

a) Steepest Descent- This is a one-dimensional minimization which uses the derivative information to simply go along the downhill in the direction of the steepest slope. In these 
simulations, it was found that steepest descent algorithm took a longer time to converge than the conjugate gradient algorithm and did not give always give lowest values of minimized energy.

b) Conjugate Gradient- This algorithm uses line searching in which information from successive line searches are stored and used to shape the rest of the minimization. This is a less time consuming and better method than steepest descent.

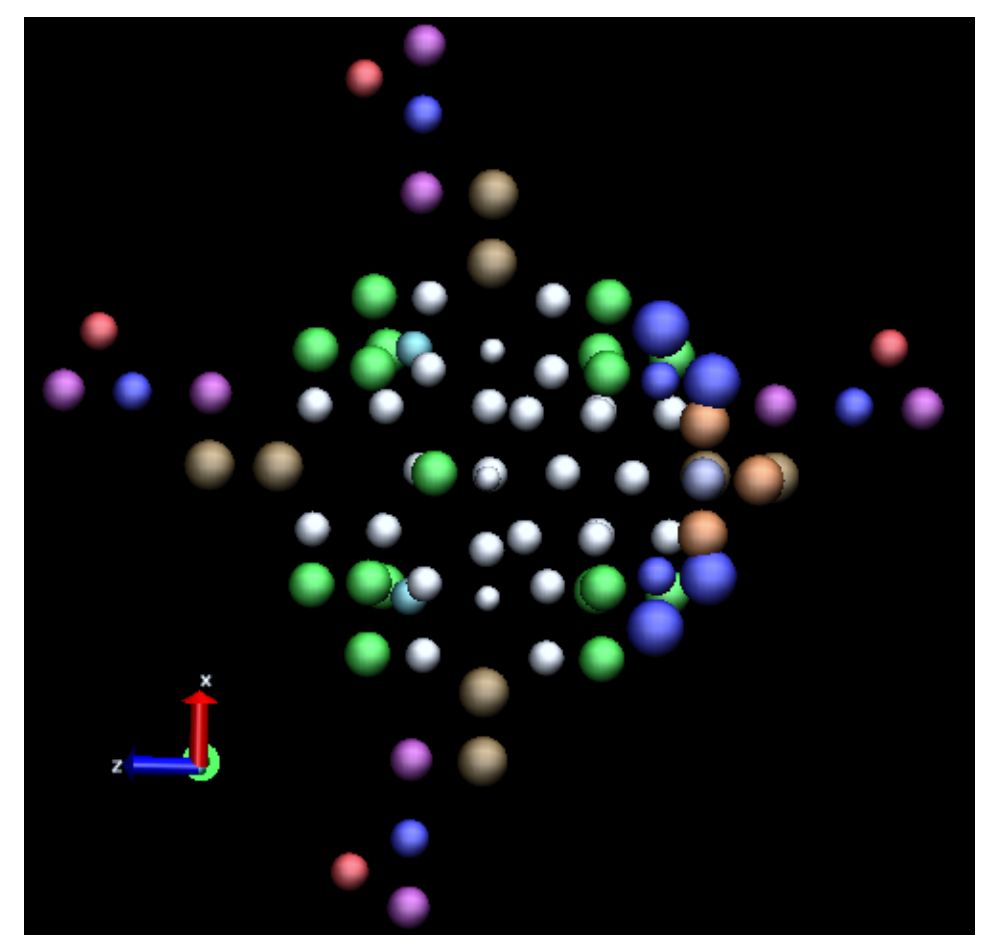

Figure 2.2. Two EPON 862 molecules modeled in a perpendicular arrangement with DETDA molecule in between. The Oxygen atom of the epoxide ring is marked red and is present along with $\mathrm{CH}_{2}$ and $\mathrm{CH}_{3}$ alkyl groups in a triangular manner at the opposite ends of the figure on the four sides. 


\section{CHAPTER 3: MODELING PROCEDURES}

\subsection{Replication of $2: 1$ to $16: 8$ model}

Different combinations of translations of $3 \AA$ and rotations of $30^{\circ}$ were applied to the 3 chains of 2:1 system to form 8 different combinations which were combined to form the unequilibrated 16:8 system. Figure 3.1 shows the 8 different replicates of the 2:1 model. This model had 16 chains of EPON 862 and 8 chains of DETDA which were replicated 27 times to form 432:216 system containing 432 chains of EPON 862 and 216 chains of DETDA.

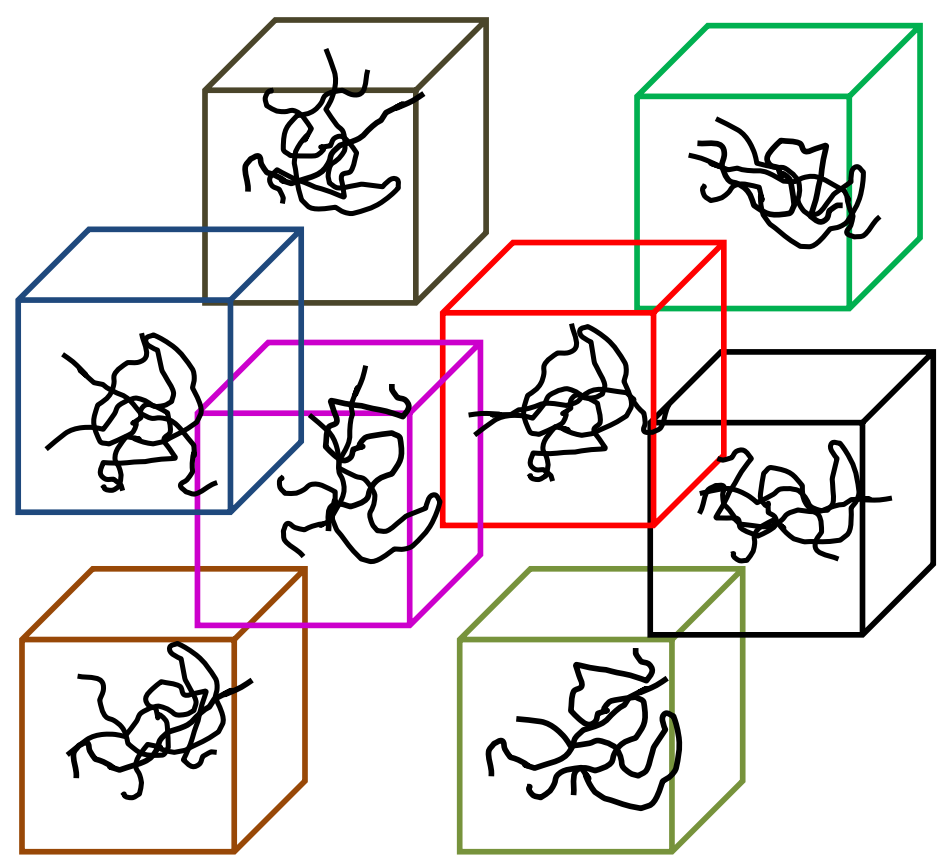

Figure 3.1. Eight times replication of $2: 1$ model. The 2:1 EPON 862-DETDA structures have been rotated and translated in different ways as mentioned so that none of them had similar conformations. 
These 8 different replicates were kept in a large cubic box of length $80 \times 80 \times 80 \AA^{3}$. This box was slowly shrunk by lengths of $10 \AA$ along all three axes after 400 picoseconds (ps) NVT dynamics in between the minimization simulations. In this time, the target volume of the simulation box was calculated based on the approximate density of an EPON 862-DETDA system which is around $1.2 \mathrm{~g} / \mathrm{cc}$ at room temperature ${ }^{46,47}$. Based on a range of $1.20 \mathrm{~g} / \mathrm{cm}^{3}-1.22 \mathrm{~g} / \mathrm{cm}^{3}$ target density, the volume of the simulation box was supposed to be around $21.24 \AA$ in length along each axis. As the simulation box size was shrunk to $40 \times 40 \times 40 \AA^{3}$ size, the rate of shrinking was slowed down by $2 \AA$ per side after each cycle of two MMs and one in-between MD. The stress relaxation procedure was completed after $20 \mathrm{MM}$ and $10 \mathrm{MD}$ simulations because the simulation box reached a volume of $21.24 \times 21.24 \times 21.24 \AA^{3}$ which corresponds to a density of $1.21 \mathrm{~g} / \mathrm{cm}^{3}$. The final pressure value of the last minimization was less than 1 atmosphere (101,325 Pascals) which indicated that the structure had almost no residual stress. This equilibrated structure was used for the subsequent crosslinking step. Appendix A consists of the codes used in the LAMMPS program for minimization and NVT dynamics for shrinking the simulation box containing the 16:8 molecular model of 16:8 system.

\subsection{Replication of crosslinked $16: 8$ to $432: 216$ model}

The equilibrated and uncrosslinked 16:8 models were crosslinked so that the chains got bonded to each other by covalent bonds. Details about the crosslinking mechanisms and the crosslinking algorithm are mentioned in Chapter 4. In this section, equilibration of the crosslinked models and how they have been replicated to form the 432:216 models are being discussed.

The crosslinked 16:8 models were equilibrated by performing two MM and one MD run alternately to remove the residual stresses generated during the formation of the crosslinks. The MD runs were NVT simulations for $100 \mathrm{ps}$ at $500 \mathrm{~K}$. The equilibrated, crosslinked 16:8 models were replicated 26 times for each crosslink density, and each 
replica was rotated and translated to form a $3 \times 3 \times 3$ array of $16: 8$ structures for each crosslink density. The replication of the 16:8 model to 27 different structures is shown in Figure 3.2. The replication was done by applying different combinations of rotation and translation to the $\mathrm{X}, \mathrm{Y}$ and $\mathrm{Z}$ coordinates of the original 16:8 model. The different replicates and the different combinations of translations and rotations applied to the coordinates are shown in Table 3.1. The large systems had 432 molecules of EPON 862 and 216 molecules of DETDA. For four different defined crosslink densities, the 16:8 models had differences in the number of bonds, angles, and dihedrals. Each of these four samples had 17,928 united atoms representing a total 25,272 explicit atoms. These four 432:216 models were further crosslinked based on the same principles used in crosslinking the 16:8 systems.

The models having a 432:216 monomer ratio of EPON 862 and DETDA chains were further equilibrated using MD and MM techniques with continuous shrinking of the volume until the models reached densities close to $1.2 \mathrm{~g} / \mathrm{cm}^{3}\left(1200 \mathrm{~kg} / \mathrm{m}^{3}\right)$. The starting volumes of the $432: 216$ models were $100 \times 100 \times 100 \AA^{3}$. The van der Waals (vdW) interactions were switched down to $0.01 \%$ to reduce the sudden spike in potential energy caused by bringing 17928 united atoms together in the first step of the equilibration process. The $\mathrm{vdW}$ interactions were not switched off completely as it can lead to 'ringspearing' effects ${ }^{48}$. With cycles of $2 \mathrm{MM}$ and one NVT dynamics in between the two MMs, the vdW interactions were increased to $33 \%$, then to $66 \%$ and finally upto $100 \%$.

Once the vdW interactions were switched to full potential, the shrinking of the box was started. Between 30 and 35 minimizations and 12 NVT simulations were required for the equilibration of each individual 432:216 EPON 862-DETDA model. At every stage of volume reduction, one minimization was performed to relax the coordinates of the atoms in the new reduced size of the simulation box. This was followed by a $100 \mathrm{ps}$ NVT simulation at $500 \mathrm{~K}$. The temperature for NVT was kept relatively high so that atoms had enough kinetic energy to sample local configuration space. This was followed by one or two minimizations, depending on the energy and pressure values obtained after the simulations. That is, if the pressure was not close to $1 \mathrm{~atm}$. after the first minimization 
after the NVT simulation, then very small changes were made to the box dimensions and a subsequent minimization was performed.

The final box dimensions were around $62 \times 62 \times 62 \AA^{3}$ and the acquired density was around $1.2 \mathrm{~g} / \mathrm{cm}^{3}$. The different 432:216 models with varying crosslink densities had different but closely matching densities. These models were further crosslinked and then again equilibrated for eliminating the residual stresses generated due to the second crosslinking step. The second crosslinking step is discussed in details in Chapter 4.

Table 3.1. Translations and Rotations applied to coordinates of $16: 8$ models to get 26 different replicates for forming the 432:216 models.

\begin{tabular}{|c|c|c|c|}
\hline Replicate & X Coordinate & Y Coordinate & Z Coordinate \\
\hline 1 & No change & No change & No change \\
\hline 2 & Cos $30^{\circ},+50 \AA$ & $\operatorname{Cos} 30^{\circ},-50 \AA$ & $-50 \AA$ \\
\hline 3 & $\operatorname{Cos} 30^{\circ},+50 \AA$ & $+50 \AA$ & $-50 \AA$ \\
\hline 4 & $-50 \AA$ & $\operatorname{Cos} 30^{\circ},+50 \AA$ & $-50 \AA$ \\
\hline 5 & $-50 \AA$ & $\operatorname{Cos} 30^{\circ},-50 \AA$ & $\operatorname{Cos} 30^{\circ},-50 \AA$ \\
\hline 6 & $+50 \AA$ & $-50 \AA$ & $\operatorname{Cos} 30^{\circ},+50 \AA$ \\
\hline 7 & $+50 \AA$ & $\operatorname{Cos} 30^{\circ},+50 \AA$ & Cos $30^{\circ},+50 \AA$ \\
\hline 8 & $\operatorname{Cos} 30^{\circ},-50 \AA$ & $-50 \AA$ & Cos $30^{\circ},+50 \AA$ \\
\hline 9 & $\operatorname{Cos} 30^{\circ},-50 \AA$ & $\operatorname{Cos} 30^{\circ},+50 \AA$ & Cos $30^{\circ},+50 \AA$ \\
\hline 10 & $\operatorname{Cos} 45^{\circ}$ & $-50 \AA$ & No change \\
\hline 11 & $\operatorname{Cos} 45^{\circ},+50 \AA$ & $\operatorname{Cos} 45^{\circ},-50 \AA$ & No change \\
\hline 12 & $+50 \AA$ & $\operatorname{Cos} 45^{\circ}$ & No change \\
\hline 13 & $\operatorname{Cos} 45^{\circ},+50 \AA$ & $+50 \AA$ & Cos $45^{\circ}$ \\
\hline 14 & No change & $+50 \AA$ & Cos $45^{\circ}$ \\
\hline 15 & $-50 \AA$ & $\operatorname{Cos} 45^{\circ},+50 \AA$ & Cos $45^{\circ}$ \\
\hline 16 & $\operatorname{Cos} 30^{\circ},-50 \AA$ & No change & Cos $45^{\circ}$ \\
\hline 17 & $\operatorname{Cos} 45^{\circ},-50 \AA$ & $\operatorname{Cos} 45^{\circ},-50 \AA$ & Cos $45^{\circ}$ \\
\hline
\end{tabular}




\begin{tabular}{|c|c|c|c|}
\hline 18 & $\operatorname{Cos} 60^{\circ}$ & $\operatorname{Cos} 60^{\circ}$ & $+50 \AA$ \\
\hline 19 & $\operatorname{Cos} 60^{\circ}$ & $-50 \AA$ & $+50 \AA$ \\
\hline 20 & $+50 \AA$ & $\operatorname{Cos} 60^{\circ}$ & $+50 \AA$ \\
\hline 21 & No change & $+50 \AA$ & $\operatorname{Cos} 60^{\circ},+50 \AA$ \\
\hline 22 & $-50 \AA$ & $\operatorname{Cos} 60^{\circ}$ & $\operatorname{Cos} 60^{\circ},+50 \AA$ \\
\hline 23 & $\operatorname{Cos} 45^{\circ}$ & $\operatorname{Cos} 30^{\circ}$ & $\operatorname{Cos} 45^{\circ},-50 \AA$ \\
\hline 24 & $\operatorname{Cos} 60^{\circ}$ & $-50 \AA$ & $\operatorname{Cos} 60^{\circ},-50 \AA$ \\
\hline 25 & $+50 \AA$ & $\operatorname{Cos} 60^{\circ}$ & $\operatorname{Cos} 45^{\circ},-50 \AA$ \\
\hline 26 & $\operatorname{Cos} 30^{\circ}$ & $\operatorname{Cos} 60^{\circ},+50 \AA$ & $-50 \AA$ \\
\hline 27 & $-50 \AA$ & $\operatorname{Cos} 45^{\circ}$ & $\operatorname{Cos} 30^{\circ},-50 \AA$ \\
\hline
\end{tabular}
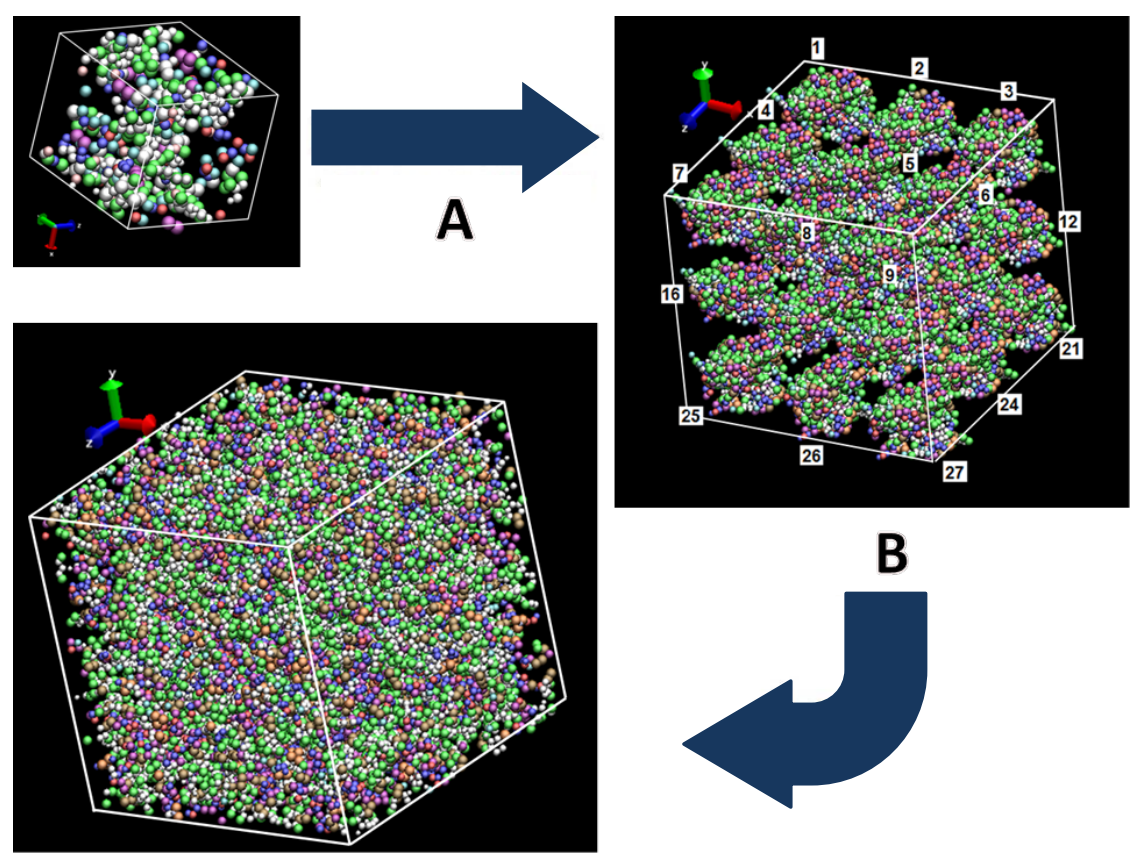

Figure 3.2. Evolution of EPON:DETDA model having 432:216 stoichiometric ratio.

(A) 16:8 structure replicated 27 times in a $3 \times 3 \times 3$ array to form a $432: 216$ structure and (B) 27 clusters arranged in a $3 \times 3 \times 3$ array and each cluster is a 16:8 crosslinked structure (Atom spheres are of same resolution for comparing sizes of simulation boxes in all 3 figures) 


\section{CHAPTER 4: CROSSLINKING ${ }^{2}$}

The 16:8 models of EPON-DETDA were crosslinked to four different extents after equilibration. These models were replicated to form the 432:216 EPON-DETDA models which were further crosslinked. The details about the crosslinking procedure are written in this chapter.

\subsection{Crosslinking procedure}

The equilibrated structure of the 16:8 model was statically crosslinked based on the root mean square (RMS) distance between the $\mathrm{N}$ atoms of DETDA and $\mathrm{CH}_{2}$ groups of the EPON 862 molecules, similar to the approach used by Yarovsky and Evans. ${ }^{33}$ Simultaneous breaking of $\mathrm{CH}_{2}-\mathrm{O}$ bonds in the epoxide ends of the EPON 862 molecules and N-H bonds of the DETDA molecules made the activated $\mathrm{CH}_{2}$ ends capable of forming crosslinks with activated $\mathrm{N}$ atoms of the DETDA molecules. A particular activated $\mathrm{N}$ could form a crosslink with the activated $\mathrm{CH}_{2}$ of any adjacent EPON 862 molecule within a specified cutoff distance. While the actual crosslinking reaction is quite complex, the fundamental mechanisms that were modeled in this work are depicted in Figures 4.1 and 4.2. Three assumptions were made for the crosslinking process:

1) Both primary amines in DETDA were assumed to have the same reactivity

2) The $\mathrm{CH}_{2}-\mathrm{O}$ and $\mathrm{N}-\mathrm{H}$ bonds were broken simultaneously (Figure 4.1)

3) One $\mathrm{N}$ atom was partially activated when it had only one activated $\mathrm{CH}_{2}$ within a defined cutoff distance.

\footnotetext{
${ }^{2}$ Portions of text in this chapter have been reprinted and Figures 4.1, 4.2, 4.3 and 4.4 have been redrawn with permission from Bandyopadhyay, A.; Valavala, P. K.; Clancy, T. C.; Wise, K. E.; Odegard, G. M. Polymer 2011, 52, (11), 2445-2452. (C) Elsevier Ltd. Please refer Appendix C.1for copyright information.
} 
The starting point of the crosslinking reaction is shown in Figure 4.1 where the nucleophilic amine of the DETDA molecule reacts with the unsubstituted epoxy $\mathrm{C}$, and the adjacent oxygen atom attains a negative charge when the $\mathrm{C}-\mathrm{O}$ bond is broken. After forming a bond with the $\mathrm{C}$ atom, the $\mathrm{N}$ atom attains a positive charge and thus the neutrality of the EPON 862-DETDA system is maintained. Crosslinks were formed by computing all RMS distances between each $\mathrm{N}$ atom and the $\mathrm{CH}_{2}$ united atoms within a defined cutoff distance. The $\mathrm{CH}_{2}$ radicals located outside the cut-off distance of a particular $\mathrm{NH}_{2}$ group were not crosslinked to that particular group. The cutoff distance was chosen to achieve a desired level of crosslinking as mentioned below. In the next step, the $\mathrm{H}^{+}$ions were formed by breaking $\mathrm{NH}_{2}$ bonds and were reacted with the $\mathrm{O}^{-}$atoms of the broken epoxide ends. This bond formation was also performed based on the closest RMS distances between the $\mathrm{O}^{-}$and $\mathrm{H}^{+}$atoms.

The second step of the crosslinking reaction is shown in Figure 4.2. A RMS distance searching program was written in AWK script for finding distances between all possible crosslinking $\mathrm{N}$ atoms and $\mathrm{CH}_{2}$ united atoms. The same program was also used to find RMS distances between $\mathrm{H}$ and $\mathrm{O}$ atoms. The script of the program is given in Appendix B.

To determine the influence of the RMS distance on the total number of crosslinks formed, the crosslink density was determined for a range of RMS cutoffs for two different molecular models constructed in the manner described in Figure 4.3. The crosslink density of the epoxy system was defined as the ratio of the total number of crosslinks that were formed to the maximum number that could be formed. For example, an epoxy network having 16 out of 32 crosslinks is defined as having a $50 \%$ crosslink density. 

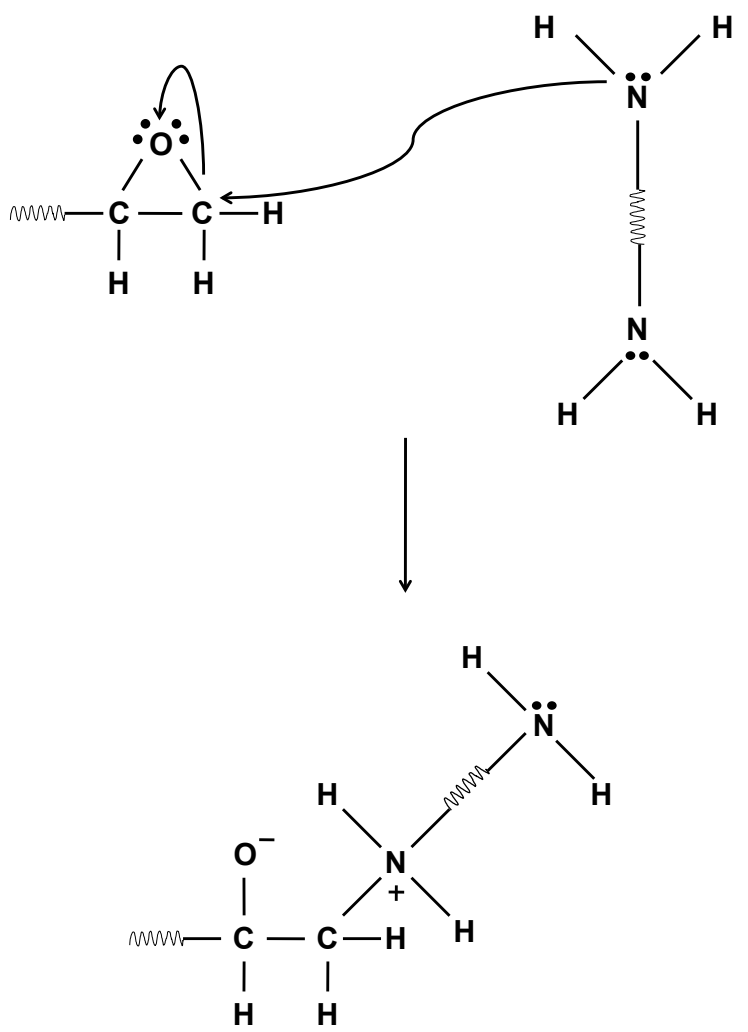

Figure 4.1. First step of Crosslinking reaction: The lone pair of electrons of the nitrogen atom attacks the carbon atom next to the epoxide oxygen, forming a $\mathrm{C}-\mathrm{N}$ bond and leaving a negative charge on the oxygen and a positive charge on the nitrogen. (The wavy lines represent the remaining parts of the EPON 862 and DETDA molecules in the respective structures).

In Figure 4.3 a steep rise can be seen where the crosslink density increased from just above $15 \%$ to almost $60 \%$ over a span of a cutoff distance between 2 and $4 \AA$. Another important aspect of this graph is the plateau over which the crosslink density increased very little over a range of 4 to $8 \AA$ and again after $10 \AA$. It is important to note that the trends of the two systems are very similar, demonstrating reproducibility in the crosslink density/RMS distance relationship. Therefore, a large increase in crosslink density occurred from $28 \%$ to $56 \%$ for the first system over a range difference of 1 Angstrom. For the second system, the large increase in crosslink density occurred from 3\% to $38 \%$ over 1 Angstrom range. This trend was close to the trend of crosslink densities found by 
Varshney et al. ${ }^{30}$ by using an alternative, dynamic-based crosslinking approach. Varshney et al. reported an increase in crosslink density from $0 \%$ to $80 \%$ over a range difference of $1 \AA$. This demonstrates that the extent of crosslinking increases rapidly over a certain range of distance between the crosslinking atoms.

Four representative crosslink densities were chosen for the subsequent modeling steps: $50 \%$ at a cutoff of $3.8 \AA, 59 \%$ at a cutoff of $5 \AA, 72 \%$ at a cutoff of $8 \AA$ and $84 \%$ at a cutoff of $10 \AA$. These crosslink densities were chosen because they represent the expected range for a stoichiometric monomer/hardener mixing ratio.

After crosslinking, new bonds, angles and dihedrals were formed. Three new bonds between $\mathrm{CH}-\mathrm{O}, \mathrm{N}-\mathrm{CH}_{2}$ and $\mathrm{O}-\mathrm{H}$ are formed due to crosslinks. Due to the formation of these new bonds, 5 different types of angles and 7 different types of dihedrals are formed. Another aspect of modeling that needs to be taken care of due to crosslinking is a change in the type of Oxygen atom which takes part in crosslinking. Since the Oxygen atom in the original epoxy ring forms a bond with $\mathrm{H}$ of the amine group with the subsequent breakage of the epoxy ring structure, the vdW coefficients were changed from ethereal to hydroxyl type Oxygen. The old bonds, angles and dihedrals were removed and few assumptions were considered for forming the new bonds, angles and dihedrals which are given below.

\section{Assumptions about Dihedral types:-}

1. $\mathrm{C}-\mathrm{N}-\mathrm{CH}_{2}-\mathrm{CH}, \mathrm{H}-\mathrm{N}-\mathrm{CH}_{2}-\mathrm{CH}$ and $\mathrm{CH}_{2}-\mathrm{N}-\mathrm{CH}_{2}-\mathrm{CH}$ were considered same

2. C-C-N-CH $\mathrm{H}_{2}$ was assumed as $\mathrm{C}-\mathrm{C}-\mathrm{N}-\mathrm{C}$ where all $\mathrm{C}$ are aromatic Carbon atoms

3. N-CH2-CH-CH 2 and $\mathrm{N}-\mathrm{CH}_{2}-\mathrm{CH}-\mathrm{O}$ were assumed as $\mathrm{C}-\mathrm{CH}-\mathrm{CH}_{2}-\mathrm{C}$

4. $\mathrm{H}-\mathrm{O}-\mathrm{CH}-\mathrm{CH} 2$ was assumed as $\mathrm{H}-\mathrm{OH}-\mathrm{CH}-\mathrm{C}$.

\section{Assumptions about Angle types:-}

1. $\mathrm{N}-\mathrm{CH}_{2}-\mathrm{CH}$ is assumed as $\mathrm{N}-\mathrm{CH}_{2}-\mathrm{CH}_{2}$ 

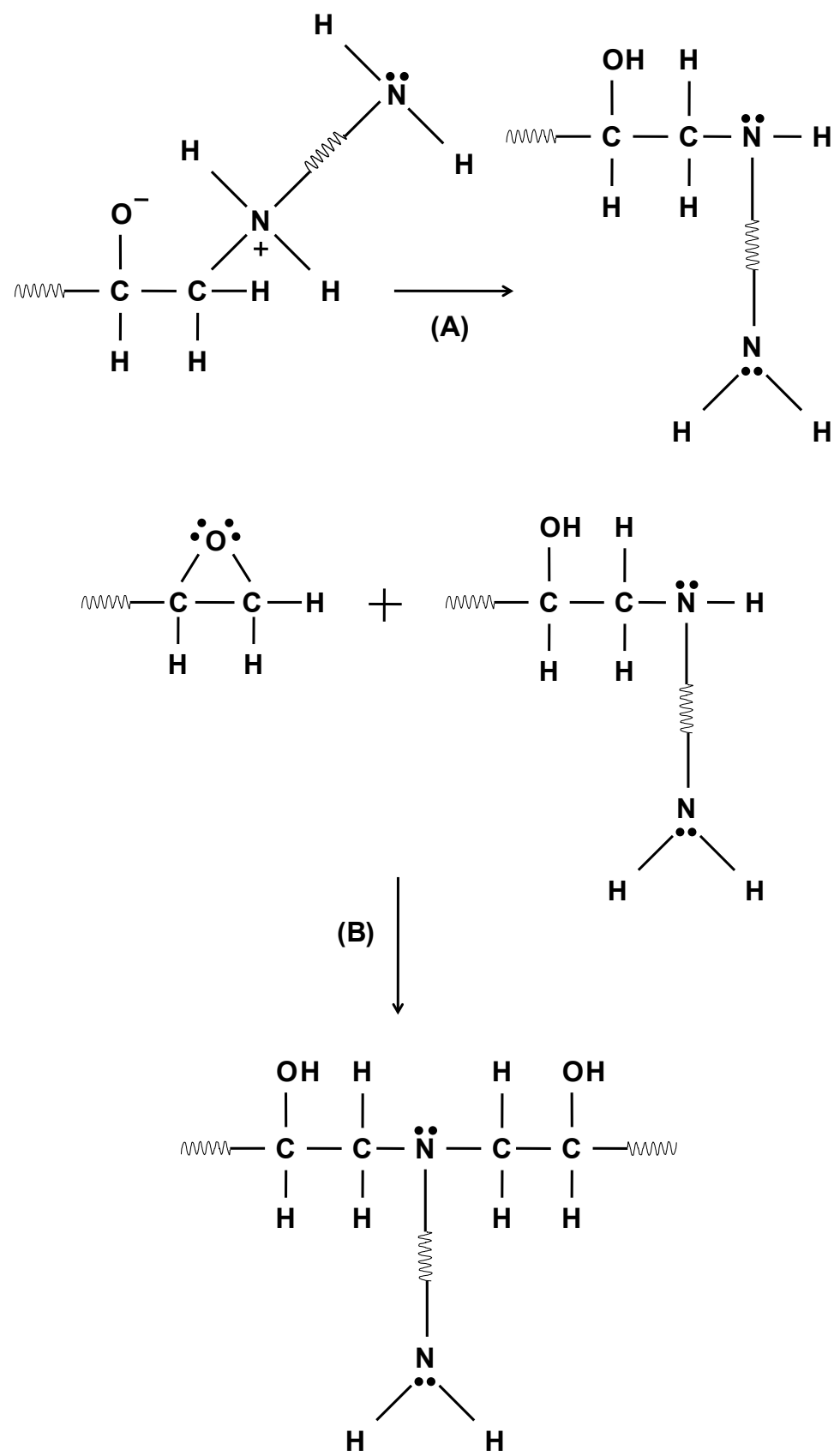

Figure 4.2. Second and Final steps of crosslinking reaction: (A) The negatively charged oxygen abstracts a proton from the neighboring protonated amine, resulting in an alcohol group and an amine group and the crosslinking is complete. (B) The same crosslinked nitrogen reacts with another epoxide end of EPON 862 in the same way and forms two crosslinks. 


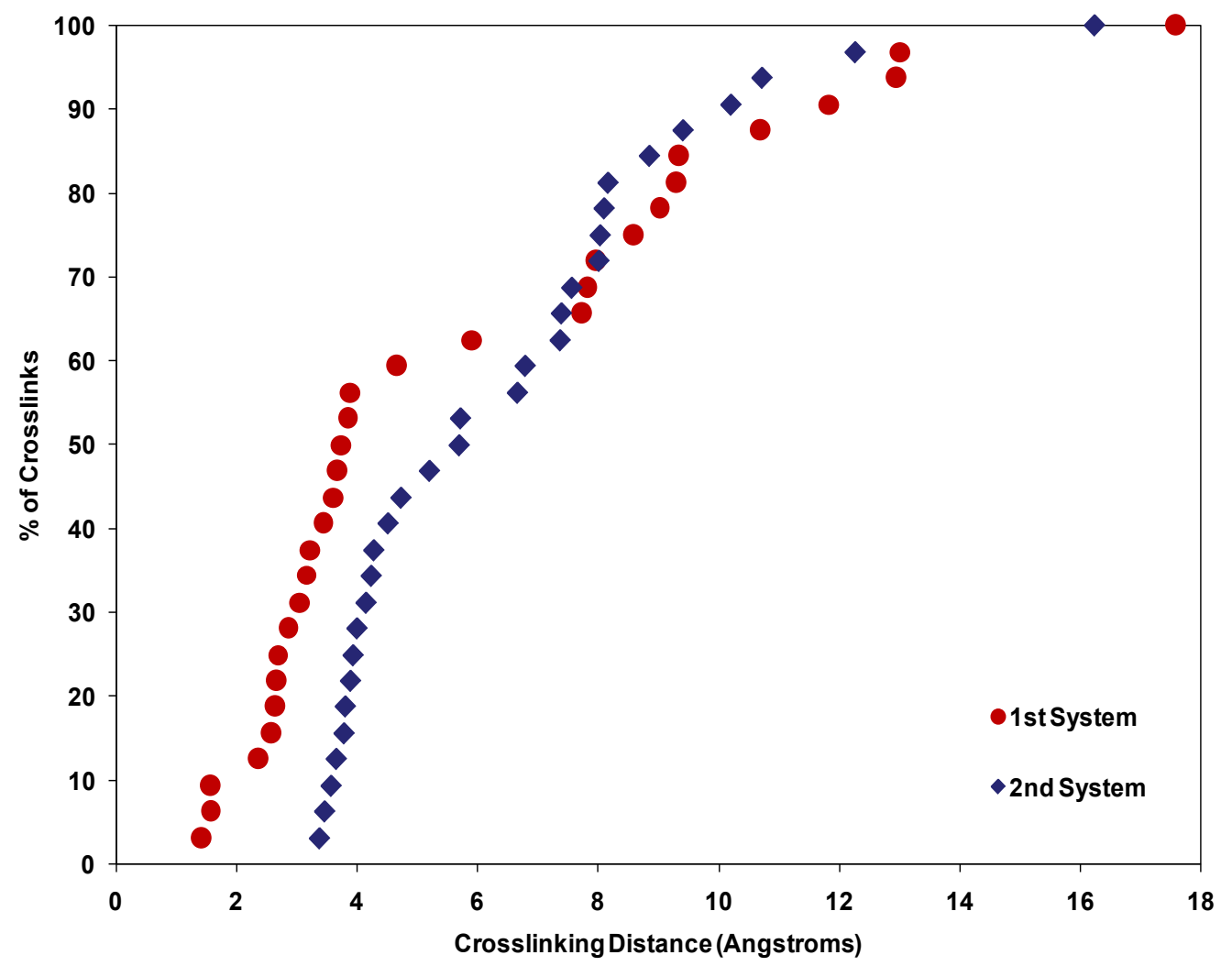

Figure 4.3. The dependence of the crosslink density on crosslinking cutoff distance for two different crosslinked structures.

The 16:8 models were further equilibrated after crosslinking to remove the residual stresses generated due to crosslinking. The details of the equilibration procedure and replication techniques for formation of the 432:216 models are given in Chapter 3. Once equilibrated, the models were further crosslinked based on RMS cutoff distance approach described above. NPT simulations were run on the equilibrated 432:216 models at various temperatures and the final coordinates of the $300 \mathrm{~K}$ simulations were used for additional crosslinking. Normal temperature and pressure conditions were used for additional crosslinking for simulating the real crosslinking process. The additional crosslinking steps were performed so that the 27 sub-units of the molecular model were crosslinked with one another, thus creating a stable solid structure and increasing the crosslink densities further. The 50\% crosslinked structure had a 54\% crosslink density 
after this step; the 59\% crosslinked structure became $63 \%$ crosslinked, the $72 \%$ crosslinked structure increased to $76 \%$ and the $84 \%$ crosslinked structure increased to $88 \%$. After this additional process of crosslinking, the structures were further equilibrated at the same volume with two NVT simulations at $500 \mathrm{~K}$ and $300 \mathrm{~K}$ for 100 picoseconds each with in-between MM minimizations. It is important to note that the equilibrated structures model an infinite network of crosslinked epoxy due to the use of periodic boundary conditions. Therefore, the modeled structures do not represent localized crosslinking, which is observed in microgels with highly-crosslinked particles on the order of $10 \AA{ }^{49}$

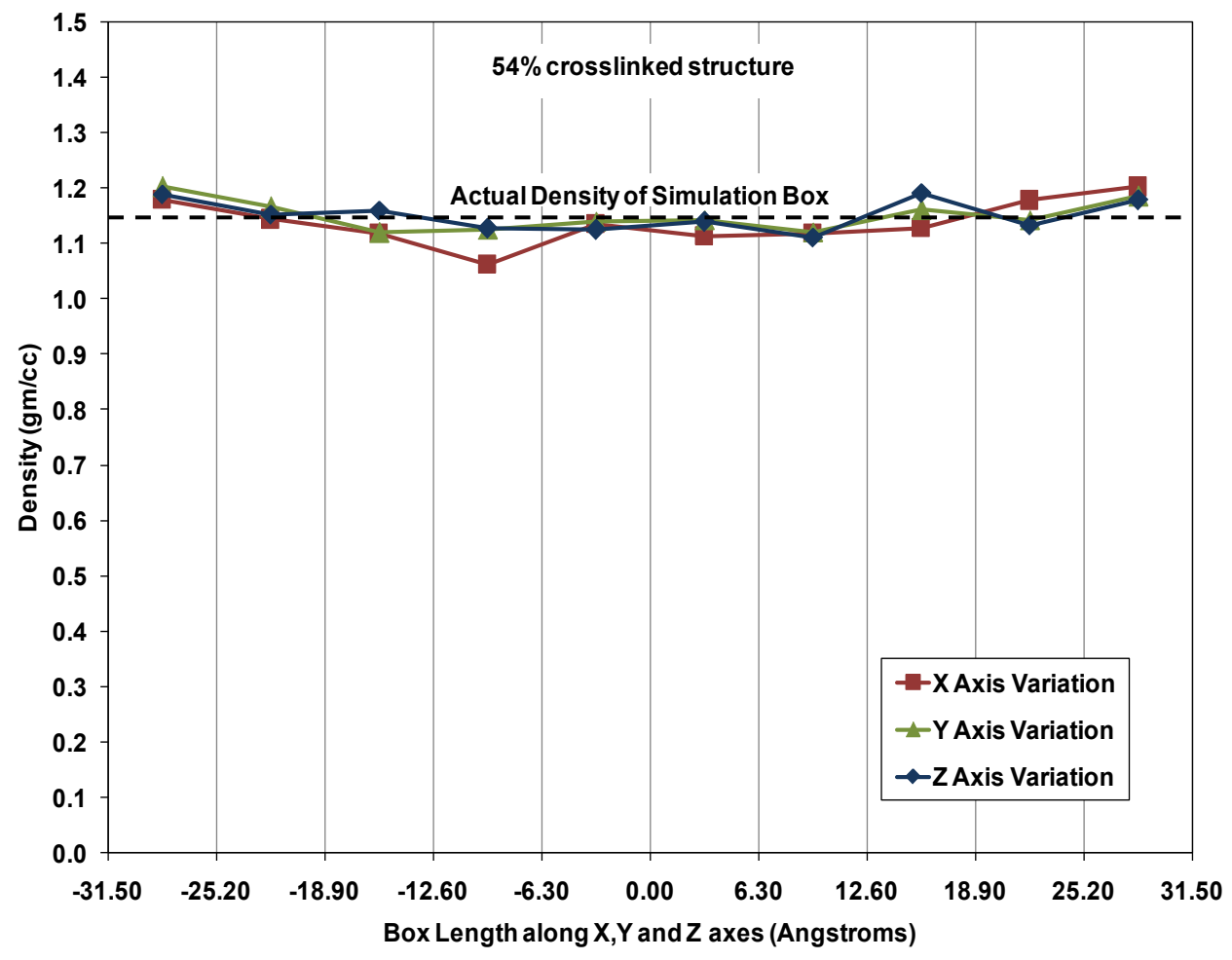



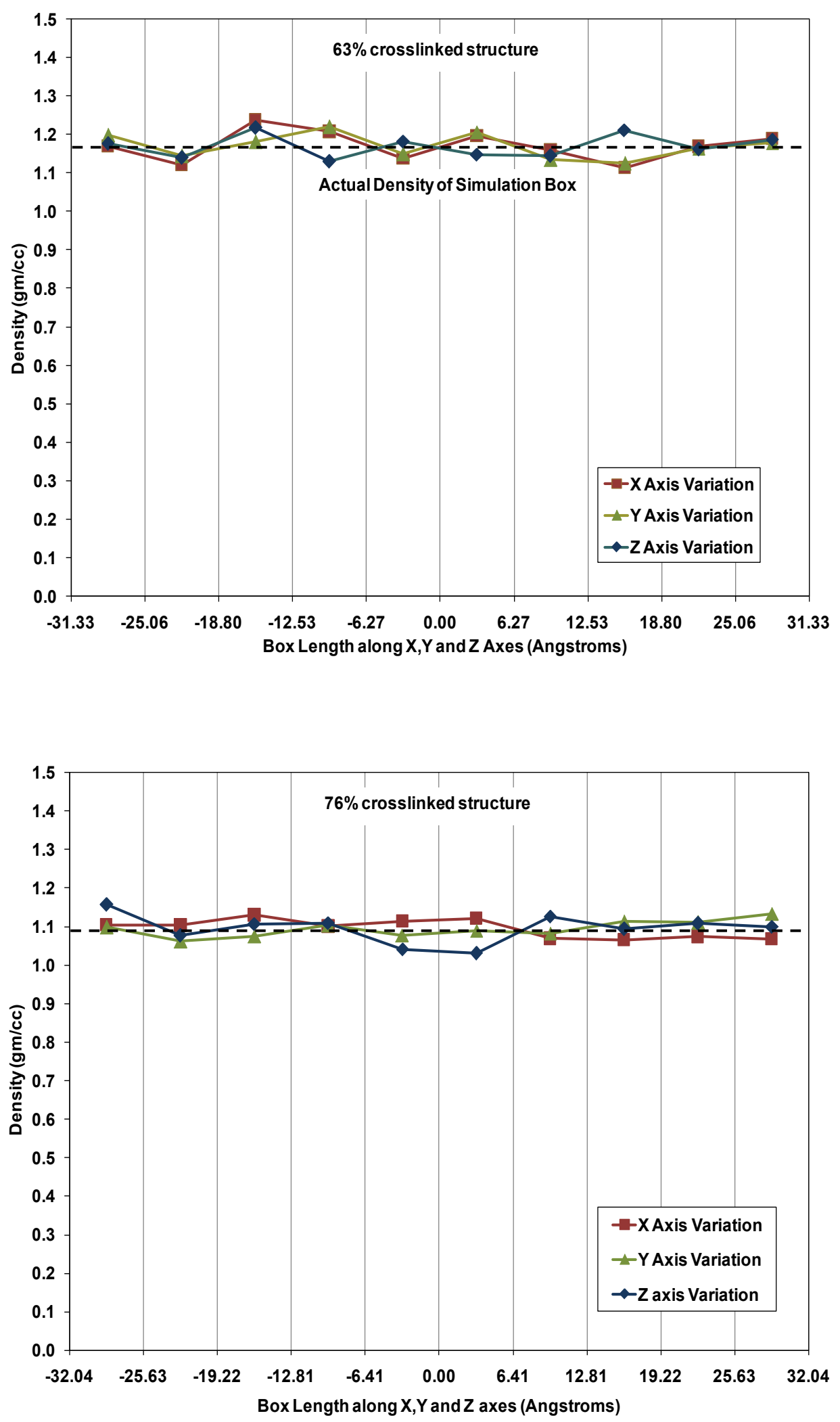


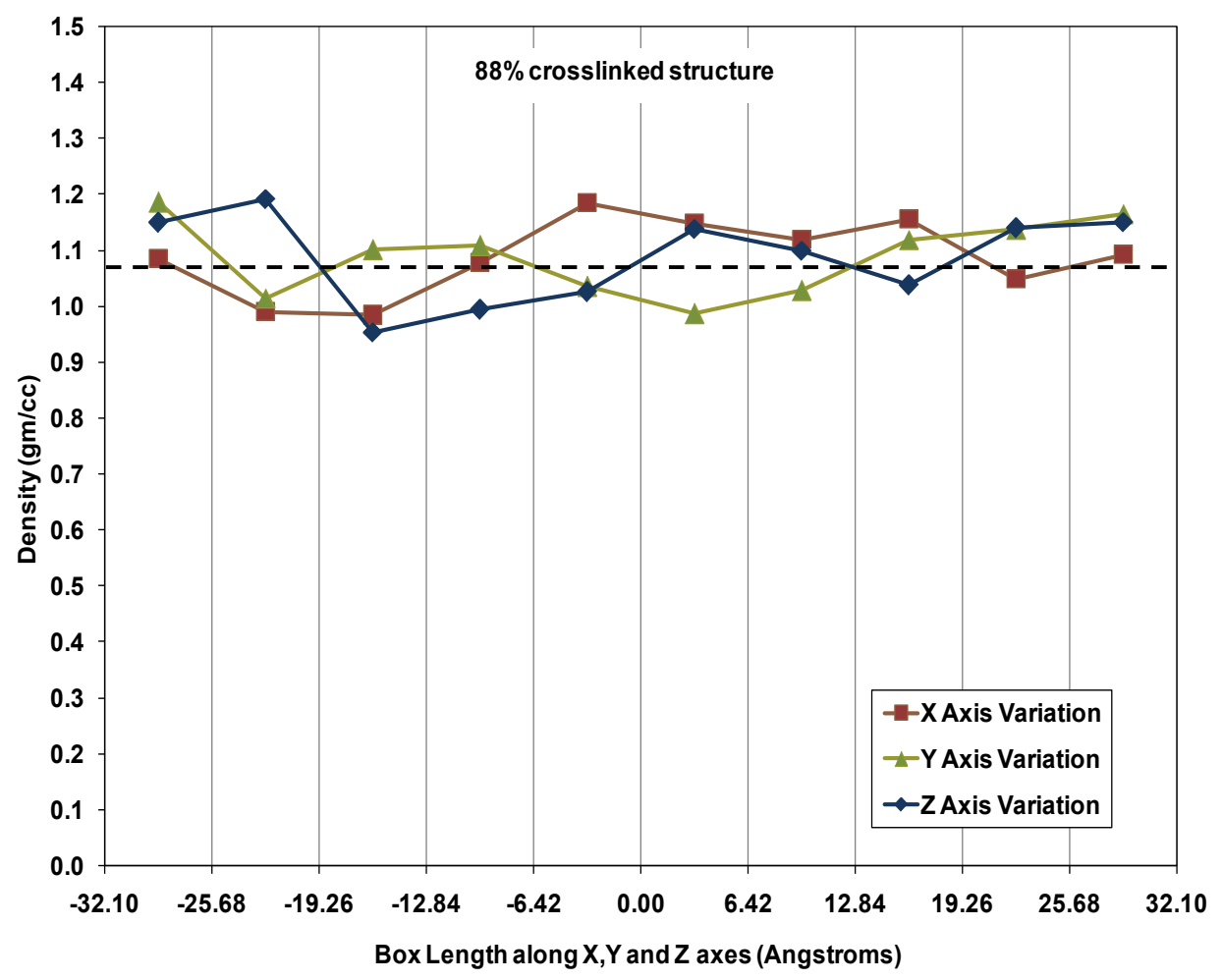

Figure 4.4. Spatial Density distributions of $54 \%, 63 \%, 76 \%$ and $88 \%$ crosslinked structures along the length of simulation box.

\subsection{Density calculations}

The spatial density distributions of these structures were calculated to determine the degree of uniformity of the polymer in the simulation box as shown in Figure 4.4. The simulation boxes for each crosslink density were equally divided into 10 divisions along the $\mathrm{X}, \mathrm{Y}$ and $\mathrm{Z}$ axes and the total masses of all the atoms present in each of those ten divisions was determined. The total mass of atoms present in each division was then divided by the volume of that division to calculate the density of atoms present in that particular division.

The data in Figure 4.4 indicates that the densities of the $54 \%, 63 \%$, and $76 \%$ crosslinked systems were uniform along all three axes of the simulation boxes. The 
spatial density distribution of $88 \%$ crosslinked structure was less uniform compared to the other three structures. The likely reason for the nonuniformity of the $88 \%$ system is because it had more crosslinked chains than the other three crosslinked models and according to the data shown in Figure 4.4, it contained bonds that were longer than any of those in the other crosslinked systems, including some in excess of $10 \AA$. Not only did the increased numbers of crosslinked chains form entanglements which reduced the mobility of the atoms in the structure and slowed equilibration, but the high compressive forces generated in the highly-stretched bonds serve to locally compress the molecular structure, further inhibiting local molecular movement. These unphysical long bonds were an artifact of the method used to crosslink the system. Beyond perturbing the massdensity uniformity, they had negative effects on the predicted physical properties as shown below. Even though the NVT simulations at $500 \mathrm{~K}$ provided a relatively large amount of kinetic energy to the molecular structure, the reduced mobility in the $88 \%$ crosslinked system resulted in a less uniform density distribution compared to the other structures. 


\section{CHAPTER 5: VALIDATION OF EQUILIBRATED CROSSLINKED MODELS $^{3}$}

Each of the equilibrated models of EPON 862-DETDA with 432:216 molecular ratio and varying degrees of crosslinking were used to determine the glass transition temperature $\left(\mathrm{T}_{\mathrm{g}}\right)$, thermal expansion coefficient, thermal and elastic properties. The values obtained for different properties were compared with the results mentioned for EPON 862DETDA in literature. This was done for validating the realistic nature of the simulated models. The procedures and results for these simulations are described in this chapter.

\subsection{Glass transition temperature range determination}

For each of the three cross-linked epoxy models, NPT (constant pressure and constant temperature) simulations were run for 400 picoseconds from $-70^{\circ} \mathrm{C}(203 \mathrm{~K})$ to $330^{\circ} \mathrm{C}$ $(603 \mathrm{~K})$ at pressures of $1 \mathrm{~atm}$. These simulations were performed to simulate the process of constant heating of the epoxy systems from cryogenic temperatures to elevated temperatures. The simulation codes are in Appendix A.3. Using the results of the NPT simulations, density versus temperature curves were plotted which are shown in Figure 5.1 for the $54 \%, 63 \%$ and $76 \%$ crosslinked systems. Data within the temperature range of $-30^{\circ} \mathrm{C}$ to $300^{\circ} \mathrm{C}$ was used for calculating glass transition temperatures. The simulation data within the initial temperature range from $-70^{\circ} \mathrm{C}$ to $-30^{\circ} \mathrm{C}$ were discarded to eliminate the effects of molecular relaxation and initial oscillation of the temperature and pressure around the set values. The density-temperature curves showed a characteristic change in slope in the $\mathrm{T}_{\mathrm{g}}$ region. Typically the $\mathrm{T}_{\mathrm{g}}$ is determined by finding the intersection between linear regression lines fit to the data points below and above the change in slope. However, the change in slope is usually gradual. As a result, the $\mathrm{T}_{\mathrm{g}}$ determination is

\footnotetext{
${ }^{3}$ Portions of text in this chapter have been reprinted and Figures 5.1 and 5.3 have been redrawn with permission from Bandyopadhyay, A.; Valavala, P. K.; Clancy, T. C.; Wise, K. E.; Odegard, G. M. Polymer 2011, 52, (11), 2445-2452. (c) Elsevier Ltd. Please refer Appendix C.1 for copyright information.
} 
highly sensitive to the manner in which the data points on the density versus temperature graph are fit. Therefore, it is more appropriate to describe the $T_{g}$ as a temperature range rather than a single temperature value. To determine the $\mathrm{T}_{\mathrm{g}}$ range, a series of linear regression lines were fit using temperature ranges of $80^{\circ}, 90^{\circ}, 100^{\circ}, 110^{\circ}$ and $120^{\circ} \mathrm{C}$ intervals of temperature for each of the crosslinked systems shown in Figure 5.1. The ranges of the intersection points from these series of fits comprised the $T_{g}$ range.

The $\mathrm{T}_{\mathrm{g}}$ was found to be in the range of $124^{\circ} \mathrm{C}-141^{\circ} \mathrm{C}$ with an average $\mathrm{T}_{\mathrm{g}}$ of $133.44^{\circ} \mathrm{C}$ for the $54 \%$ crosslinked structure. For the $63 \%$ crosslinked structure, an average $\mathrm{T}_{\mathrm{g}}$ of $142.10^{\circ} \mathrm{C}$ was found in the range of $132^{\circ} \mathrm{C}-149^{\circ} \mathrm{C}$. For the $76 \%$ crosslinked structure, an average $\mathrm{T}_{\mathrm{g}}$ of $151.20^{\circ} \mathrm{C}$ was found in the range of $143^{\circ} \mathrm{C}-157^{\circ} \mathrm{C}$. From the data it is clear that the average $T_{g}$ increased as the crosslink density increased, which is likely due to the increasing number of covalent bonds as the crosslink density increases. As a result, there is more resistance to increases in free volume as the temperature increases for increased levels of crosslinking. Similar increases in $\mathrm{T}_{\mathrm{g}}$ due to additional crosslinking have been observed in graphite-epoxy composites. ${ }^{18,50}$

In Figure 5.1, the density of the $54 \%$ crosslinked system is lower than that of the $76 \%$ crosslinked system at high temperatures, while this trend is opposite at lower temperatures. The reason for this behavior can also be explained based on the difference in crosslink density. 54\% crosslinked structure had more uncrosslinked freely-moving polymer chains that reoriented themselves into a dense configuration at lower temperatures. At high temperatures, the uncrosslinked epoxy chains can lead to more expansion of the volume and thus the $54 \%$ crosslinked structure had a lower density than the $76 \%$ crosslinked structure. All these NPT simulations were performed by using equilibrated configurations of these crosslinked systems. During equilibration, volumes of the crosslinked structures were decreased based on two criteria:

1. The pressure has to decrease along with the energy during a minimization

2. The final equilibration should lead to a pressure of close to 1 atmosphere with the structure attaining a density of around $1.2 \mathrm{~g} / \mathrm{cm}^{3}$ 
The equilibration process of the $63 \%$ crosslinked structure made its density slightly higher than the densities of the equilibrated $54 \%$ and $76 \%$ crosslinked structures. As the density was already a bit high before the NPT simulations were started, the $63 \%$ crosslinked structure's density varied over a range which did not overlap the density variations of the other two systems. In this research, the focus was placed on the variations of the densities with respect to temperature, not on the absolute value of the densities. This issue would likely be resolved if multiple material systems were independently constructed for each crosslink density. Because of limited computational recourses, only one structure was established for each crosslink density for the current study.

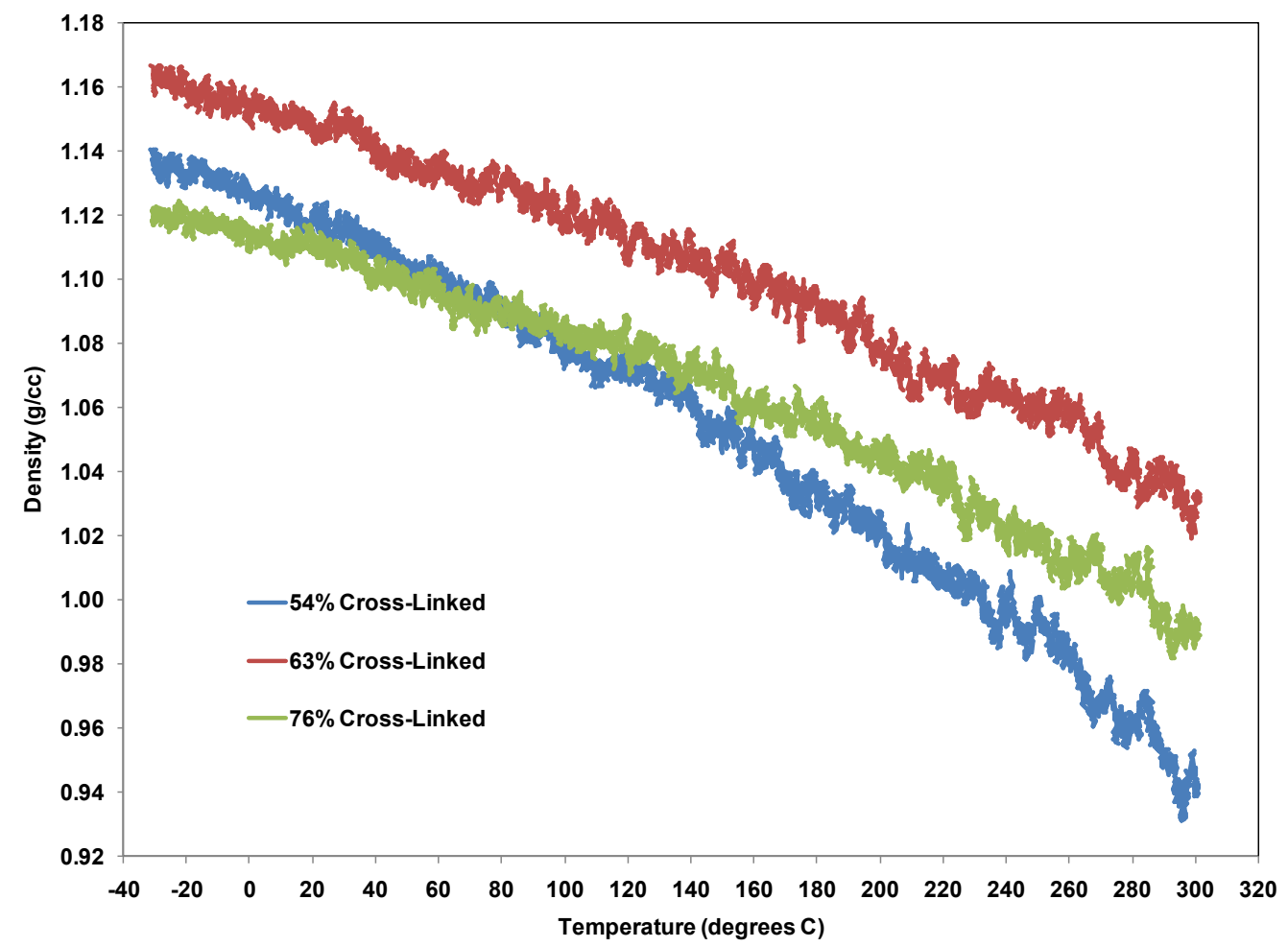

Figure 5.1. Density vs. temperature curves for $54 \%, 63 \%$ and $76 \%$ crosslinked system 
Varshney et al. ${ }^{30}$ predicted a $\mathrm{T}_{\mathrm{g}}$ of $105^{\circ} \mathrm{C}$ for the same EPON 862-DETDA system but with a crosslink density of $95 \%$. Fan et al. ${ }^{35}$ predicted the $\mathrm{T}_{\mathrm{g}}$ for a $100 \%$ crosslinked EPON 862-DETDA system to be $109^{\circ} \mathrm{C}$. Miller et al. ${ }^{19}$ experimentally measured a $\mathrm{T}_{\mathrm{g}}$ of $150^{\circ} \mathrm{C}$ for the same epoxy system, though the actual crosslink density was unknown. Clearly, the presently predicted values of all three crosslinked systems agree with the experimental values more than they agree with the predicted values in the literature. Both Varshney et al.'s work and Fan et al.'s work have predicted $T_{g}$ values much less than experimentally measured values. This is especially surprising since the simulated cooling rates are much faster than the experimental cooling rate, which should lead to higher predicted values of $T_{g}$. The predicted values in the current study do not show such a discrepancy with experiment, which indicates that the chosen OPLS force field, equilibration process, and simulated heating process accurately modeled the molecular behavior of the epoxy system.

NPT simulations for the $88 \%$ crosslinked structure were also performed, but, the simulations failed to give reasonable results beyond a temperature range of $90^{\circ} \mathrm{C}-100^{\circ} \mathrm{C}$. This is likely due to the same issue discussed in Chapter 4 in the context of the spatial density distributions. Specifically, the presence of unphysical long crosslink bonds leads to very large localized forces and unrealistic behavior in the structure.

\subsection{Volume shrinkage and thermal expansion coefficients}

Using the results from the NPT simulations described in the previous sub-section, the volume shrinkages with respect to the volume at $300^{\circ} \mathrm{C}$ for the $54 \%, 63 \%$, and $76 \%$ crosslinked systems for the temperature range of $-30^{\circ} \mathrm{C}$ to $300^{\circ} \mathrm{C}$ were determined and are plotted in Figure 5.2. From the plot it is clear that all three systems experienced significant changes in volume when heated to elevated temperatures. It is also clear that the $54 \%$ crosslinked system exhibited a significantly larger amount of shrinkage than the $63 \%$ and $76 \%$ systems, which were nearly identical. This is likely due to the difference in the number of covalent bonds present in the three structures. The $54 \%$ crosslinked 
structure had fewer covalent bonds and a larger number of free chains with higher mobility than the $63 \%$ and $76 \%$ crosslinked structures. Therefore, at decreasing temperatures, the $54 \%$ crosslinked model was able to adapt a more compact conformation than the $63 \%$ and $76 \%$ crosslinked models.

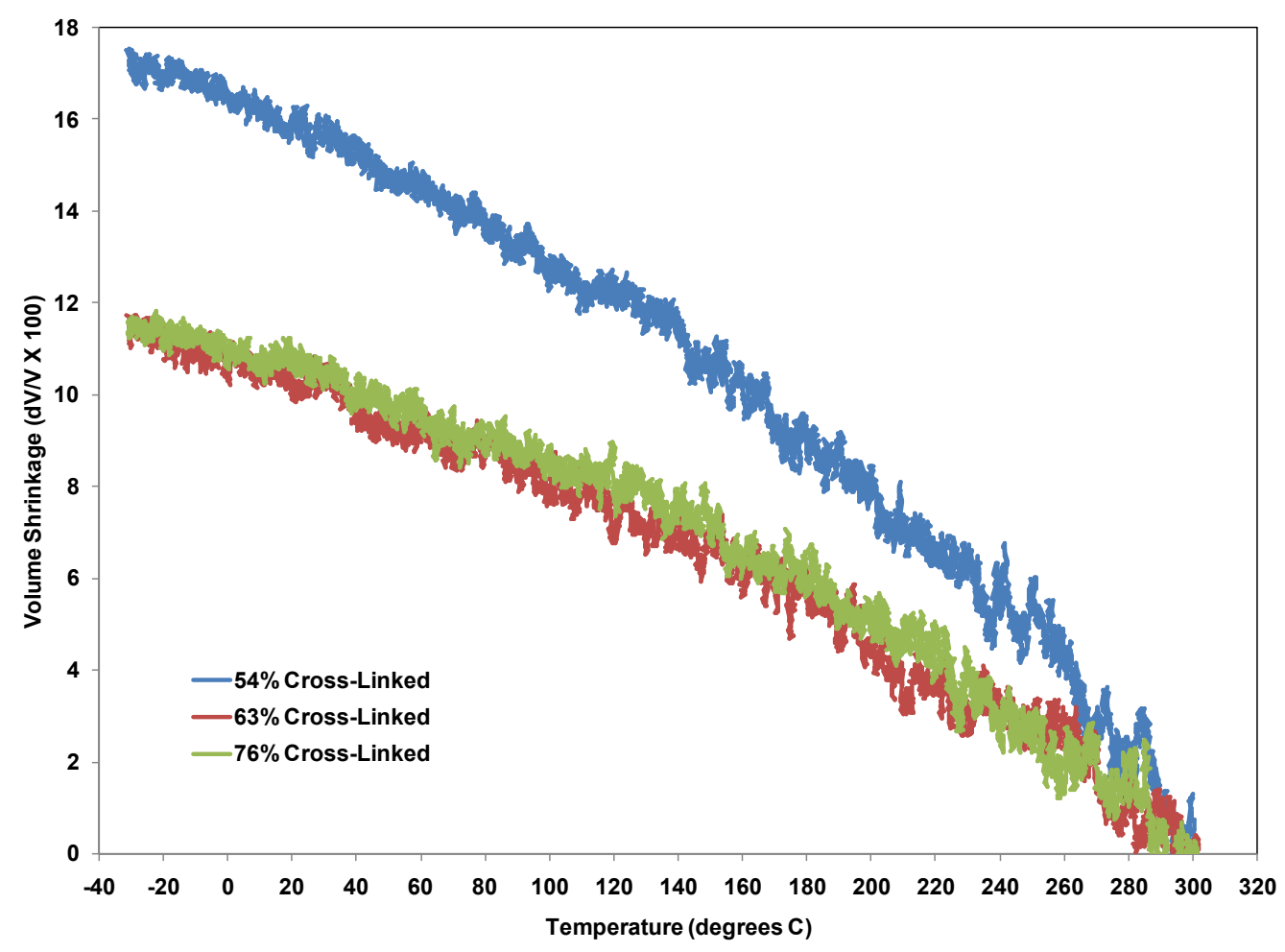

Figure 5.2. Volume shrinkages with respect to the volume at $300^{\circ} \mathrm{C}$ for $54 \%, 63 \%$ and $76 \%$ crosslinked structures

Linear regression lines were fitted on the volume shrinkage curves shown in Figure 5.2 to determine the coefficient of volumetric thermal expansion (CVTE) in both the rubbery and glassy regimes. Because the method of fitting the data can affect the resulting predicted values of CVTE (similar to the predicted $T_{g}$ described above), two different ranges were chosen to fit the curves for both the rubbery and glassy regions. In the glassy regime, the data were fit for the $0^{\circ}-120^{\circ} \mathrm{C}$ range and the $20^{\circ}-120^{\circ} \mathrm{C}$ 
degree range. For the rubbery region, ranges of $160^{\circ}-280^{\circ} \mathrm{C}$ degrees and $160^{\circ}-260^{\circ} \mathrm{C}$ degrees were fit. Therefore, temperature ranges of $100^{\circ}$ and $120^{\circ} \mathrm{C}$ were fit above and below the $\mathrm{T}_{\mathrm{g}}$, and the CVTE was calculated with

$$
\beta=\frac{1}{V_{O}}\left(\frac{\partial V}{\partial T}\right)_{P}
$$

where $V_{o}$ is the initial volume of the simulation box before the NPT simulation, and the subscript $P$ implies a constant-pressure process. The coefficient of linear thermal expansion (CLTE) is defined as

$$
\alpha=\frac{\beta}{3}=\frac{1}{L_{O}}\left(\frac{\partial L}{\partial T}\right)_{P}
$$

where $L_{o}$ is the initial length of each side of the cubic simulation box before the NPH simulation. The CLTE values obtained for the three crosslinked systems are given in Table 5.1. These values are the averages of the CLTE values obtained over the temperature ranges of $100^{\circ}$ and $120^{\circ} \mathrm{C}$.

The results shown in Table 5.1 generally indicate an increasing trend in the coefficients of expansion with decreasing crosslink density, which is likely because the polymer chains are less constrained in lower-crosslink systems, resulting in greater mobility during the thermal expansion process. This also explains the greater expansion that was predicted above $T_{\mathrm{g}}$ for each of the crosslink densities. The results were found to be consistent with those reported by Fan et al. ${ }^{35}$ and Wang et al ${ }^{51}$. Fan et al. predicted CLTE values of $18.5 \times 10^{-5 \circ} \mathrm{C}^{-1}$ above $\mathrm{T}_{\mathrm{g}}$ and $5.5 \times 10^{-5 \circ} \mathrm{C}^{-1}$ below $\mathrm{T}_{\mathrm{g}}$ for a $100 \%$ crosslinked EPON 862-DETDA system. Wang et al's experimental work with the pure 
EPON 862-DETDA system gave CLTE values of $18 \times 10^{-5 \circ} \mathrm{C}^{-1}$ above $\mathrm{T}_{\mathrm{g}}$ and $6.4 \times 10^{-5 \circ} \mathrm{C}^{-1}$ below $\mathrm{T}_{\mathrm{g}}$.

Table 5.1. Thermal Expansion Coefficients of crosslinked structures

\begin{tabular}{|c|c|c|c|}
\hline \multicolumn{3}{|c|}{ Coefficient of Linear Thermal Expansion $(\boldsymbol{\alpha}) \times 10^{-5}\left({ }^{\mathbf{0}} \mathbf{C}^{-\mathbf{1}}\right)$} \\
\hline & $54 \%$ & $63 \%$ & $76 \%$ \\
\hline Above $\mathbf{T}_{\mathbf{g}}$ & 20.0 & 13.6 & 14.0 \\
\hline Below $\mathbf{T}_{\mathbf{g}}$ & 12.9 & 9.1 & 8.6 \\
\hline
\end{tabular}

\subsection{Elastic properties (first approach)}

Simulated deformations were performed on all three crosslinked systems to determine their elastic properties. In these simulations, strains were imposed on the periodic MD models in the NVT ensemble, and the corresponding averaged stress components (virial stress) were determined for a complete stress-strain response. Two types of strains were applied on the structures: volumetric and three-dimensional shear strains. Relations among different elastic constants were used to calculate Young's modulus and Poisson's ratio from the values of bulk modulus and shear modulus obtained through simulations. This was the first approach. NVT simulations were run at $300 \mathrm{~K}$ (room temperature) for 200 picoseconds with timesteps of 0.2 femtoseconds. Strain increments were applied at every timestep such that the desired cumulative strain was reached by the end of the 200picosecond simulation. It is important to note that although the elastic response of polymers is generally dependent on applied strain rate, and the simulated deformations are at relatively high strain rates, it is expected that the predicted elastic properties are 
close to those observed experimentally. Although excellent agreement between experiment and high-strain rate simulations has been observed in the literature ${ }^{52-54}$, the reason for the apparent lack of strain-rate effects in predicted properties is unclear.

For the volumetric strains, equal strain magnitudes were applied in all three coordinate directions in both tension and compression according to kinematic Equation 5.3

$$
\varepsilon_{x x}=\varepsilon_{y y}=\varepsilon_{z z}= \pm 0.005
$$

where $\varepsilon_{i j}$ is the infinitesimal strain tensor component with respect to coordinate directions $i$ and $j$. The overall dilatation of the molecular model was

$$
\Delta=\varepsilon_{x x}+\varepsilon_{y y}+\varepsilon_{z z}
$$

For each timestep in these simulations, the overall hydrostatic stress $\sigma_{h}$ of the model was calculated by

$$
\sigma_{h}=\frac{1}{3}\left(\sigma_{x x}+\sigma_{y y}+\sigma_{z z}\right)
$$

where $\sigma_{i j}$ is the volume-averaged virial stress tensor component with respect to the coordinate directions $i$ and $j$. For each timestep of the final 198 picoseconds of the simulations, the hydrostatic stress and dilatation were used to perform a linear regression analysis to establish the bulk modulus 


$$
K=\frac{\sigma_{h}}{\Delta}
$$

The bulk moduli calculated for positive and negative dilatations were averaged. The data gathered during the first 2 picoseconds of the simulations were not used in the regression analysis because molecular structures typically undergo rapid, local relaxation during the initial stages of MD simulation. The structures were well-equilibrated before the start of these deformations and thus did not need significant time for relaxation. In the initial 11.5 picoseconds of the deformation simulation, the initial oscillation of the total pressure values died out. Nearly one million data points were used to calculate the bulk modulus for each epoxy system. The simulation codes for calculating volumetric deformations are provided in Appendix A.4.

Similarly, a three-dimensional shear strain was applied to the molecular models

$$
\gamma_{x y}=\gamma_{y z}=\gamma_{z x}= \pm 0.005
$$

where $\gamma_{i j}$ is the infinitesimal engineering shear strain component with respect to the $i$ and $j$ coordinate directions. The corresponding volume-averaged shear stresses $\sigma_{y Z}, \sigma_{X Z \text {, and }}$ $\sigma_{x y}$ were calculated for each timestep. Each shear stress component was compared to the corresponding applied shear strain for each timestep of the final 198 picoseconds of the simulations. A linear regression analysis was performed to determine the corresponding shear modulus, which is given by

$$
G=\frac{\sigma_{x y}}{\gamma_{x y}}
$$


For each crosslink density, the three calculated shear moduli were averaged for both positive and negative applied shear strains. The simulation codes for calculating shear deformations are given in Appendix A.5.

After calculating bulk moduli and shear moduli for all the crosslinked structures, Young's moduli $(E)$ and Poisson's ratios $(v)$ were calculated according to

$$
\begin{gathered}
E=\frac{9 K G}{3 K+G} \\
v=\frac{3 K-2 G}{2(3 K+G)}
\end{gathered}
$$

Using Equations 5.3-5.10, the elastic properties were calculated for the $54 \%, 63 \%$ and $76 \%$ crosslinked structures and the values are given in Table 5.2.

Table 5.2. Mechanical properties of crosslinked models based on $1^{\text {st }}$ approach (units in $\mathrm{GPa})$

\begin{tabular}{|c|c|c|c|c|}
\hline Units in GPa & $\begin{array}{c}K \text { (bulk } \\
\text { modulus) }\end{array}$ & $\begin{array}{c}G \text { (shear } \\
\text { modulus) }\end{array}$ & $\begin{array}{c}E \text { (Young's } \\
\text { modulus) }\end{array}$ & $\begin{array}{c}\text { (Poisson' } \\
\text { s ratio) }\end{array}$ \\
\hline $54 \%$ Crosslinked & 2.961 & 0.154 & 0.453 & 0.475 \\
\hline $63 \%$ Crosslinked & 2.914 & 0.707 & 1.963 & 0.388 \\
\hline $76 \%$ Crosslinked & 2.661 & 0.831 & 2.258 & 0.359 \\
\hline $\begin{array}{c}\text { Experimental } \\
\text { sample }\end{array}$ & & $0.6-1.0$ & $1.6-2.9$ & $0.35-0.43$ \\
\hline
\end{tabular}


The results in Table 5.2 show an increasing trend in Young's modulus and shear modulus among the 54\%, 63\% and $76 \%$ crosslinked structures. Littell et al. ${ }^{55}$ experimentally measured mechanical properties of the same epoxy system and reported Young's modulus values of $1.6-2.9 \mathrm{GPa}$, shear modulus values of $0.6-1.0 \mathrm{GPa}$, and Poisson's ratio in the range of $0.35-0.43$. Fan et al. ${ }^{35}$ predicted Young's modulus of 3.75 GPa for their $100 \%$ crosslinked EPON-DETDA computational model. The results obtained in this computational study are thus consistent with the literature ${ }^{35,55}$.

The bulk modulus shows a very small decreasing trend with increasing crosslink density, signifying that volumetric deformation probably does not have a strong sensitivity to crosslinking. The increasing trends in shear modulus and Young's modulus with increasing crosslink density indicate that with crosslinking, the molecular structure becomes stiffer because of the presence of more covalent bonds. Similar trends have been reported in other epoxy systems by Gupta et al. ${ }^{56}$ and in epoxy-nanotube composites by Miyagawa et al. ${ }^{57}$ Lees and Davidson ${ }^{58}$, Lee and Neville, ${ }^{59}$ and Burhans et al. ${ }^{60}$ discuss data that show increasing distances between reactive sites in epoxies result in decreasing crosslink densities and decreasing elastic properties. It is important to note that this trend is not always observed, specifically, Vakil and Martin ${ }^{61}$ reported that glassy modulus is not affected by the degree of crosslinking. Another important observation is the similarity of shear modulus, Young's modulus, and Poisson's ratio values of the $63 \%$ and $76 \%$ crosslinked structures. This similarity in mechanical properties is in agreement with the volume shrinkage results discussed above. It is important to note that these results may be sensitive to the limited number of modeled systems at each crosslink density. That is, if multiple systems had been individually constructed at each crosslink density, the apparent trends could differ slightly. Because of the uniform distribution of density and the agreement between computed and measured $T_{g}$ values (described above), the trends in elastic moduli should be accurately reflected in the modeled molecular structures. Furthermore, it is important to note that although the predicted elastic properties are intuitive, that is, the elastic moduli are the same magnitude as the majority of polymers (Young's modulus between 1 to $5 \mathrm{GPa}$ ), the importance of the results is in the model 
validation and predicted trends as a function of crosslink density and the ability to predict this trend computationally.

\subsection{Elastic properties (second approach)}

In Table 5.2 showing elastic constants in the previous section, the calculated value of shear modulus for $54 \%$ crosslinked system seemed to be a small value and the corresponding Young's modulus seemed to be also small. Though there is no reported evidence in literature that a decrease in crosslinking will lead to significant decrease in moduli, but a $78 \%$ decrease in shear modulus value due to $7 \%$ decrease in crosslink density seemed unrealistic. The bulk modulus values obtained from simulations were close for the different crosslinked systems as expected because volumetric deformations are not very sensitive to changes in number of crosslinks inside the molecular models.

The second approach was to calculate Young's modulus from simulations by applying uniaxial tensile deformations on the molecular models. For the uniaxial tensile deformations, strains were individually applied along each of the principal axes of the simulation box using the "fix deform" and "fix nph" commands in the LAMMPS software package. The simulation codes are given in Appendix A.6. Axial strains were applied such that Poisson contractions were allowed in the transverse directions. For each model, the tensile strain was divided equally over 200 picoseconds with timesteps of 0.4 femtoseconds. Tensile strains of magnitudes $\pm 0.003, \pm 0.005$, and \pm 0.007 were applied in each direction. A representative stress vs. strain graph for calculating Young's modulus is shown in Figure 5.3. A linear regression analysis of stress vs. strain was performed over the final 180 picoseconds of each simulation to determine the corresponding Young's modulus $(E)$ as shown in Figure 5.3. The stresses calculated from the simulations are in atmospheres and the values reported in Tables 5.2 and 5.3 are in GPa. The conversion was done by using a conversion factor of 1 atmosphere $=0.000101325 \mathrm{GPa}$. The slope in 
the trendline obtained after linear regression analysis in Figure 5.3 is the Young's modulus which is calculated as $32195 \mathrm{~atm} .=0.000101325 \times 32195=3.262 \mathrm{GPa}$.

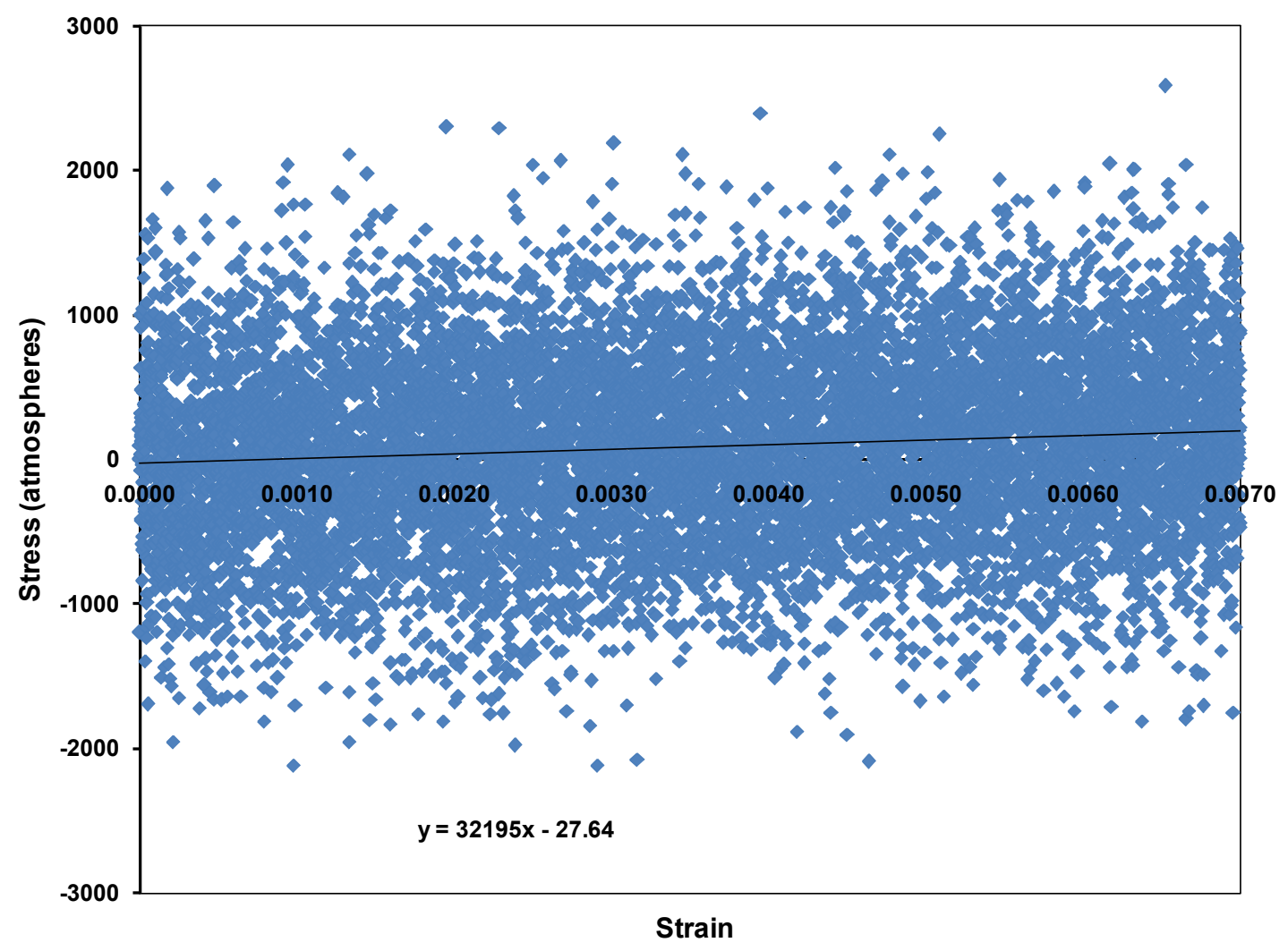

Figure 5.3. Stress vs Strain graph for tensile deformation along Y-axis at $0.7 \%$ strain of $70 \%$ crosslinked model

The Young's moduli were averaged over all three axes and all three strain levels in both tension and compression. Using the values obtained for Bulk moduli and Young's moduli, shear moduli $(G)$ were calculated for all molecular systems as

$$
G=\frac{3 K E}{9 K-E}
$$


The Poisson's ratio was calculated using values obtained for $K, E$ and $G$ as

$$
v=\frac{3 K-E}{6 K}
$$

The predicted Young's and shear moduli are shown in Table 5.3 for the entire range of overall crosslink densities. From the Table 5.3 it is clear that there is an increasing trend in both moduli as the crosslink density increases. In Table 5.3, the results for 54\% crosslinked system seem more realistic than the results in Table 5.2. The magnitude of the predicted elastic properties is similar to those reported in the literature for the same epoxy system. ${ }^{56-58,62,63}$

Table 5.3. Mechanical properties of crosslinked models based on $2^{\text {nd }}$ approach (units in $\mathrm{GPa})$

\begin{tabular}{|c|c|c|c|c|}
\hline & $\begin{array}{c}K \text { (bulk } \\
\text { modulus) }\end{array}$ & $\begin{array}{c}E \text { (Young's } \\
\text { modulus) }\end{array}$ & $\begin{array}{c}G \text { (shear } \\
\text { modulus) }\end{array}$ & $\begin{array}{c}\text { v (Poisson's } \\
\text { ratio) }\end{array}$ \\
\hline $54 \%$ Crosslinked & 2.961 & 0.743 & 0.255 & 0.458 \\
\hline $63 \%$ Crosslinked & 2.914 & 1.322 & 0.464 & 0.424 \\
\hline $76 \%$ Crosslinked & 2.661 & 1.652 & 0.592 & 0.397 \\
\hline $\begin{array}{c}\text { Experimental } \\
\text { sample } 55\end{array}$ & & $1.6-2.9$ & $0.6-1.0$ & $0.35-0.43$ \\
\hline
\end{tabular}




\section{CHAPTER 6: MODELING OF PHYSICALLY AGED SAMPLES ${ }^{4}$}

Physical aging is generally characterized as an increase in mass density (volumetric relaxation) and/or a decrease in molecular configurational energy (enthalpy relaxation) of amorphous or semicrystalline materials when exposed to temperatures below the glass transition $\left(T_{g}\right)$ for extended periods of time. Physical aging usually results in decreases in toughness and viscoelastic response of polymers and other glassy materials. This is clearly a concern for the industries that use epoxy resins for applications that require acceptable levels of structural durability, reliability, and safety for extended periods of exposure to sub- $T_{g}$ temperatures.

During the last several decades, a large number of studies have focused on the experimental characterization of physically-aged epoxies. ${ }^{62}$ These studies have described a great number of observed thermo-mechanical behaviors of aged epoxies and speculated on the physical nature of these observations. However, despite the breadth of data and theories on observed physical aging behavior, many questions still exist regarding the exact molecular mechanisms that are associated with physical aging. It is possible that some of these questions can be answered using computational molecular modeling techniques in which the molecular structure and behavior of epoxy networks can be simulated for a wide range of exposure conditions.

Several studies have focused on the molecular modeling of physical aging in glassy material systems. ${ }^{64-70}$ In general, these studies have followed an approach in which molecular structures of simple coarse-grained material systems are simulated until critical relaxation events (volume and enthalpy relaxation) occur in the molecular structure. These simulated events generally occur over ambiguously-defined time frames. The reason for the simulation of relatively simple materials over ambiguous time frames is

\footnotetext{
${ }^{4}$ Portions of text in this chapter have been reprinted and Figure 6.2 has been redrawn with permission from Odegard, G. M.; Bandyopadhyay, A. Journal of Polymer Science Part B-Polymer Physics 2011, 49, (24), 1695-1716. (C) John Wiley and Sons Inc. Please refer Appendix C.2for copyright information.
} 
due to the immense computational expense of detailed molecular simulations. While real physical aging events occur over the course of hours, days, or years; molecular simulation of fully atomistic models, using approaches such as Molecular Dynamics (MD), can only simulate molecular behavior on the femtosecond to nanosecond time scales. Although these studies incorporate neither the specific molecular structure of engineering materials nor clearly-defined time scales, they have provided valuable insights into the molecular-level behavior of glass materials when subject to physical aging. However, to fully understand the physical nature of physical aging of specific material systems, fully atomistic models of engineering materials must be simulated.

The objective of this study was to develop a MD method to predict the molecular structure of an epoxy material when subjected to various levels of physical aging. Because of the computational challenges described above, the developed approach did not directly simulate the physical aging process. Instead, a method was established to efficiently predict the molecular structure that closely resembles that of the epoxy at specific times during the physical aging process. In this chapter, a detailed description of physical aging is followed by descriptions of the epoxy material (EPON 862/DETDA) and of the simulation procedure. The method is demonstrated by applying it to the epoxy aged at a temperature $40^{\circ} \mathrm{C}$ below $T_{g}$ for a range of crosslink densities. From these simulations, the influence of crosslink density on the physical aging process is established.

\subsection{Physical Aging}

Because of the rigidity and complexity of the crosslinked network of EPON 862DETDA system, the structure exists in a glassy state that cannot realistically reconfigure itself into a purely ordered state. As a consequence of the locked-in amorphous molecular structure, there exists significant free volume in the molecular structure, that is, specific volume in excess of that found in the ordered state at a given temperature (shaded region 
in Figure 6.1). It is important to note that many authors define free volume as the volume that is not occupied by polymer molecules; however, this definition is complicated by the ambiguous definition of the volume of a molecule in an amorphous structure. The free volume decreases as the amorphous structure is aged at sub- $T_{g}$ temperatures for extended periods of time. This reduction in free volume occurs as the material contracts to achieve a lower-energy molecular state. Figure 6.1 shows how the unaged amorphous state undergoes decrease in free volume such that the overall volume is decreased (mass density increased), yet the orientation of the molecules remains the same.

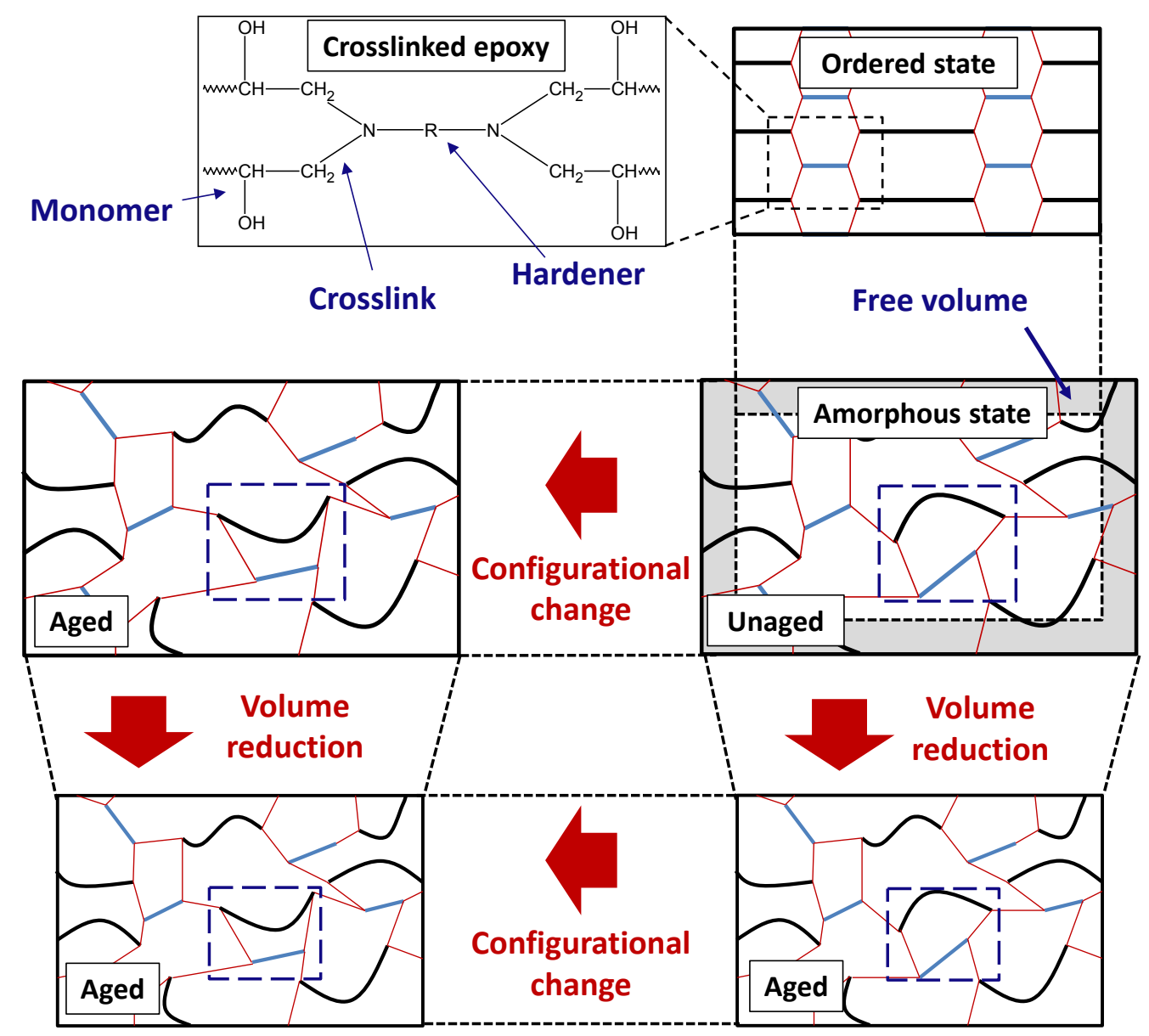

Figure 6.1. Schematic showing the definition of free volume, volumetric reduction, and configurational change in a crosslinked epoxy polymer 
During the physical aging process, configurational changes on the molecular level can occur in epoxies that do not result in an overall change in the amount of free volume when an epoxy is subjected to sub- $T_{g}$ annealing. This process is shown in Figure 6.1 where the unaged polymer exhibits a re-arrangement of molecular segments to achieve a lower-energy structure.

As an epoxy sample is cooled from the rubbery state along the glass-transition temperature range, the specific volume decreases and the rate of decrease slows down as the cooling temperature passes through the glass transition region. As shown in Figure 6.2 , the rate of cooling dictates the rate of decrease of specific volume and enthalpy. A slower cooling rate $q_{2}$ allows more time for the crosslinked epoxy chains to reorient themselves into a lower energy configuration and attain a smaller volume $B$ at room temperature compared to the higher volume $A$ attained due to the faster cooling rate $q_{1}$. The epoxy structure is glassy at volume $B$ and experiences very small changes in chain movements because of low kinetic energies of the covalently bonded atoms. But with the passage of time, the sluggish chain movements lead to further decrease in free volume and the specific volume of the epoxy sample reach the volume $C$. This volumetric relaxation is caused by physical aging and the temperature at which this aging occurs is the aging temperature $T_{a}$. But there is a limit to which these chains can move around at this low temperature and because of the rigid crosslinked nature of the glassy state, the epoxy sample will not be able to reach the hypothetical volume $D$ which is characteristic of the crystalline state. Extrapolation of the cooling curve from volume $\mathrm{C}$ shows that due to physical aging, the mid-point of the glass transition range has shifted to a lower value $T_{f}$ from the mid-point of the glass transition range of the unaged sample at $T_{g}\left(q_{2}\right)$. Discussion about the shifting of glass transition temperature range due to physical aging is mentioned elsewhere. 


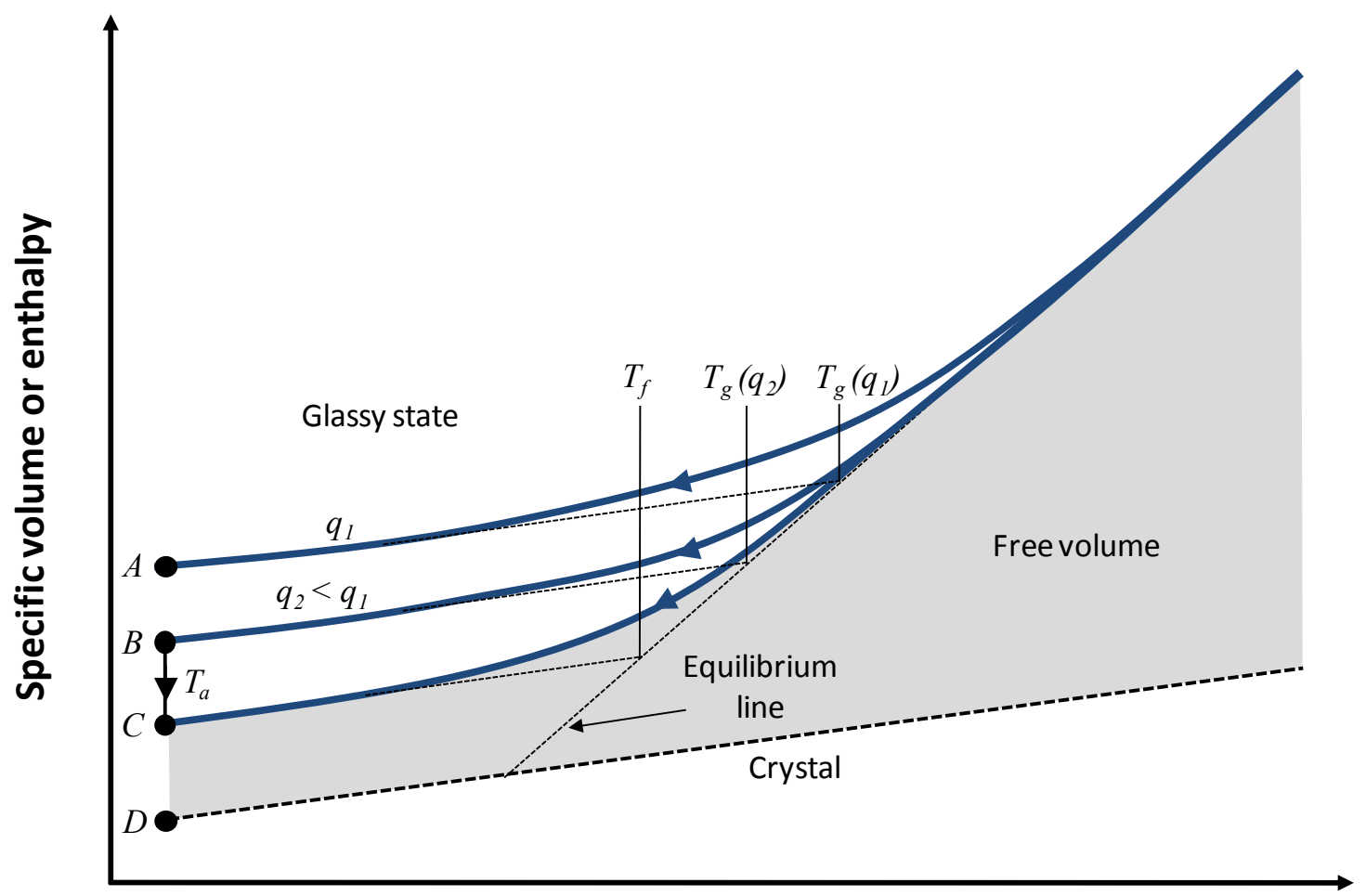

Temperature

Figure 6.2. Specific volume vs. temperature for a typical epoxy polymer. The shaded region indicates the amount of free volume in the polymer

A thermodynamic quantity that serves as a useful physical aging metric to characterize the influence of these molecular-level mechanisms occurring during aging is the specific enthalpy, $h$

$$
h=u+p v
$$

where $u$ is the specific internal energy, $p$ is the pressure, and $v$ is the specific volume. In the case of physical aging of an epoxy system, the internal energy can be defined as the sum of the potential and kinetic energies associated with the atoms that form the molecular structure. The enthalpy definition is more useful when considering its change from a reference point by 


$$
d h=d u+p d v+v d p
$$

The process of physical aging is usually observed under conditions of constant pressure in laboratory and practical conditions. If it is assumed that the pressure exerted onto an aging material does not change during the aging process, then Equation 6.2 becomes

$$
d h=d u+p d v
$$

The first term on the right-hand side of Equation 6.3 represents the change in the internal energy during the physical aging process. That is, it represents the change in the potential and kinetic energies associated with the atoms that form the molecular structures. The change in internal energy can be induced by the type of configurational changes shown in Figure 6.1. The second term on the right-hand-side of Equation 6.3 represents the contribution of enthalpy change from the change in volume (reduction in free volume). Therefore, the specific enthalpy incorporates the influences of volume change and molecular reconfiguration on the thermodynamic state of the material held at a constant pressure.

As a result of these two mechanisms, a wide range of thermo-mechanical behaviors of epoxy resins are affected during physical aging. ${ }^{62}$ Measurable decreases in bulk-level enthalpy (enthalpy relaxation) and bulk-level volume (volume relaxation) are often observed during the physical aging process. Reductions in toughness, tensile strength, viscoelastic response are generally observed with increasing physical aging times. Despite the increasing knowledge of the influences of physical aging on thermomechanical properties, there is still an unexplained difference in the overall relaxation rates of volume and enthalpy in polymers. ${ }^{71}$ 


\subsection{Modeling procedure}

Multiple samples for each crosslink density: 2 samples for $63 \%, 3$ samples for $70 \%$, and 3 samples for $76 \%$ were used in this physical aging study. Because physical aging occurs over macro-size time scales (hours to years) and MD simulations occur over nanosize time scales (femtoseconds to nanoseconds), the physical aging process could not be directly simulated for the type of MD models considered here. Instead, an approach was followed to establish a relationship between the aging time $t_{a}$ of the polymer and the corresponding change in specific volume $\Delta v$ of the MD simulation box in which $\Delta v=v_{0}-$ $v$ where $v_{0}$ is the specific volume of the unaged state (baseline model described above) and $v$ is the specific volume for a particular $t_{a}$. The $t_{a} / \Delta v$ relationship is useful because it allows molecular models of epoxies to be developed for any state of aging, characterized by $t_{a}$ for a particular aging temperature, by simply reducing the MD simulation box by $\Delta v$ using an NPT simulation and equilibrating (using an NVT simulation). Thus, the approach used herein provides molecular structures at snapshots in time that closely resemble the aged molecular system without the need to simulate the entire physical aging process. It is important to note that the associated changes in $\Delta v$ are small enough to avoid the creation of significant residual stresses in the molecular model for realistic physically-aged states.

The critical assumption made in this approach is that on the molecular level, the constant dynamic motion of the atoms, as simulated via an NPT simulation, results in momentary states (snapshots in time) in which the molecular structure has conformational and free volume characteristics that would represent a physically-aged state for a particular $t_{a}$ and aging temperature. The specific enthalpy can be determined for these snapshots in time and correlated with specific enthalpies measured experimentally for a particular aging time and temperature. The MD simulation box volumes associated with these snapshots in time can then be used as an independent parameter that controls the simulated level of physical aging. The resulting MD models 
can then be used to predict thermo-mechanical properties for a particular polymer at a particular aged state.

The method used in this study consists of three basic steps: (1) Establish a relationship between $\Delta v$ and $\Delta h\left(\Delta h=h_{\mathrm{o}}-h\right)$ via MD simulation, (2) determine the relationship between $\Delta h$ and $t_{a}$ from experimental data, and (3) determine the relationship between $\Delta v$ and $t_{a}$. The details of each of these steps for the EPON 862-DETDA epoxy system are described below.

\subsection{Results and Discussions}

In the first step, the relationship between $\Delta h$ and $\Delta v / v_{0}$ was established for each of the samples of each crosslink density. NPT simulations were conducted on the baseline MD models at a pressure of $1 \mathrm{~atm}$ for $400 \mathrm{ps}$ at a temperature of $T_{g}-40^{\circ} \mathrm{C}$. The $T_{g}$ of each of the crosslinked systems was established previously. ${ }^{63}$ At 2 fs intervals during these simulations the values of $\Delta v / v_{o}$ and $\Delta h$ were recorded. Each pair $\left(\Delta v / v_{o}, \Delta h\right)$ represented a state corresponding to a specific fluctuation in free volume and conformational change in the epoxy network. Figure 6.3 shows the corresponding $\Delta h$ vs $\Delta v / v_{o}$ data sets for each of the simulated material systems. A linear regression was fit to each of the data sets, and the corresponding regression slope $\alpha$ represented the $\Delta h$ vs $\Delta v / v_{o}$ relationship

$$
\Delta h=\alpha\left(\frac{\Delta v}{v_{O}}\right)
$$

In Equation 6.4, $\Delta v$ has been normalized over specific volume of the unaged state $V_{o}$ so that the value of $\alpha$ is not dependent on volume units but only on enthalpy units. In Equation 6.4, $\Delta h$ and $\alpha$ have units of $\mathrm{J} / \mathrm{g}$. Although the data shown in Figure 6.3 shows a large amount of scatter, which is expected for an MD simulation like this, it was assumed 
that a linear trend was sufficient to describe the $\Delta h$ vs $\Delta v / v_{o}$ relationship, and that $y$ intercept of the regressions were zero-valued. The data in Figure 6.3 indicate that specific enthalpy and specific volume are positively correlated. That is, both relaxation measures increase and decrease simultaneously, as expected.

It is important to note that Equation 6.4 implies a relationship between the enthalpy of the molecular system and the corresponding specific volume of the MD simulation box. Equation 6.4 does not imply a relationship between bulk-level enthalpy relaxations and volumetric relaxations. Because bulk-level enthalpy and volumetric relaxations do not have a linear relationship for polymers, as described above, the volumetric term in Equation 6.4 is intended to only relate to the MD simulation box volume. Of course, for MD simulation box volumes that are orders of magnitude larger than the one investigated herein, a relationship between simulation box volume and bulk volume may be determined. However, because of the limits of modern computational resources, such a relationship is not considered for the current study.

Table 6.1. Values of the constant $\alpha(\mathrm{J} / \mathrm{g})$ for each sample of each crosslink density.

\begin{tabular}{|c|c|c|c|}
\hline & $\mathbf{6 3 \%}$ & $\mathbf{7 0 \%}$ & $\mathbf{7 6 \%}$ \\
\hline Sample 1 & 319.11 & 302.68 & 256.35 \\
\hline Sample 2 & 233.83 & 238.01 & 227.71 \\
\hline Sample 3 & - & 239.59 & 212.71 \\
\hline Average & 276.47 & 260.09 & 232.26 \\
\hline $\begin{array}{l}\text { Standard } \\
\text { deviation }\end{array}$ & 60.302 & 36.889 & 22.172 \\
\hline
\end{tabular}




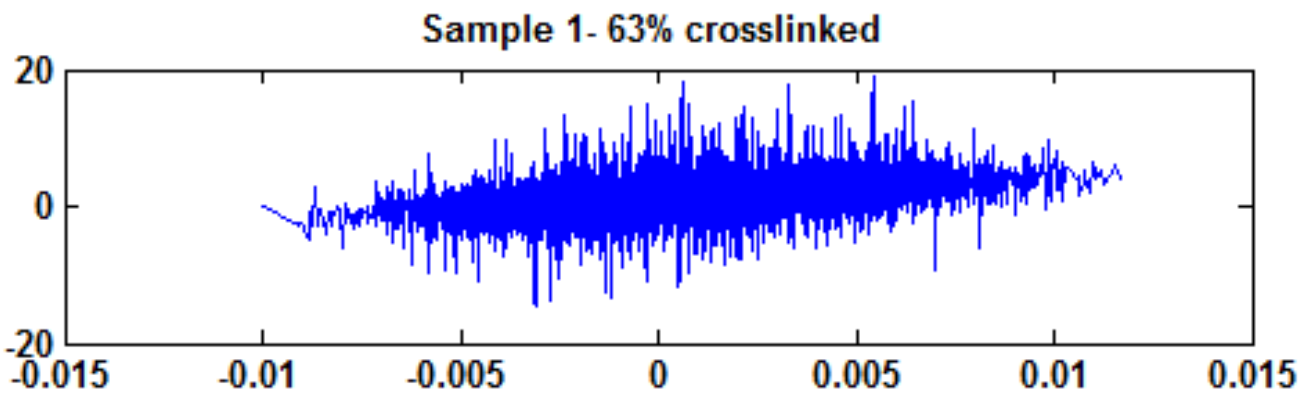

Sample 2- $63 \%$ crosslinked

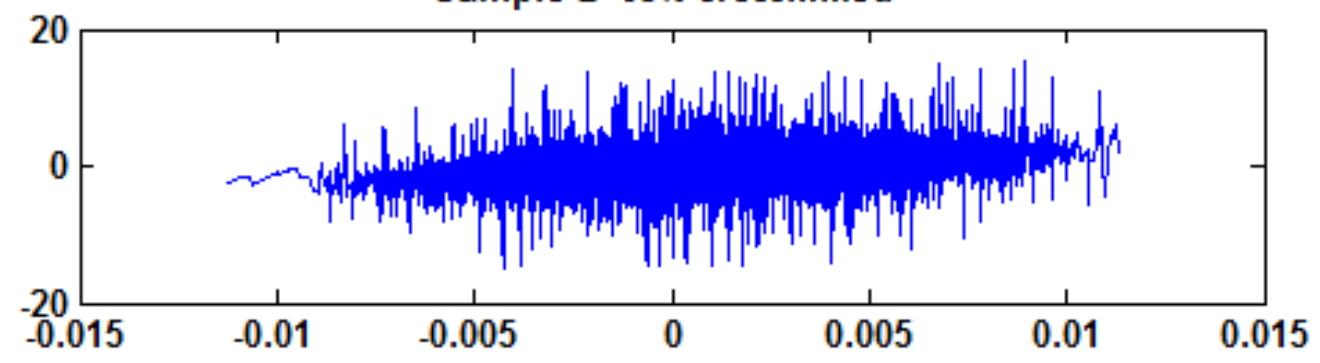

Sample 3- 70\% crosslinked

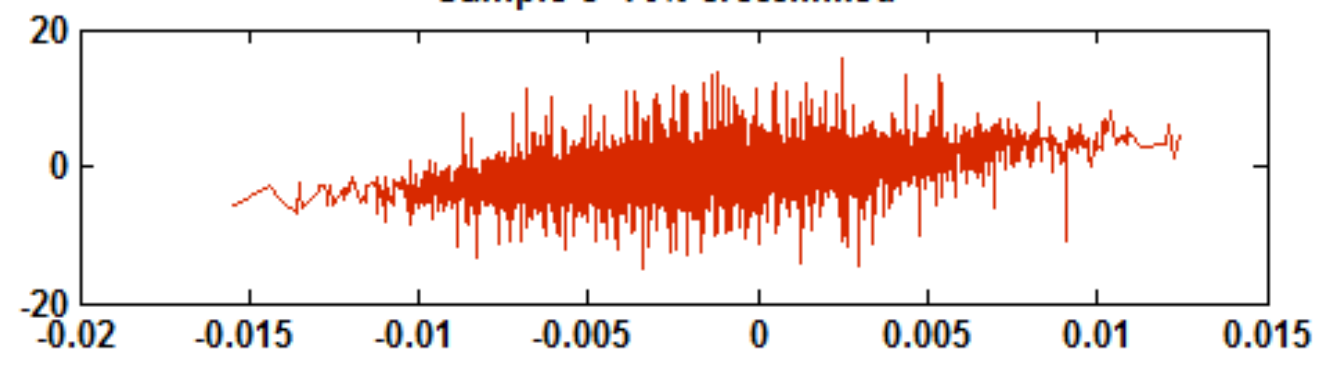

Sample 4- 70\% crosslinked

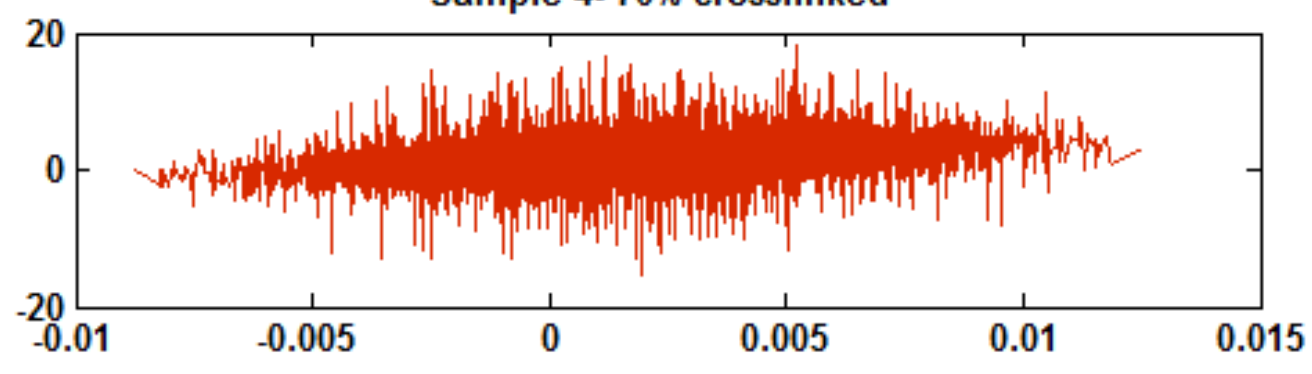




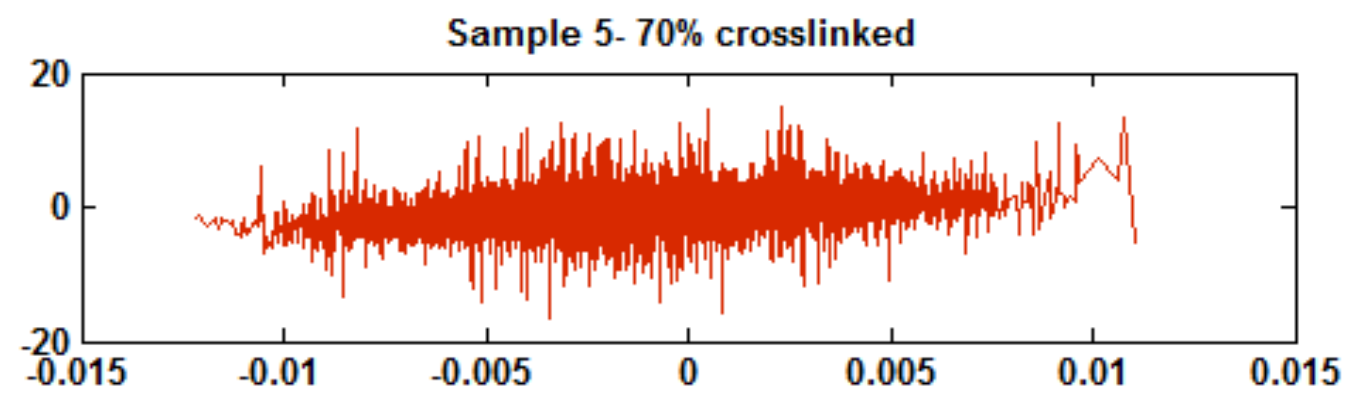

Sample 6 - $76 \%$ crosslinked

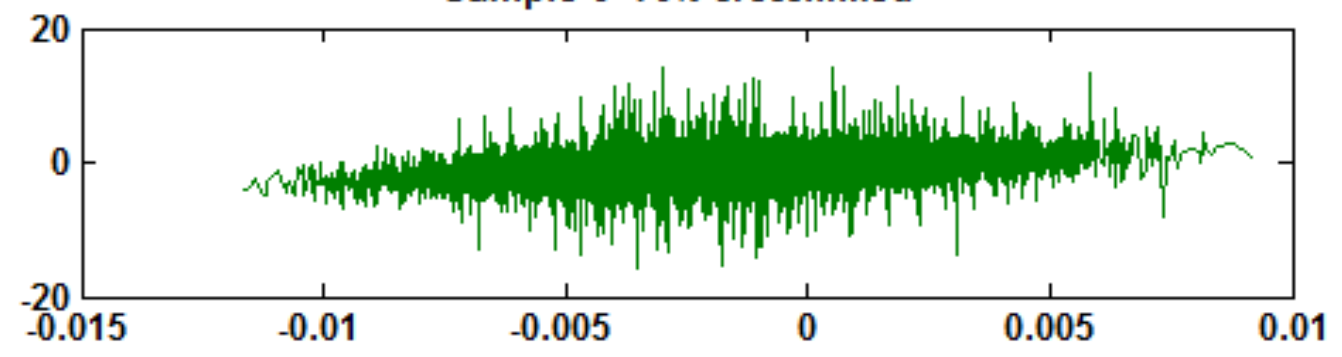

Sample 7- 76\% crosslinked

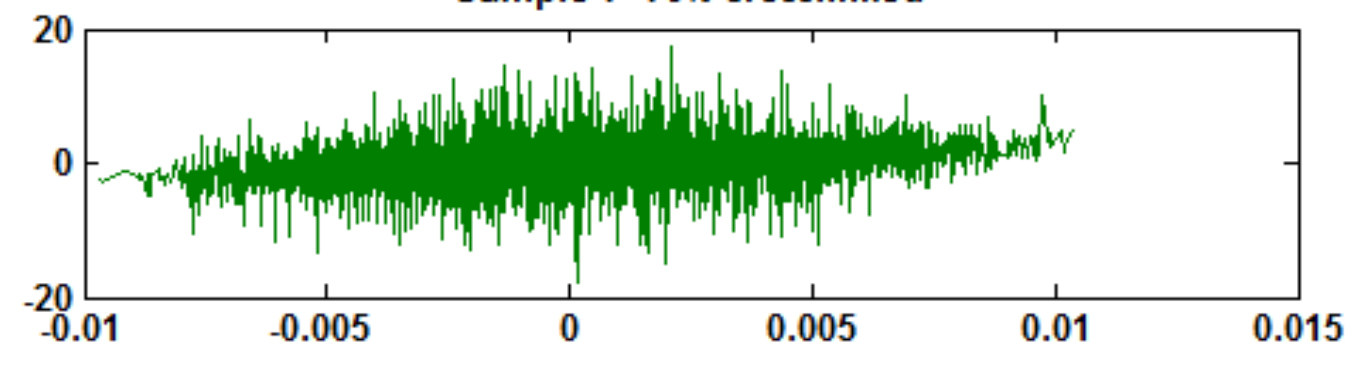

Sample 8- $76 \%$ crosslinked

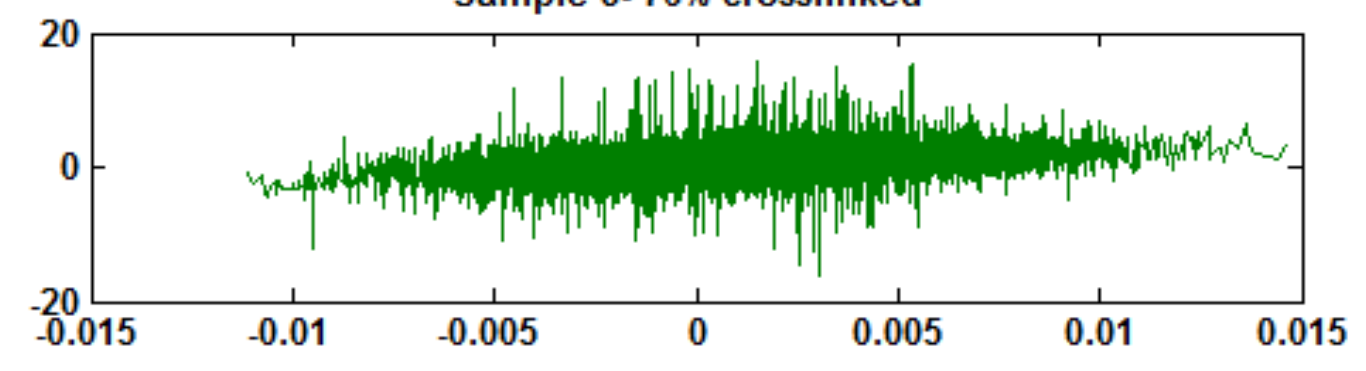

Figure 6.3. Change in enthalpy $(\Delta h)$ vs. change in volume $\left(\Delta v / v_{o}\right)$ for eight different samples of crosslinked EPON 862-DETDA molecular models. Units- $\Delta h$ in $\mathrm{J} / \mathrm{g}, \Delta v / v_{o}$ is unitless 
Table 6.1 lists the values of $\alpha$ for each of the samples of each crosslink density. The average values of $\alpha$ shown in Table 6.1 decrease for increasing levels of crosslinking. This trend is likely because of the decreasing levels of conformational change that can occur as the polymer network is subjected to increasing levels of crosslinks. Because the number of conformational changes decreases, the values of $\Delta h$ decrease with respect to $\Delta v / v_{o}$, thus causing a decrease in the value of $\alpha$ per Equation 6.4. The standard deviation data in Table 6.1 also indicates that the predicted values of $\alpha$ was relatively consistent between individual samples. It is expected that increases in the number of atoms in the MD model would result in decreases in the standard deviation of $\alpha$ values, albeit with slower simulation times.

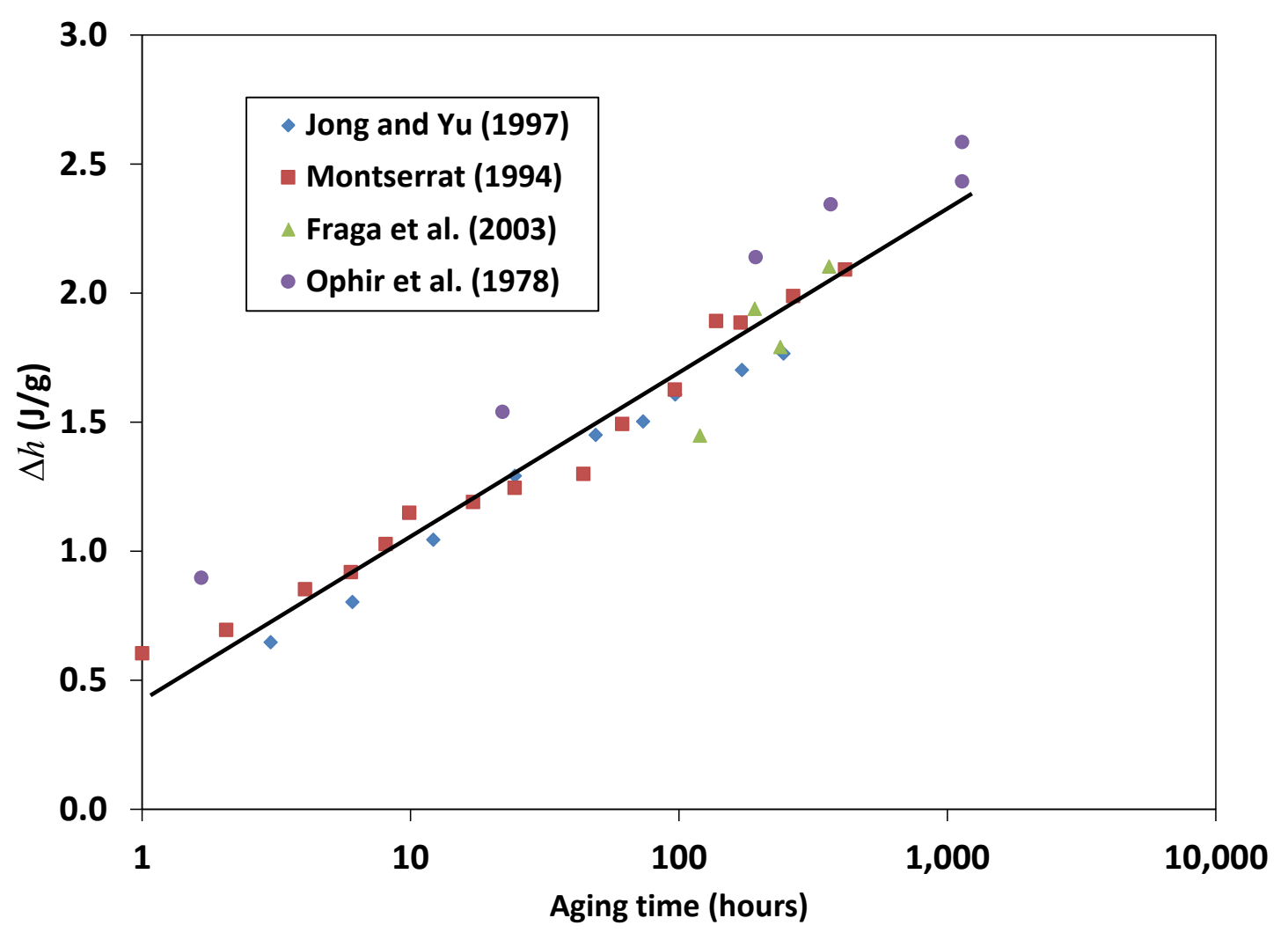

Figure 6.4. Experimental data for specific enthalpy relaxation for epoxy. The solid line is a linear regression fit for the four data sets. 
For the second step, experimental data was obtained from the literature ${ }^{13,72-74}$ that relates specific enthalpy relaxation to aging time for $T_{g^{-}} 40^{\circ} \mathrm{C}$. Figure 6.4 shows the enthalpy relaxation of the epoxy for various aging times. Although the epoxy systems investigated in these studies ${ }^{13,72-74}$ are not exactly the same as the one considered herein, it is assumed that their enthalpy relaxation response is close to EPON 862-DETDA. The data indicates that all four independent studies show similar enthalpy relaxation behavior for the different epoxy systems. Also shown in Figure 6.4 is a linear regression line that fits the data to the following form

$$
\Delta h=\beta \ln \left(t_{a}\right)+\gamma
$$

where $\beta$ and $\gamma$ are fitting constants and $t_{a}$ has units of hours. A least-squares analysis on the combined data sets shown in Figure 6.4 yielded $\beta=0.27 \mathrm{~J} / \mathrm{g}$ and $\gamma=0.46 \mathrm{~J} / \mathrm{g}$. Therefore, Equation 6.5, along with the appropriate values of $\beta$ and $\gamma$, relates the expecting specific enthalpy relaxation to the aging time and acts as a calibration for relating the molecular modeling results to the aging time, as explained below.

In the third step of the simulation procedure the specific enthalpy relaxation measure in Equation 6.4 was directly related to analogous measure in Equation 6.5. As a result, the specific volume of the MD model can be related to the aging time via

$$
\frac{\Delta v}{v_{o}}=\frac{\beta}{\alpha} \ln \left(t_{a}\right)+\frac{\gamma}{\alpha}
$$

The significance of Equation 6.6 is that $\Delta v$ is directly related to the aging time $t_{a}$, which allows for the development of molecular models that resemble the physically-aged state at pre-selected amounts of aging time. Specifically, the desired physical aging time can 
be input into Equation 6.6, and the corresponding change in specific volume of the simulation box can be calculated. This change in specific volume can be applied to an equilibrated baseline epoxy molecular model to establish a model that resembles the aged molecular structure. The resulting model will have the corresponding changes in specific volume (free volume) and enthalpy relaxation incorporated directly. The aged molecular models of epoxy can be used further to predict thermo-mechanical properties for that particular aging time. It is important to note that $\Delta v$ only describes the adjustment to the simulation box specific volume, not the overall relaxation volume of the epoxy. Because volume relaxation and enthalpy relaxation rates are typically different in polymers (for unknown reasons) $)^{71}$, and because the method described herein is based on enthalpy relaxation, Equation 6.6 cannot be used to reliably predict the bulk volume relaxation of epoxy.

\subsection{Conclusions of physical aging study}

This research has explored the MD modeling of the physical aging of crosslinked epoxy materials. Although the physical aging process cannot be simulated directly due to the large discrepancy between actual and simulated time scales, the method developed can be used to efficiently establish equilibrated MD models of crosslinked epoxies that resemble the corresponding structures that are physically aged for various annealing times. The results of this study indicate that MD models of various aged states can be established by simply reducing the volume of MD models and equilibrating the resulting structure. The key to successfully establishing such models is to precisely determine the relationship between reductions in MD simulation box volume and the corresponding physical aging time. It is hypothesized that this relationship can be determined by sampling different states for an extended MD simulation in the NPT ensemble for a fully atomistic system. This relationship has been determined for the EPON 862-DETDA epoxy system for $T_{g}-T_{a}=40^{\circ} \mathrm{C}$, and could be determined for other epoxy systems at different aging times in a similar manner. 


\section{CHAPTER 7: SCOPE OF FUTURE WORK}

Since molecular dynamics is still an upcoming technique of computational research and epoxies are being studied more for development of lighter materials; the scope of future work in this field is enormous. There are unanswered questions about the deformation and failure mechanisms occurring in epoxies at the molecular scale during unaged and aged conditions. EPON 862-DETDA is also being used along with graphene sheets for the construction of composite materials and thus the interaction between graphene sheets and the epoxy polymer is of considerable interest. Influence of the distribution of crosslinks has been a subject of interest and this has been studied using MD recently by Bandyopadhyay and Odegard. $^{75}$

\subsection{Failure studies in unaged conditions}

Considerable amount of research can be done on the following topics using MD:

a) Crazing- Crazing is a highly localized deformation which leads to formation of voids at the molecular level. ${ }^{76-79}$ This behavior is observed in epoxies that have been reinforced with nano-particles. For highly cross-linked epoxies, crazing occurs by the combination of local cross-link scission and/or chain realignment. The craze zone appears as a stress-whitened region in the macroscopic scale and the coalescence of craze zones leads to the formation of macroscopic cracks at elevated loading levels. Mechanism of crosslink bond breakage due to formation of craze zones can be understood by using Molecular Dynamics.

b) Interfacial failure- The primary failure mechanism of carbon fiber-epoxy interface is the debonding of the two phases. ${ }^{80}$ Although there is no covalent bonding between the two phases, an interfacial region is usually present between the fiber and the bulk epoxy matrix regions. ${ }^{81}$ More information about this interfacial failure can be obtained by using molecular models at the nano scale. 
c) Bond breakage using Reax force field- The discovery of Reax force field has introduced a new dimension in MD as it is the most realistic force field available at this time. The force field allows for simulation of bond breakage with energy calculations of bond breakage, bond formation and energy contribution from lone pairs. ${ }^{82-84}$ Using Reax force field can provide a new understanding of the failure mechanisms happening in epoxies at the nano scale.

\subsection{Other phenomena of physical aging}

Apart from volume shrinkage and enthalpy relaxation, the following phenomena are found to occur during physical aging and MD techniques can be attempted to study these phenomena.

a) Thermal rejuvenation- The effects of volume shrinkage can be reversed through rejuvenation. Rejuvenation means the process of erasing the effects of aging by reversing the aging process. There are various rejuvenation mechanisms for epoxies that have been discussed in the literature. ${ }^{21,85-90}$ The most effective mechanism is thermal rejuvenation which occurs above $T_{g}$. When an aged epoxy polymer is heated above the $\mathrm{T}_{\mathrm{g}}$ and held at that temperature for a long time, all effects of physical aging history are removed, and the material returns back to its un-aged form. If the rejuvenated polymer is cooled once again below $\mathrm{T}_{\mathrm{g}}$, then it will follow the curve corresponding to the appropriate cooling rate, as shown in Figure 6.2. It might be interesting to see whether the same phenomenon can be simulated by MD or not. Thorough understanding of the physics behind thermal rejuvenation and movement of crosslinked polymer chains during this phenomenon can be understood through MD.

b) Mechanical rejuvenation- A considerable amount of debate has surrounded the concept of mechanical rejuvenation. ${ }^{88-90}$ It is also known that mechanical deformations can cause temporary changes in the specific volume of an epoxy. ${ }^{89,90}$ 
Struik suggested that large deformations in polymers might influence the state of physical aging. ${ }^{21,90}$ This means that large scale deformations create free volume, irrespective of shear, tensile or compressive deformations. Because physical aging is caused by a reduction in free volume, Struik reported that the increases in free volume caused by large deformations erased part of the physical aging history. But McKenna and co-workers have shown ${ }^{88,89}$ that despite the momentary changes in the volume of an epoxy subjected to various levels of deformation, the baseline volume recovery is unaffected by the applied mechanical deformation. ${ }^{91}$ This debate can be solved by the use of molecular modeling.

c) Changes in elastic modulus- Many studies have addressed the measurement of the elastic modulus of aged epoxy polymers. ${ }^{12,15,16,92-98}$ Static tensile-testing, ${ }^{15,16,95,96,98}$ compression testing, ${ }^{12,92,93,97}$ and 3-point bending ${ }^{94}$ approaches to measure the Young's modulus of the epoxy polymer using the stress-strain curve have been used in these studies. Many of these studies have reported no conclusive influence of aging on the elastic modulus. ${ }^{15,16,92-94,97} \mathrm{Hu}{ }^{95}$ showed a small but consistent increase in elastic moduli as a function of aging time for an epoxy composite subjected to shear-dominated and axial tension stress states with respect to the reinforcing fiber directions. Shi et al. ${ }^{96}$ observed an increase in Young's modulus with aging time for epoxy coatings. G'Sell and Mckenna ${ }^{12}$ showed a very small increase in the compressive modulus with aging time. Kong et al. ${ }^{98}$ also observed increases in Young's modulus with aging time. From these studies, it is clear that if there is an influence of physical aging on the elastic modulus of epoxy, it is generally small, and shows an increasing modulus with increasing levels of physical aging. Deformations of atomistic models at various levels of aging can be used to predict if there is any increasing trend of elastic moduli with aging or there is no correlation. 


\subsection{Chemical and Hydro-thermal aging}

a) Chemical aging- Chemical aging is a process involving photochemical, oxidative, or thermal degradation which occurs due to formation or breakage of covalent chemical bonds. These chemical processes lead to permanent changes in the network structures of epoxies and degrades the mechanical properties of cured resins. $7,14,18,99-102$ Modeling of chemical aging can be challenging as the photochemical changes are difficult to model. As chemical aging involves formation of more crosslinks and breakage of some particular bonds in epoxies, traditional force fields like OPLS and AMBER can never be used for modeling.

a) Hydro-thermal aging- Hydrothermal aging is the change that occurs in the bulk behavior of epoxy resins due to the combined action of temperature and the presence of water molecules. This change is due to the change in density of the bulk material as well as hydrolysis of chemical bonds. The most important manifestation of hydrothermal bonding is the loss in adhesive strength of epoxies and increased delamination of epoxy composites. ${ }^{8,17,103-110}$ Though some MD research has been done on the absorption of water by epoxies ${ }^{110,111}$, coupling the interaction of water and temperature with aging times has not been studied using MD.

Thus there remains an infinite scope of molecular modeling research in the field of thermosetting polymers. The work described in this dissertation is a small progress in this vast field of MD research and considerable work can be done based on the assumptions and techniques invented during the course of this research. The results mentioned in Chapter 5 and the equations derived in Chapter 6 based on physical aging simulations can be useful for further research on EPON 862-DETDA polymer and other similar epoxy systems. 


\section{REFERENCES}

1. Potter, W. G., Epoxide Resins. In Springer-Verlag: New York, 1970.

2. Apicella, A.; Nicolais, L. Industrial \& Engineering Chemistry Product Research and Development 1981, 20, (1), 138-144.

3. Barral, L.; Cano, J.; Lopez, J.; Lopez-Bueno, I.; Nogueira, P.; Abad, M. J.; Ramirez, C. European Polymer Journal 1999, 35, (3), 403-411.

4. Barral, L.; Cano, J.; Lopez, J.; Lopez-Bueno, I.; Nogueira, P.; Abad, M. J.; Ramirez, C. Journal of Thermal Analysis and Calorimetry 2000, 60, (2), 391-399.

5. Bockenheimer, C.; Fata, D.; Possart, W. Journal of Applied Polymer Science 2004, 91, (1), 361-368.

6. Bockenheimer, C.; Fata, D.; Possart, W. Journal of Applied Polymer Science 2004, 91, (1), 369-377.

7. Damian, C.; Espuche, E.; Escoubes, M. Polymer Degradation and Stability 2001, 72, (3), 447-458.

8. Fata, D.; Possart, W. Journal of Applied Polymer Science 2006, 99, (5), 2726-2736.

9. Fraga, F.; Castro-Diaz, C.; Rodriguez-Nunez, E.; Martinez-Ageitos, J. M. Polymer 2003, 44, (19), 5779-5784.

10. Frankland S.J.V, C. T. C., Hinkley J.A., The Effect of Water on the Work of Adhesion at Epoxy Interfaces by Molecular Dynamics Simulation. In American Institute of Aeronautics and Astronautics: Palm Springs, CA, 2009.

11. Frigione, M.; Naddeo, C.; Acierno, D. Journal of Polymer Engineering 2001, 21, (1), 2351.

12. Gsell, C.; McKenna, G. B. Polymer 1992, 33, (10), 2103-2113.

13. Jong, S. R.; Yu, T. L. Journal of Polymer Science Part B-Polymer Physics 1997, 35, (1), 69-83.

14. Khayankarn, O.; Pearson, R. A.; Verghese, N.; Shafi, A. Journal of Adhesion 2005, 81, (9), 941-961.

15. Kong, E. S. W. Advances in Polymer Science 1986, 80, 125-171.

16. Leveque, D.; Schieffer, A.; Mavel, A.; Maire, J. F. Composites Science and Technology 2005, 65, (3-4), 395-401. 
17. Lin, Y. C.; Chen, X.; Zhang, H. J.; Wang, Z. P. Materials Letters 2006, 60, (24), 29582963.

18. Mijovic, J. Journal of Composite Materials 1985, 19, (2), 178-191.

19. Miller S., R. G. D., Bail J.L., Kohlman L.W., Binienda W.K. , Effects of Hygrothermal Cycling on the Chemical, Thermal, and Mechanical Properties of 862/W Epoxy Resin. In Aircraft Airworthiness and Sustainment Conference, Austin, TX, 2010.

20. Plazek, D. J.; Frund, Z. N. Journal of Polymer Science Part B-Polymer Physics 1990, 28, (4), 431-448.

21. Struik, L. C. E., Physical Aging in Amorphous Polymers and Other Materials. Elsevier Scientific Publishing Company: New York, 1978.

22. Acitelli, P., Sacher. Polymer 1971, 12, (5), 335-343.

23. Fitz, B. D.; Mijovic, J. Macromolecules 1999, 32, (12), 4134-4140.

24. Levita, G.; Livi, A.; Rolla, P. A.; Culicchi, C. Journal of Polymer Science Part BPolymer Physics 1996, 34, (16), 2731-2737.

25. Stevens, M. J. Macromolecules 2001, 34, (8), 2710-2718.

26. Tsige, M.; Stevens, M. J. Macromolecules 2004, 37, (2), 630-637.

27. Carmesin, I.; Kremer, K. Macromolecules 1988, 21, (9), 2819-2823.

28. Jo, W. H.; Ko, M. B. Macromolecules 1994, 27, (26), 7815-7824.

29. Jo, W. H.; Ko, M. B. Macromolecules 1993, 26, (20), 5473-5478.

30. Varshney, V.; Patnaik, S. S.; Roy, A. K.; Farmer, B. L. Macromolecules 2008, 41, (18), 6837-6842.

31. Goodman, J. M., Chemical Applications of Molecular Modelling. The Royal Society of Chemistry: Cambirdge, UK, 1997.

32. Doherty, D. C.; Holmes, B. N.; Leung, P.; Ross, R. B. Computational and Theoretical Polymer Science 1998, 8, (1-2), 169-178.

33. Yarovsky, I.; Evans, E. Polymer 2002, 43, (3), 963-969.

34. Wu, C. F.; Xu, W. J. Polymer 2006, 47, (16), 6004-6009.

35. Fan, H. B.; Yuen, M. M. F. Polymer 2007, 48, (7), 2174-2178.

36. Fan, H. B.; Chan, E. K. L.; Wong, C. K. Y.; Yuen, M. M. F. Journal of Electronic Packaging 2007, 129, (1), 35-40.

37. Heine, D. R.; Grest, G. S.; Lorenz, C. D.; Tsige, M.; Stevens, M. J. Macromolecules 2004, 37, (10), 3857-3864. 
38. Duffy, E. M.; Kowalczyk, P. J.; Jorgensen, W. L. Journal of the American Chemical Society 1993, 115, (20), 9271-9275.

39. Jorgensen, W. L.; Maxwell, D. S.; TiradoRives, J. Journal of the American Chemical Society 1996, 118, (45), 11225-11236.

40. Weiner, S. J.; Kollman, P. A.; Case, D. A.; Singh, U. C.; Ghio, C.; Alagona, G.; Profeta, S.; Weiner, P. Journal of the American Chemical Society 1984, 106, (3), 765-784.

41. Watkins, E. K.; Jorgensen, W. L. Journal of Physical Chemistry A 2001, 105, (16), 41184125 .

42. Leach, A. R., Molecular Modelling: Principles and Applications. In 2nd ed.; Pearson Education Limited: 2001; pp 170-176.

43. Plimpton, S. Journal of Computational Physics 1995, 117, (1), 1-19.

44. Hoover, W. G. Physical Review A 1985, 31, (3), 1695-1697.

45. Goodman, J. M., Chemical Applications of Molecular Modelling. 1 ed.; Royal Society of Chemistry: 1998; p 166.

46. Tack, J. L.; Ford, D. M. Journal of Molecular Graphics \& Modelling 2008, 26, (8), 12691275 .

47. Gou, J. H.; Minaie, B.; Wang, B.; Liang, Z. Y.; Zhang, C. Computational Materials Science 2004, 31, (3-4), 225-236.

48. Holck, O. D., E.; Wunderle, B.; Bauer, J.; Michel, B.; Reichl, H., Molecular modeling of a 3D-crosslinked epoxy resin and its interface to native $\mathrm{SiO} 2$ - Property prediction in microelectronic packaging. In Electronic Components and Technology Conference (ECTC), Las Vegas, NV, USA, 2010; pp 135 - 143

49. Vanlandingham, M. R.; Eduljee, R. F.; Gillespie, J. W. Journal of Applied Polymer Science 1999, 71, (5), 699-712.

50. Lee, A.; Mckenna, G. B. Polymer 1988, 29, (10), 1812-1817.

51. Wang, S. R.; Liang, Z. Y.; Gonnet, P.; Liao, Y. H.; Wang, B.; Zhang, C. Advanced Functional Materials 2007, 17, (1), 87-92.

52. Frankland, S. J. V.; Harik, V. M.; Odegard, G. M.; Brenner, D. W.; Gates, T. S. Composites Science and Technology 2003, 63, (11), 1655-1661.

53. Clancy, T. C.; Frankland, S. J. V.; Hinkley, J. A.; Gates, T. S. Polymer 2009, 50, (12), 2736-2742.

54. Raaska, T.; Niemela, S.; Sundholm, F. Macromolecules 1994, 27, (20), 5751-5757. 
55. Littell, J. D.; Ruggeri, C. R.; Goldberg, R. K.; Roberts, G. D.; Arnold, W. A.; Binienda, W. K. Journal of Aerospace Engineering 2008, 21, (3), 162-173.

56. Gupta, V. B.; Drzal, L. T.; Lee, C. Y. C.; Rich, M. J. Polymer Engineering and Science 1985, 25, (13), 812-823.

57. Miyagawa, H.; Drzal, L. T. Polymer 2004, 45, (15), 5163-5170.

58. Lees, S.; Davidson, C. L. Journal of Biomechanics 1977, 10, (8), 473-486.

59. Lee, H.; Neville, K., In Handbook of Epoxy resins, McGraw-Hill: New York, 1967; pp $18-19$.

60. A.S. Burhans, C. F. P., R.F. Sellers and S.G. Smith, High performance epoxy resin systems for fiber-reinforced composites- preliminary paper. In 21 st Annual Meeting of the Reinforced Plastics Division, Society of Plastic Industry, 1965.

61. Vakil, U. M.; Martin, G. C. Journal of Applied Polymer Science 1992, 46, (12), 20892099.

62. Odegard, G. M.; Bandyopadhyay, A. Journal of Polymer Science Part B-Polymer Physics 2011, 49, (24), 1695-1716.

63. Bandyopadhyay, A.; Valavala, P. K.; Clancy, T. C.; Wise, K. E.; Odegard, G. M. Polymer 2011, 52, (11), 2445-2452.

64. Chen, K.; Schweizer, K. S. Physical Review Letters 2007, 98, (16), 4.

65. Isner, B. A.; Lacks, D. J. Physical Review Letters 2006, 96, (2), 025506.

66. Lacks, D. J.; Osborne, M. J. Physical Review Letters 2004, 93, (25), 255501.

67. Rottler, J.; Robbins, M. O. Physical Review Letters 2005, 95, (22), 255504.

68. Utz, M.; Debenedetti, P. G.; Stillinger, F. H. Physical Review Letters 2000, 84, (7), 14711474.

69. Warren, M.; Rottler, J. Physical Review E 2007, 76, (3), 031802.

70. Warren, M.; Rottler, J. Physical Review E 2008, 78, (4), 041502.

71. Simon, S. L.; Plazek, D. J.; Sobieski, J. W.; McGregor, E. T. Journal of Polymer Science Part B-Polymer Physics 1997, 35, (6), 929-936.

72. Montserrat, S. Journal of Polymer Science Part B-Polymer Physics 1994, 32, (3), 509522 .

73. Fraga, F.; Castro-Diaz, C.; Rodriguez-Nunez, E.; Martinez-Ageitos, J. M. Polymer 2003, $44,5779-5784$.

74. Ophir, Z. H.; Emerson, J. A.; Wilkes, G. L. Journal of Applied Physics 1978, 49, (10), 5032-5038. 
75. Bandyopadhyay, A.; Odegard, G. M., Molecular modeling of crosslink distribution in epoxy polymers: Journal Article in preparation. In Michigan Technological University: 2012.

76. Anderson, T. L., In Fracture Mechanics: Fundamentals and Applications, 3rd ed.; CRC Press: Boca Raton, 2005.

77. Bucknall, C. B., In Toughened Plastics, Applied Science Publishers: London, 1977.

78. Donald, A. M.; Kramer, E. J.; Bubeck, R. A. Journal of Polymer Science Part B-Polymer Physics 1982, 20, (7), 1129-1141.

79. Donald, A. M.; Kramer, E. J. Journal of Polymer Science Part B-Polymer Physics 1982, 20, (5), 899-909.

80. Wool, R. P.; Hanser, C., Polymer interfaces: structure and strength. In Polymer International, Munich, 1995; Vol. 38, pp 305-306.

81. Odegard, G. M.; Clancy, T. C.; Gates, T. S. Polymer 2005, 46, (2), 553-562.

82. Han, S. S.; Kang, J. K.; Lee, H. M.; van Duin, A. C. T.; Goddard, W. A. Journal of Chemical Physics 2005, 123, (11).

83. Sanz-Navarro, C. F.; Astrand, P. O.; Chen, D.; Ronning, M.; van Duin, A. C. T.; Jacob, T.; Goddard, W. A. Journal of Physical Chemistry A 2008, 112, (7), 1392-1402.

84. Sanz-Navarro, C. F.; Astrand, P. O.; Chen, D.; Ronning, M.; van Duin, A. C. T.; Mueller, J. E.; Goddard, W. A. Journal of Physical Chemistry C 2008, 112, (33), 12663-12668.

85. Lee, A.; McKenna, G. B. Polymer Engineering and Science 1990, 30, (7), 431-435.

86. Lee, J. K.; Hwang, J. Y. Polymer Journal 2003, 35, (2), 191-196.

87. Lee, J. K.; Hwang, J. Y.; Gillham, J. K. Journal of Applied Polymer Science 2001, 81, (2), 396-404.

88. McKenna, G. B. Journal of Physics-Condensed Matter 2003, 15, (11), S737-S763.

89. Santore, M. M.; Duran, R. S.; McKenna, G. B. Polymer 1991, 32, (13), 2377-2381.

90. Struik, L. C. E. Polymer 1997, 38, (16), 4053-4057.

91. Odegard, G. M.; A., B., Physical Aging of Epoxy Polymers and Their Composites: A Review (in preparation). In Michigan Technological University: 2010.

92. Oyanguren, P. A.; Vallo, C. I.; Frontini, P. M.; Williams, R. J. J. Polymer 1994, 35, (24), 5279-5282.

93. Chang, T. D.; Brittain, J. O. Polymer Engineering and Science 1982, 22, (18), 1221 1227.

94. Lin, Y. G.; Sautereau, H.; Pascault, J. P. Journal of Applied Polymer Science 1986, 32, (4), 4595-4605. 
95. Hu, H. W. Journal of Mechanics 2007, 23, (3), 245-252.

96. Shi, X. D.; Fernando, B. M. D.; Croll, S. G. Journal of Coatings Technology and Research 2008, 5, (3), 299-309.

97. Cook, W. D.; Mehrabi, M.; Edward, G. H. Polymer 1999, 40, (5), 1209-1218.

98. Kong, E. S. W.; Wilkes, G. L.; McGrath, J. E.; Banthia, A. K.; Mohajer, Y.; Tant, M. R. Polymer Engineering and Science 1981, 21, (14), 943-950.

99. Devanne, T.; Bry, A.; Audouin, L.; Verdu, J. Polymer 2005, 46, (1), 229-236.

100. Frigione, M.; Naddeo, C.; Acierno, D. Journal of Polymer Engineering 2001, 21, (4), 349-367.

101. Parvatareddy, H.; Wang, J. Z.; Dillard, D. A.; Ward, T. C.; Rogalski, M. E. Composites Science and Technology 1995, 53, (4), 399-409.

102. Meiser, A.; Willstrand, K.; Fehling, P.; Possart, W. Journal of Adhesion 2008, 84, (4), 299-321.

103. Ivanova, K. I.; Pethrick, R. A.; Affrossman, S. Journal of Applied Polymer Science 2001, 82, (14), 3477-3485.

104. Possart, W.; Kruger, J. K.; Wehlack, C.; Muller, U.; Petersen, C.; Bactavatchalou, R.; Meiser, A. Comptes Rendus Chimie 2006, 9, (1), 60-79.

105. Soulier, J. P.; Berruet, R.; Chateauminois, A.; Chabert, B.; Gauthier, R. Polymer Communications 1988, 29, (8), 243-246.

106. Buehler, F. U.; Seferis, J. C. Composites Part a-Applied Science and Manufacturing 2000, 31, (7), 741-748.

107. Dermitzaki E., W. B., Bauer J., Walter H., Michel, B. In Structure property correlation of epoxy resins under the influence of moisture; and comparison of diffusion coefficient with MDsimulations, EuroSimE 2008, 20-23 April 2008; IEEE: 2008.

108. Komai, K.; Minoshima, K.; Shibutani, T. Jsme International Journal Series I-Solid Mechanics Strength of Materials 1991, 34, (3), 381-388.

109. Selzer, R.; Friedrich, K. Journal of Materials Science 1995, 30, (2), 334-338.

110. Wu, C. F.; Xu, W. J. Polymer 2007, 48, (18), 5440-5448.

111. Domotor, G.; Hentschke, R. Macromolecular Theory and Simulations 2004, 13, (6), 506511. 


\section{APPENDIX A}

\section{LAMMPS sample codes for energy minimization, NVT dynamics,}

measurement of elastic moduli and glass-transition temperature

\section{A.1. Molecular Energy Minimization simulation}

\#Input file for parallel batch minimizations of EPON-DETDA with 70\% crosslinks with $50 \%$ crosslinked cluster

units real

dimension 3

boundary $\mathrm{p} \mathrm{p} \mathrm{p}$

atom_style molecular

neighbor 6.0 bin

neigh_modify every 1 delay 0 check yes

echo screen

\#OPLS potentials

bond_style harmonic

angle_style harmonic

dihedral style opls

pair_style lj/cut/opt 10.0

pair_modify mix arithmetic

\#variables, read and dump

variable a uloop 12

variable $\mathrm{k}$ universe 5.010 .015 .020 .025 .030 .035 .040 .045 .050 .055 .060 .0

$\log \log . \$ \mathrm{k}$

read_data DataFile_432isto216_70XLfrom58point5XL_6thmin.xyz

dump EPON-DETDA all custom 10000 epon432isto216_70XLfrom58point5XL.\$k tag

mol type $\mathrm{x}$ y $\mathrm{z}$

\#minimization

min_style cg

min_modify dmax \$k

minimize 0.00 .010000001000000

next k a

clear

jump input.70XLfrom58point5XL_batchminimization_epon432isto21 


\section{A.2. NVT Molecular Dynamics simulation for equilibration}

\#Input file for first NVT after first minimization of 70\% crosslinked model with $50 \%$ crosslinked cluster

units real

dimension 3

boundary $\mathrm{p} \mathrm{p} \mathrm{p}$

atom_style molecular

neighbor 4.0 bin

neigh_modify every 1 delay 5 check yes page 1000000 one 100000

echo screen

\#OPLS potentials

bond_style harmonic

angle_style harmonic

dihedral_style opls

pair_style 1j/cut/opt 10.0

pair_modify mix arithmetic

read_data DataFile_432isto216_70XLfrom58point5XL_1stmin.xyz

\#dynamics commands

\#initial velocities

compute 1 all temp

compute 2 all pe

compute 3 all ke/atom

velocity all create 500.0500 .0

\#fixes

fix 1 all nvt 500.0500 .010 .0

dump EPONDETDA all xyz 100000

epon432isto216_70XLfrom58point5XL_1stNVT.xyz

\#run

timestep 0.2

thermo 100

thermo_modify lost warn

thermo_style custom step temp pe ke etotal evdwl etail epair ebond eangle edihed emol press vol

run 500000 


\section{A.3. Simulated heating for measuring Glass-Transition Temperature and volume shrinkage using NPT (constant pressure and temperature) ensemble}

\#Input file of simulated heating of $76 \%$ crosslinked EPON 432:216 molecule with DETDA for measuring Glass-Transition temperature

units real

dimension 3

boundary $\mathrm{p} \mathrm{p} \mathrm{p}$

atom_style molecular

neighbor 4.0 bin

neigh_modify every 1 delay 0 check yes page 1000000 one 100000

echo screen

\#OPLS potentials

bond_style harmonic

angle_style harmonic

dihedral_style opls

pair_style $1 \mathrm{j} /$ cut/opt 10.0

pair_modify mix arithmetic

read_data FinalData432_216_76XLinkd_forNPT.xyz

\#dynamics commands

\#initial velocities

compute 1 all temp

compute 2 all pressure 1

compute 3 all pe

velocity all create 203.0203 .0

\#fixes

fix 1 all temp/rescale 2203.0603 .01 .01 .0

fix 2 all npt temp 203.0603 .02 iso 0.10 .110 .0 drag 6.0

dump EPONDETDA all xyz 100000.0 epon_76percent_heatingforTg.xyz

\#run

timestep 0.4

thermo 50

thermo_style custom step temp pe etotal evdwl lx ly lz pxx pyy pzz pxy pxz pyz press vol

run 5000000 


\section{A.4. Simulations for measuring positive and negative volumetric strains for calculation of bulk modulus}

\#Input file for $63 \%$ crosslinked EPON-DETDA with $0.5 \%$ positive volumetric strain at $300 \mathrm{~K}$ for calculating bulk modulus

units real

dimension 3

boundary $\mathrm{p} p \mathrm{p}$

atom_style molecular

neighbor 4.0 bin

neigh_modify every 1 delay 0 check yes page 1000000 one 100000

echo screen

\#OPLS potentials

bond_style harmonic

angle_style harmonic

dihedral_style opls

pair_style $1 \mathrm{j} /$ cut/opt 10.0

pair_modify mix arithmetic

read_data DataFile_432isto216_63percent_forModulusCalc.xyz

\#dynamics commands

\#initial velocities

compute 1 all temp

compute 2 all pressure 1

compute 3 all pe

velocity all create 300.0300 .0

\#fixes

fix 1 all deform $1 \mathrm{x}$ scale $1.005 \mathrm{y}$ scale $1.005 \mathrm{z}$ scale 1.005 remap $\mathrm{v}$ units box

fix 2 all nvt/sllod 300.0300 .010 .0

dump EPONDETDA all xyz 100000.0 epon_63percent_0.5STRAIN_300K_200ps.xyz

\#run

timestep 0.2

thermo 100

thermo_modify lost warn

thermo_style custom step temp pe etotal evdwl lx ly lz pxx pyy pzz pxy pxz pyz press vol run 1000000 
\#Input file for $63 \%$ crosslinked EPON-DETDA with $0.5 \%$ negative volumetric strain at $300 \mathrm{~K}$ for calculating bulk modulus

units real

dimension 3

boundary $\mathrm{p} \mathrm{p} \mathrm{p}$

atom_style molecular

neighbor 4.0 bin

neigh_modify every 1 delay 0 check yes page 1000000 one 100000

echo screen

\#OPLS potentials

bond_style harmonic

angle_style harmonic

dihedral_style opls

pair_style lj/cut/opt 10.0

pair_modify mix arithmetic

read_data DataFile_432isto216_63percent_forModulusCalc.xyz

\#dynamics commands

\#initial velocities

compute 1 all temp

compute 2 all pressure 1

compute 3 all pe

velocity all create 300.0300 .0

\#fixes

fix 1 all deform $1 \mathrm{x}$ scale $0.995 \mathrm{y}$ scale $0.995 \mathrm{z}$ scale 0.995 remap $\mathrm{v}$ units box

fix 2 all nvt/sllod 300.0300 .010 .0

dump EPONDETDA all xyz 100000.0 epon_63percent_0.5STRAIN_300K_200ps.xyz

\#run

timestep 0.2

thermo 100

thermo_modify lost warn

thermo_style custom step temp pe etotal evdwl lx ly lz pxx pyy pzz pxy pxz pyz press vol

run 1000000 


\section{A.5. Simulations for measuring positive and negative shear strains for calculation of shear modulus}

\#Input file for $63 \%$ crosslinked EPON-DETDA with $0.5 \%$ positive shear strain at $300 \mathrm{~K}$ for calculating shear modulus

units real

dimension 3

boundary $\mathrm{p} p \mathrm{p}$

atom_style molecular

neighbor 4.0 bin

neigh_modify every 1 delay 0 check yes page 1000000 one 100000

echo screen

\#OPLS potentials

bond style harmonic

angle style harmonic

dihedral_style opls

pair_style lj/cut/opt 10.0

pair_modify mix arithmetic

read_data DataFile_432isto216_63percent_forModulusCalc.xyz

change_box triclinic

\#dynamics commands

\#initial velocities

compute 1 all temp

compute 2 all pressure 1

compute 3 all pe

velocity all create 300.0300 .0

\#fixes

fix 1 all deform 1 xy final 0.3149879751 xz final 0.3149879751 yz final 0.3149879751 remap $\mathrm{v}$ units box

fix 2 all nvt/sllod 300.0300 .010 .0

dump EPONDETDA all xyz 100000.0 epon_63percent_0.5positiveshear300K_200ps.xyz

\#run

timestep 0.2

thermo 100

thermo_modify lost warn

thermo_style custom step temp pe etotal evdwl lx ly lz pxx pyy pzz pxy pxz pyz press vol

run 1000000 
\# Input file for $63 \%$ crosslinked EPON-DETDA with $0.5 \%$ negative shear strain at $300 \mathrm{~K}$ for calculating shear modulus

units real

dimension 3

boundary $\mathrm{p} \mathrm{p} \mathrm{p}$

atom_style molecular

neighbor 4.0 bin

neigh_modify every 1 delay 0 check yes page 1000000 one 100000

echo screen

\#OPLS potentials

bond_style harmonic

angle_style harmonic

dihedral_style opls

pair_style lj/cut/opt 10.0

pair_modify mix arithmetic

read_data DataFile_432isto216_63percent_forModulusCalc.xyz

change_box triclinic

\#dynamics commands

\#initial velocities

compute 1 all temp

compute 2 all pressure 1

compute 3 all pe

velocity all create 300.0300 .0

\#fixes

fix 1 all deform 1 xy final -0.3149879751 xz final -0.3149879751 yz final -0.3149879751 remap $\mathrm{v}$ units box

fix 2 all nvt/sllod 300.0300 .010 .0

dump EPONDETDA all xyz 100000.0

epon_63percent_0.5negativeshear300K_200ps.xyz

\#run

timestep 0.2

thermo 100

thermo modify lost warn

thermo_style custom step temp pe etotal evdwl lx ly lz pxx pyy pzz pxy pxz pyz press vol run 1000000 


\section{A.6. NPH (constant enthalpy and pressure) simulations for measuring tensile strains along $X, Y$ and $Z$ axes for calculation of Young's modulus}

\#NPH simulation input file for 63\% crosslinked EPON-DETDA with 59\% clusters for $0.5 \%$ tensile strain at $300 \mathrm{~K}$ along $\mathrm{X}$ direction for measuring Young's modulus

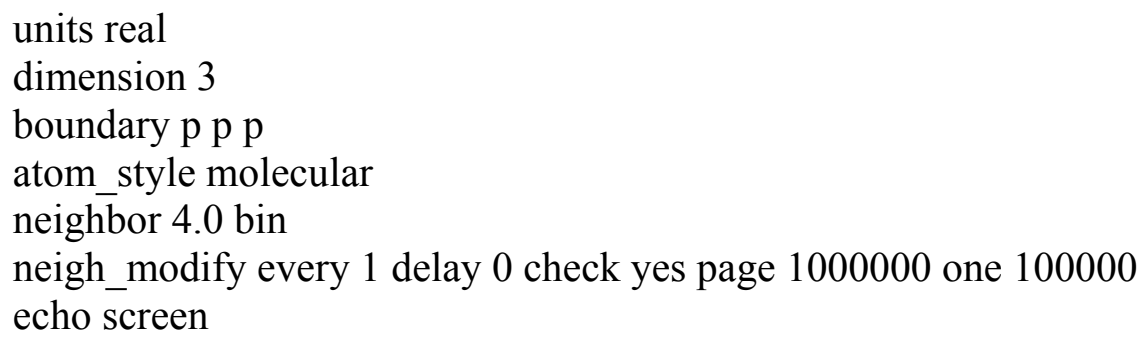


\#NPH simulation input file for 63\% crosslinked EPON-DETDA with 59\% clusters for $0.5 \%$ tensile strain at $300 \mathrm{~K}$ along Y direction for measuring Young's modulus

units real

dimension 3

boundary $\mathrm{p} \mathrm{p} \mathrm{p}$

atom_style molecular

neighbor 4.0 bin

neigh_modify every 1 delay 0 check yes page 1000000 one 100000

echo screen

\#OPLS potentials

bond_style harmonic

angle_style harmonic

dihedral_style opls

pair_style lj/cut/opt 10.0

pair_modify mix arithmetic

read_data DataFile_63XLfrom59XL_ModCalc_Ylineartension.xyz

\#dynamics commands

\#initial velocities

compute 1 all temp

compute 2 all pressure 1

compute 3 all pe

velocity all create 300.0300 .0

\#fixes

fix 1 all deform 1 y scale 1.005 remap $\mathrm{v}$ units box

fix 2 all nph x $0.00 .010 .0 \mathrm{z} 0.00 .010 .0$ couple none

fix 3 all temp/rescale 1300.0300 .010 .01 .0

dump EPONDETDA all xyz 50000.0

epon63XL_Y_lineartension_0.5strain300K_200ps.xyz

\#run

timestep 0.4

thermo 50

thermo_style custom step temp pe etotal evdwl ebond eangle edihed emol lx ly lz pxx pyy pzz pxy pxz pyz press vol

thermo_modify lost warn

run 5000000 
\# NPH simulation input file for 63\% crosslinked EPON-DETDA with 59\% clusters for $0.5 \%$ tensile strain at $300 \mathrm{~K}$ along $\mathrm{Z}$ direction for measuring Young's modulus

units real

dimension 3

boundary $\mathrm{p} \mathrm{p} \mathrm{p}$

atom_style molecular

neighbor 4.0 bin

neigh_modify every 1 delay 0 check yes page 1000000 one 100000

echo screen

\#OPLS potentials

bond_style harmonic

angle_style harmonic

dihedral_style opls

pair_style lj/cut/opt 10.0

pair_modify mix arithmetic

read_data DataFile_63XLfrom59XL_ModCalc_Zlineartension.xyz

\#dynamics commands

\#initial velocities

compute 1 all temp

compute 2 all pressure 1

compute 3 all pe

velocity all create 300.0300 .0

\#fixes

fix 1 all deform $1 \mathrm{z}$ scale 1.005 remap $\mathrm{v}$ units box

fix 2 all nph x 0.00 .010 .0 y 0.00 .010 .0 couple none

fix 3 all temp/rescale 1300.0300 .010 .01 .0

dump EPONDETDA all xyz 50000.0

epon63XL_Z_lineartension_0.5strain300K_200ps.xyz

\#run

timestep 0.4

thermo 50

thermo_style custom step temp pe etotal evdwl ebond eangle edihed emol lx ly lz pxx pyy pzz pxy pxz pyz press vol

thermo_modify lost warn

run 5000000 


\section{APPENDIX B}

\section{AWK script for finding distances between crosslinking atoms}

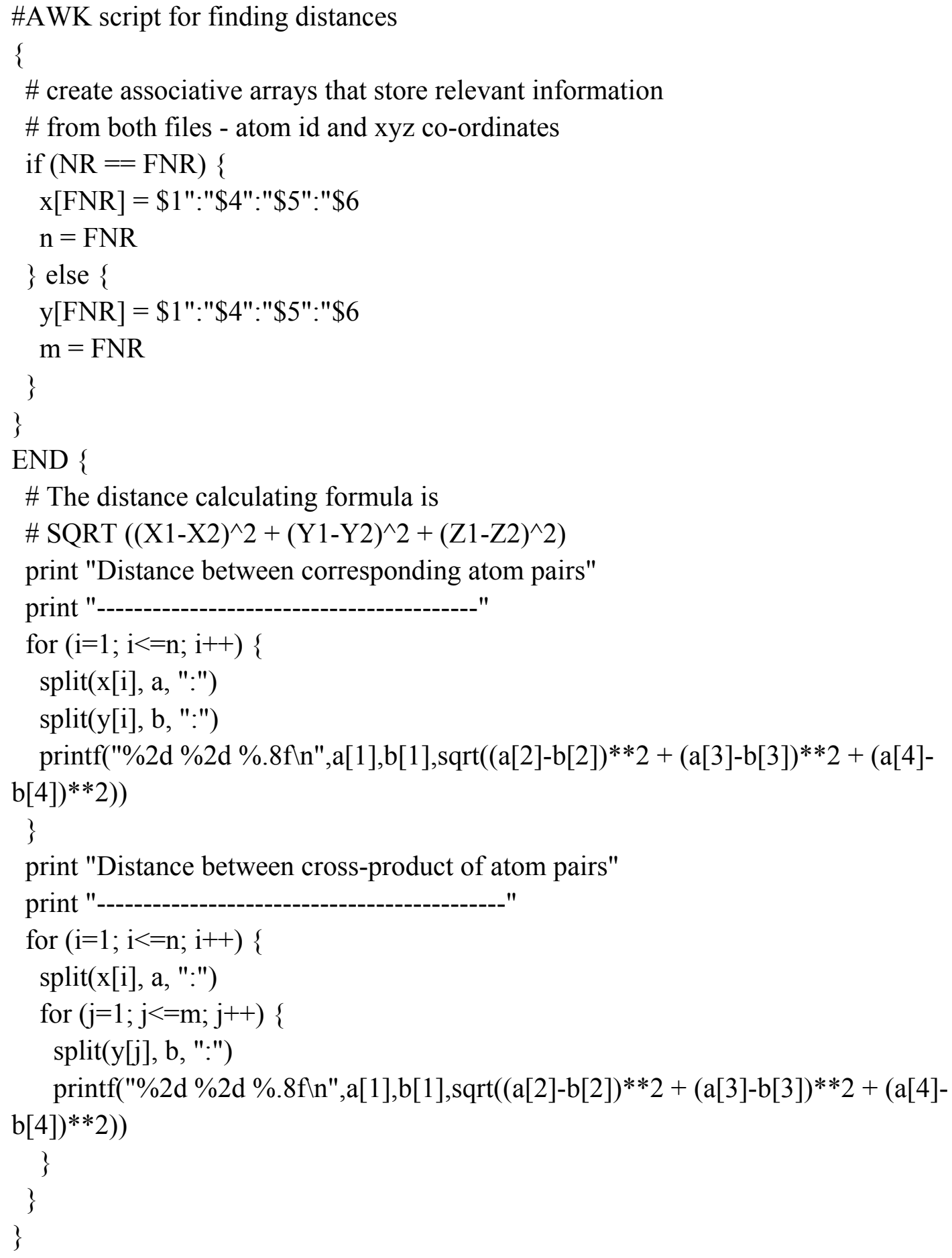




\section{APPENDIX C}

\section{Copyright Agreements and Permissions}

\section{C.1. Copyright agreement for using selected text and figures 2.2, 4.1, 4.2,}

\section{3, 4.4, 5.1, 5.3 in Chapters 2, 3, 4 and 5}

Article title: Molecular Modeling Of Crosslinked Epoxy Polymers: The Effect Of Crosslink Density On Thermomechanical Properties

Reference: JPOL14622

Journal title: Polymer

Corresponding author: Dr. Gregory M. Odegard

First author: Ananyo Bandyopadhyay

PDF offprint dispatch: 5-5-2011

We are pleased to inform you that a PDF file of your published article Molecular Modeling Of Crosslinked Epoxy Polymers: The Effect Of Crosslink Density On Thermomechanical Properties is attached to this e-mail for you to view and download. Please note that this article is published therefore content updates are no longer possible at this point.

If you wish to order paper offprints or reprints, please contact our customer support team: http://epsupport.elsevier.com.

To order a copy of the issue, please contact your nearest Sales

Office: http://www.elsevier.com/salesoffices.

Details on offprints and reprints: http://www.elsevier.com/locate/reprints.

To view and print PDF files you will need Adobe Reader (version 5.0 or higher). This program is freely available and can be downloaded from http://www.adobe.com/products/acrobat/readstep.html.

With a view to copyright stipulations please be advised that:

This article was originally published in a journal published by Elsevier, and the attached copy is provided by Elsevier for the author's benefit and for the benefit of the author's institution, for non-commercial research and educational use including without limitation use in instruction at your institution, sending it to specific colleagues that you know, and providing a copy to your institution's administrator. 
All other uses, reproduction and distribution, including without limitation commercial reprints, selling or licensing copies or access, or posting on open internet sites, personal or institution's website or repository, are prohibited. For exceptions, permission may be sought for such use through Elsevier's permissions site at http://www.elsevier.com/locate/permissionusematerial.

\section{POSTING AND COPYRIGHT POLICIES}

As an author you retain significant rights for use of your own work, including the right to:

- Post a pre-print version of the article on various websites (with some exceptions)

- Make copies (print or electronic) of the article for your own personal use, including classroom teaching - Use the article in a printed compilation of your own works For more information on our full copyright policy please consult http://www.elsevier.com/authorsrights.

Copyright (c) 2011 Elsevier B.V. All rights reserved. Please read our privacy policy at http://www.elsevier.com/privacypolicy. 


\section{JOURNAL PUBLISHING AGREEMENT}

\section{YOUR ARTICLE DETAILS}

\section{Elsevier Ltd}

Article:

Corresponding author:

E-mail address:

Journal:

Our reference

PII:

DOI:

\section{YOUR STATUS}

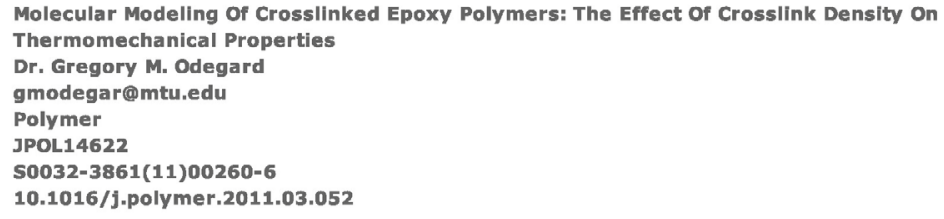

» I am one author signing on behalf of all co-authors of the manuscript

» I am not a US Government employee but some of my co-authors are

\section{DATA PROTECTION \& PRIVACY}

\$I do not wish to receive news, promotions and special offers about products and services from Elsevier Ltd and its affiliat worldwide.

\section{ASSIGNMENT OF PUBLISHING RIGHTS}

I hereby assign toElsevier Ltdthe copyright in the manuscript identified above (government authors not electing to transfer agree to assign a non-exclusive(ADDED) licence) and any supplemental tables, illustrations or other information submitted therewith that are intended for publication as part of or as a supplement to the manuscript (the "Article") in all forms and media (whether now known or hereafter developed), throughout the world, in all languages, for the full term of copyright, effective when and if the article is accepted for publication. This transfer includes the right to provide the Article in electronic and online forms and systems. No revisions, additional terms or addenda to this Agreement can be accepted without our express written consent. Authors at institutions that place restrictions on copyright assignments, including those that do so due to policies about local institutional repositories, are encouraged to obtain a waiver from those institutions so that the author can accept our publishing agreement.

\section{RETENTION OF RIGHTS FOR SCHOLARLY PURPOSES}

I understand that I retain or am hereby granted (without the need to obtain further permission) rights to use certain versions of the Article for certain scholarly purposes, as described and defined below ("Retained Rights"), and that no rights in patents, trademarks or other intellectual property rights are transferred to the journal.

The Retained Rights include the right to use the Preprint or Accepted Author Manuscript for Personal Use, Internal Institutional Use and for ; and the Published Journal Article for Personal Use and Internal Institutional Use.

\section{AUTHOR REPRESENTATIONS / ETHICS AND DISCLOSURE}

I affirm the Author Representations noted below, and confirm that I have reviewed and complied with the relevant Instructions to Authors, the Ethics in Publishing policy, and Conflicts of Interest disclosure. For further information see the publishing ethics page at http://www.elsevier.com/publishingethics and the journal home page.

Author representations

» The article I have submitted to the journal for review is original, has been written by the stated authors and has not been

» The article is not currently being considered for publication by any other journal and will not be submitted for such review this journal.

* The article contains no libellous or other unlawful statements and does not contain any materials that violate any persona of any other person or entity.

» I have obtained written permission from copyright owners for any excerpts from copyrighted works that are included and sources in my article.

\$ If I am using any personal details or images of patients or research subjects, I have obtained written permission or cons (or, where applicable, the next of kin). See http://www.elsevier.com/patientphotographs for further information.

»If the article was prepared jointly with other authors, I have informed the co-author(s) of the terms of this publishing agr signing on their behalf as their agent, and I am authorized to do so.

\section{FUNDING AGENCY AND SPONSORSHIP OPTIONS}

I have also been made aware of the journal's policies with respect to funding agency requirements such as the NIH 'PublicAccess' policy, and the rapid publication 'ArticlesInPress' service. See $h$ ttp://www. elsevier.com/fundinqbodyagreements for details.

For more information about the definitions relating to this agreement click here.

$\checkmark$ I have read and agree to the terms of the Journal Publishing Agreement.. 


\section{C.2. Copyright agreement for using selected text and figure 6.2 in Chapter 6}

\section{JOHN WILEY AND SONS LICENSE TERMS AND CONDITIONS}

Mar 29, 2012

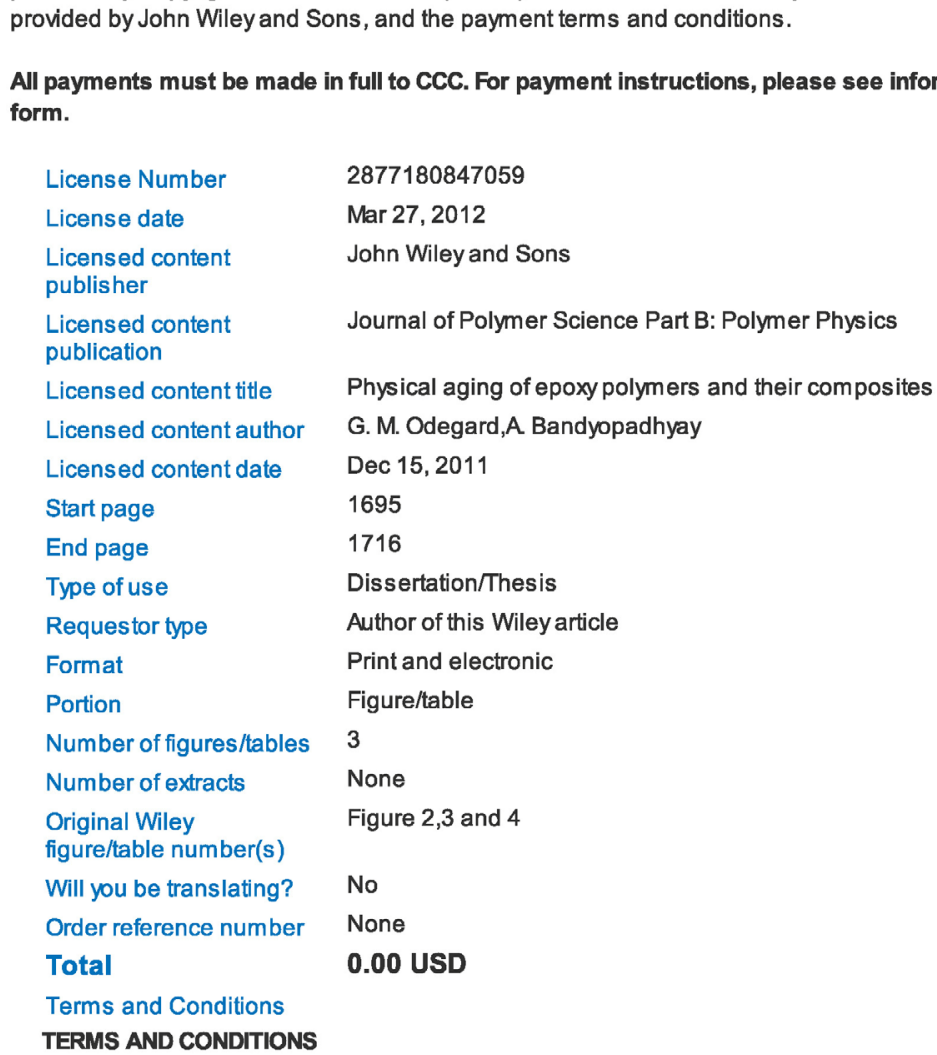
form.

Terms and Conditions

TERMS AND CONDITIONS

All payments must be made in full to CCC. For payment instructions, please see information listed at the bottom of this

This copyrighted material is owned by or exclusively licensed to John Wiley \& Sons, Inc. or one of its group companies (each a "Wiley Company") or a society for whom a Wiley Company has exclusive publishing rights in relation to a particular journal (collectively WILEY"). By clicking "accept" in connection with completing this licensing transaction, you agree that the following terms and conditions apply to this transaction (along with the billing and payment terms and conditions established by the Copyright Clearance Center Inc., ("CCC's Billing and Payment terms and conditions"), at the time that you opened your Rights link account (these are available at any time at httip://mvaccount.copvriaht.com)

Terms and Conditions

1. The materials you have requested permission to reproduce (the "Materials") are protected by copyright.

2. You are hereby granted a personal, non-exclusive, non-sublicensable, non-transferable, worldwide, limited license to reproduce the Materials for the purpose specified in the licensing process. This license is for a one-time use only with a maximum distribution equal to the number that you identified in the licensing process. Any form of republication granted by this licence must be completed within two years of the date of the grant of this licence (although copies prepared before 
may be distributed thereafter). The Materials shall not be used in any other manner or for any other purpose. Permission is granted subject to an appropriate acknowledgement given to the author, title of the material/book/journal and the publisher. You shall also duplicate the copyright notice that appears in the Wiley publication in your use of the Material. Permission is also granted on the understanding that nowhere in the text is a previously published source acknowledged for all or part of this Material. Any third party material is expressly excluded from this permission.

3. With respect to the Materials, all rights are reserved. Except as expressly granted by the terms of the license, no part of the Materials may be copied, modified, adapted (except for minor reformatting required by the new Publication), translated, reproduced, transferred or distributed, in any form or by any means, and no derivative works may be made based on the Materials without the prior permission of the respective copyright owner. You may not alter, remove or suppress in any manner any copyright, trademark or other notices displayed by the Materials. You may not license, rent, sell, loan, lease, pledge, offer as security, transfer or assign the Materials, or any of the rights granted to you hereunder to any other person.

4. The Materials and all of the intellectual property rights therein shall at all times remain the exclusive property of John Wiley \& Sons Inc or one of its related companies (WILEY) or their respective licensors, and your interest therein is only that of having possession of and the right to reproduce the Materials pursuant to Section 2 herein during the continuance of this Agreement. You agree that you own no right, title or interest in or to the Materials or any of the intellectual property rights therein. You shall have no rights hereunder other than the license as provided for above in Section 2. No right, license or interest to any trademark, trade name, service mark or other branding ("Marks") of WILEY or its licensors is granted hereunder, and you agree that you shall not assert any such right, license or interest with respect thereto.

5. NEITHER WILEY NOR ITS LICENSORS MAKES ANYWARRANTY OR REPRESENTATION OF ANY KIND TO YOU OR ANY THIRD PARTY, EXPRESS, IMPLIED OR STATUTORY, WITH RESPECT TO THE MATERIALS OR THE ACCURACY OF ANY INFORMATION CONTAINED IN THE MATERIALS, INCLUDING, WITHOUT LIMITATION, ANY IMPLIED WARRANTY OF MERCHANTABILITY, ACCURACY, SATISFACTORY QUALITY, FITNESS FOR APARTICULAR PURPOSE, USABILITY, INTEGRATION OR NON-INFRINGEMENT AND ALL SUCH WARRANTIES ARE HEREBY EXCLUDED BY WILEY AND ITS LICENSORS AND WAIVED BYYOU.

6. WILEY shall have the right to terminate this Agreement immediately upon breach of this Agreement by you.

7. You shall indemnify, defend and hold harmless WILEY, its Licensors and their respective directors, officers, agents and employees, from and against any actual or threatened claims, demands, causes of action or proceedings arising from any breach of this Agreement by you.

8. IN NO EVENT SHALL WILEY OR ITS LICENSORS BE LIABLE TO YOU OR ANY OTHER PARTY OR ANY OTHER PERSON OR ENTITY FOR ANY SPECIAL, CONSEQUENTIAL, INCIDENTAL, INDIRECT, EXEMPLARY OR PUNITIVE DAMAGES, HOWEVER CAUSED, ARISING OUT OF OR IN CONNECTION WITH THE DOWNLOADING, PROVSIONING VIEWING OR USE OF THE MATERIALS REGARDLESS OF THE FORM OF ACTION, WHETHER FOR BREACH OF CONTRACT, BREACH OF WARRANTY, TORT, NEGLIGENCE, INFRINGEMENT OR OTHERWISE (INCLUDING, WITHOUT LIMITATION, DAMAGES BASED ON LOSS OF PROFITS, DATA, FILES, USE, BUSINESS OPPORTUNITY OR CLAIMS OF THIRD PARTIES), AND WHETHER OR NOT THE PARTYHAS BEEN ADVSED OF THE POSSIBILITY OF SUCH DAMAGES. THIS LIMITATION SHALL APPLY NOTWITHSTANDING ANY FAILURE OF ESSENTIAL PURPOSE OF ANY LIMITED REMEDY PROVIDED HEREIN.

9. Should any provision of this Agreement be held by a court of competent jurisdiction to be illegal, invalid, or unenforceable, that provision shall be deemed amended to achieve as nearly as possible the same economic effect as the original provision, and the legality, validity and enforceability of the remaining provisions of this Agreement shall not be affected or impaired thereby.

10. The failure of either party to enforce any term or condition of this Agreement shall not constitute a waiver of either party's right to enforce each and every term and condition of this Agreement. No breach under this agreement shall be deemed waived or excused by either party unless such waiver or consent is in writing signed by the party granting such waiver or consent. The waiver by or consent of a party to a breach of any provision of this Agreement shall not operate or be construed as a waiver of or consent to any other or subsequent breach by such other party.

11. This Agreement may not be assigned (including by operation of law or otherwise) by you without WILEY's prior written consent.

12. Any fee required for this permission shall be non-refundable after thirty $(30)$ days from receipt. 
13. These terms and conditions together with CCC's Billing and Payment terms and conditions (which are incorporated herein) form the entire agreement between you and WILEY concerning this licensing transaction and (in the absence of fraud) supersedes all prior agreements and representations of the parties, oral or written. This Agreement may not be amended except in writing signed by both parties. This Agreement shall be binding upon and inure to the benefit of the parties' successors, legal representatives, and authorized assigns.

14. In the event of any conflict between your obligations established by these terms and conditions and those established by CCC's Billing and Payment terms and conditions, these terms and conditions shall prevail.

15. WILEY expressly reserves all rights not specifically granted in the combination of (i) the license details provided by you and accepted in the course of this licensing transaction, (ii) these terms and conditions and (iii) CCC's Billing and Payment terms and conditions.

16. This Agreement will be void if the Type of Use, Format, Circulation, or Requestor Type was misrepresented during the licensing process.

17. This Agreement shall be governed by and construed in accordance with the laws of the State of New York, USA, without regards to such state's conflict of law rules. Any legal action, suit or proceeding arising out of or relating to these Terms and Conditions or the breach thereof shall be instituted in a court of competent juris diction in New York County in the State of New York in the United States of America and each party hereby consents and submits to the personal juris diction of such court, waives any objection to venue in such court and consents to service of process by registered or certified mail, return receipt requested, at the last known address of such party.

\section{Wiley Open Access Terms and Conditions}

All research articles published in Wiley Open Access journals are fully open access: immediately freely available to read, download and share. Articles are published under the terms of the Creative Commons Attribution Non Commercial License. which permits use, distribution and reproduction in any medium, provided the original work is properly cited and is not used for commercial purposes. The license is subject to the Wiley Open Access terms and conditions: Wiley Open Access articles are protected by copyright and are posted to repositories and websites in accordance with the terms of the Creative Commons Attribution Non Commercial License. At the time of deposit, Wiley Open Access articles include all changes made during peer review, copyediting, and publishing. Repositories and websites that host the article are responsible for incorporating any publisher-supplied amendments or retractions issued subsequently.

Wiley Open Access articles are also available without charge on Wiley's publishing platform, Wiley Online Library or any successor sites.

\section{Use by non-commercial users}

For non-commercial and non-promotional purposes individual users may access, download, copy, display and redistribute to colleagues Wiley Open Access articles, as well as adapt, translate, text- and data-mine the content subject to the following conditions:

- The authors' moral rights are not compromised. These rights include the right of "paternity" (also known as "attribution" the right for the author to be identified as such) and "integrity" (the right for the author not to have the work altered in such a way that the author's reputation or integrity may be impugned).

- Where content in the article is identified as belonging to a third party, it is the obligation of the user to ensure that any reuse complies with the copyright policies of the owner of that content.

- If article content is copied, downloaded or otherwise reused for non-commercial research and education purposes, a link to the appropriate bibliographic citation (authors, journal, article title, volume, issue, page numbers, DOI and the link to the definitive published version on Wiley Online Library) should be maintained. Copyright notices and disclaimers must not be deleted.

- Any translations, for which a prior translation agreement with Wiley has not been agreed, must prominently dis play the s tatement: "This is an unofficial translation of an article that appeared in a Wiley publication. The publisher has not endorsed this translation."

Use by commercial "for-profit" organisations

Use of Wiley Open Access articles for commercial, promotional, or marketing purposes requires further explicit 
permission from Wiley and will be subject to a fee. Commercial purposes include:

- Copying or downloading of articles, or linking to such articles for further redistribution, sale or licensing;

- Copying, downloading or posting by a site or service that incorporates advertising with such content;

- The inclusion or incorporation of article content in other works or services (other than normal quotations with an appropriate citation) that is then available for sale or licensing, for a fee (for example, a compilation produced for marketing purposes, inclusion in a sales pack)

- Use of article content (other than normal quotations with appropriate citation) by for-profit organisations for promotional purposes

- Linking to article content in e-mails redistributed for promotional, marketing or educational purposes;

- Use for the purposes of monetary reward by means of sale, resale, licence, loan, transfer or other form of commercial exploitation such as marketing products

- Print reprints of Wiley Open Access articles can be purchased from: corporatesales@wilev.com

Other Terms and Conditions:

BY CLICKING ON THE "I AGREE..." BOX, YOU ACKNOWLEDGE THAT YOU HAVE READ AND FULLYUNDERSTAND EACH OF THE SECTIONS OF AND PROVISIONS SET FORTH IN THIS AGREEMENT AND THAT YOU ARE IN AGREEMENT WITH AND ARE WILLING TO ACCEPT ALL OF YOUR OBLIGATIONS AS SET FORTH IN THIS AGREEMENT.

v1.7

If you would like to pay for this license now, please remit this license along with your payment made payable to "COPYRIGHT CLEARANCE CENTER" otherwise you will be invoiced within 48 hours of the license date. Payment should be in the form of a check or money order referencing your account number and this invoice number RLNK500748424. Once you receive your invoice for this order, you may pay your invoice by credit card. Please follow instructions provided at that time.

Make Payment To:

Copyright Clearance Center

Dept 001

P.O. Box 843006

Boston, MA 02284-3006

For suggestions or comments regarding this order, contact RightsLink Customer Support: customercare@copyright.com or +1-877-622-5543 (toll free in the US) or +1-978-646-2777.

Gratis licenses (referencing $\mathbf{\$ 0}$ in the Total field) are free. Please retain this printable license for your reference. No payment is required. 


\section{C.3. Permission to use figure 1.3a in Chapter 1}

Re: Permission to use Bumpy Funnel Landscape Fri Mar 302012 10:54:08 GMT-0400 image in $\mathrm{PhD}$ dissertation

From: nrohring@notes.cc.sunysb.edu

To: abandyop@mtu.edu

Dear Ananyo,

Ken Dill has granted permission for you to use this figure for the purpose that you indicated.

Best wishes,

Nancy Rohring

Administrative Director

Laufer Center for Physical

and Quantitative Biology

Stony Brook University

Stony Brook, NY 11794-5252

631-632-4132

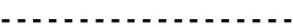

From: Ananyo Bandyopadhyay <abandyop@mtu.edu>

To: nancy rohring <nancy.rohring@stonybrookedu>

Date: $\quad$ 03/29/2012 03:16 PM

Subject: Permission to use Bumpy Funnel Landscape image in PhD dissertation

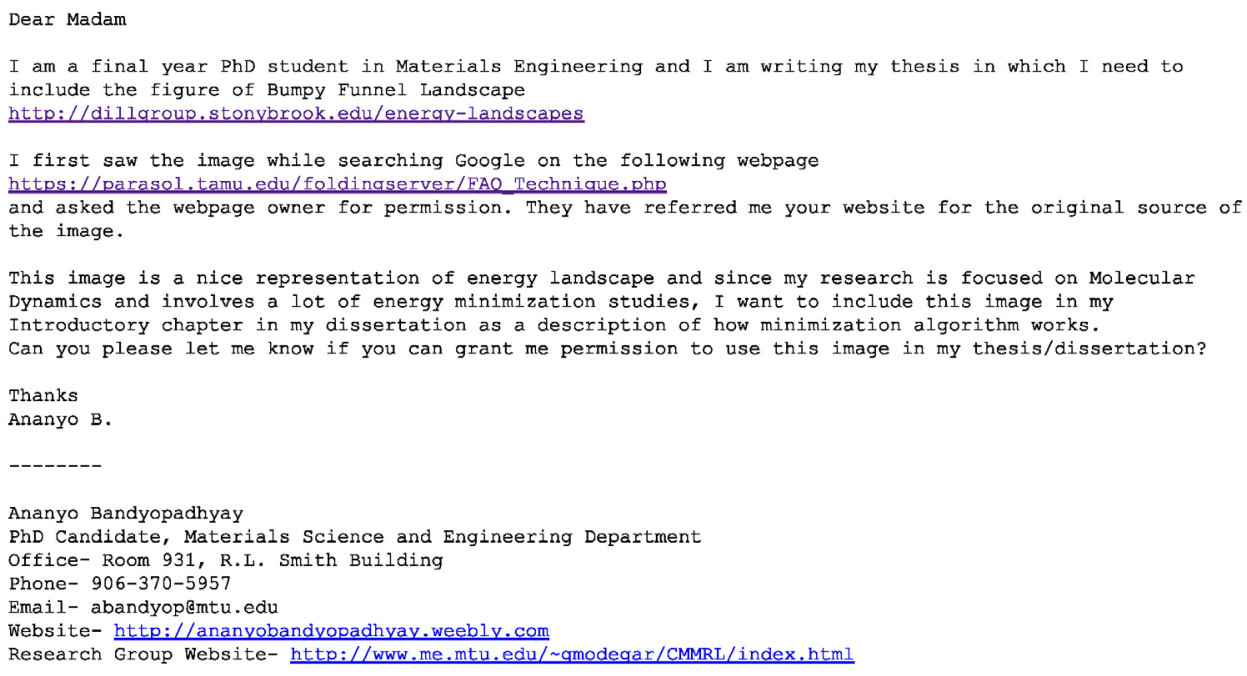

